\title{
Design and Commissioning of an Experiment to Characterize the Performance of a Lithium-Bromide Absorption Chiller
}

\author{
By \\ Geoffrey Johnson \\ B.Eng., Carleton University, 2008
}

A thesis submitted to the Faculty of Graduate and Postdoctoral Affairs in partial fulfillment of the requirements for the degree of

Master

in

Applied Science

Carleton University

Ottawa, Ontario

(C) 2011, Geoffrey Johnson 
Library and Archives

Canada

Published Heritage

Branch

395 Wellington Street

Ottawa ON K1A ON4

Canada
Bibliothèque et

Archives Canada

Direction du

Patrimoine de l'édition

395 , rue Wellington

Ottawa ON K1A ON4

Canada
Your file Votre référence

ISBN: 978-0-494-81680-6

Our file Notre référence

ISBN: 978-0-494-81680-6
NOTICE:

The author has granted a nonexclusive license allowing Library and Archives Canada to reproduce, publish, archive, preserve, conserve, communicate to the public by telecommunication or on the Internet, loan, distribute and sell theses worldwide, for commercial or noncommercial purposes, in microform, paper, electronic and/or any other formats.

The author retains copyright ownership and moral rights in this thesis. Neither the thesis nor substantial extracts from it may be printed or otherwise reproduced without the author's permission.
AVIS:

L'auteur a accordé une licence non exclusive permettant à la Bibliothèque et Archives Canada de reproduire, publier, archiver, sauvegarder, conserver, transmettre au public par télécommunication ou par l'Internet, prêter, distribuer et vendre des thèses partout dans le monde, à des fins commerciales ou autres, sur support microforme, papier, électronique et/ou autres formats.

L'auteur conserve la propriété du droit d'auteur et des droits moraux qui protège cette thèse. $\mathrm{Ni}$ la thèse ni des extraits substantiels de celle-ci ne doivent être imprimés ou autrement reproduits sans son autorisation.
In compliance with the Canadian Privacy Act some supporting forms may have been removed from this thesis.

While these forms may be included in the document page count, their removal does not represent any loss of content from the thesis.
Conformément à la loi canadienne sur la protection de la vie privée, quelques formulaires secondaires ont été enlevés de cette thèse.

Bien que ces formulaires aient inclus dans la pagination, il n'y aura aucun contenu manquant.

\section{Canadä}




\section{Abstract}

Solar air conditioning systems based on absorption chillers could help relieve the central electrical grid of the burden caused by residential air conditioning during the cooling season. Currently it is unclear whether residential solar air conditioning systems based on absorption chillers can succeed in Canada. Building performance simulation may be used to answer questions regarding the potential of solar air conditioning systems based on absorption chillers. Current methods of building performance simulation of solar air conditioning systems based on absorption chillers rely on absorption chiller models whose calibration should be improved. Consequently, there is a need for reliable absorption chiller performance data. In this research, a facility has been developed to characterize the performance of an absorption chiller. For this facility, an absorption chiller with a nominal cooling capacity of $35 \mathrm{~kW}$ has been acquired. This facility has been used to measure the performance of the acquired absorption chiller for a variety of controlled boundary conditions. It is intended that the performance data gathered in this research be used as part of a data set to calibrate a model of an absorption chiller in the future for building performance simulation. 


\section{Acknowledgements}

The author is grateful for the funding provided by Natural Resources Canada along with the Natural Sciences and Engineering Research Council of Canada through the Solar Buildings Research Network and through Ian Beausoleil-Morrison's Discovery Grant.

Special thanks to Stephanie Seemel, Jimmy Ly, Rabita Huq and Briana Kemery who contributed to the thermopile and thermocouple calibration and to the operation of the facility developed in this research.

I would like to acknowledge my supervisor, Dr. Ian Beausoleil-Morrison, who has shown nothing but patience with this project. I would also like to acknowledge my fiancée and parents who have supported me unconditionally since before the beginning of this work. 


\section{Table of Contents}

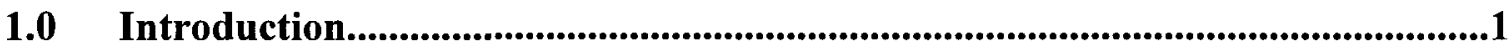

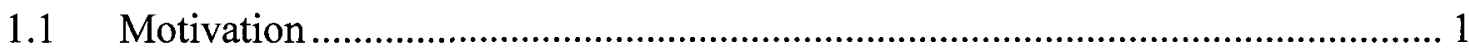

1.2 Potential for Solar Thermal Air Conditioning in Canada ................................... 2

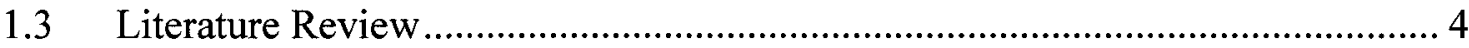

1.3.1 Simulation Based Studies of Solar Air Conditioning Systems Based on

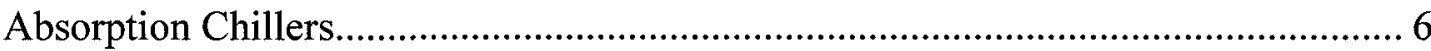

1.3.2 Experimental Studies of Solar Air Conditioning Systems Based on Absorption

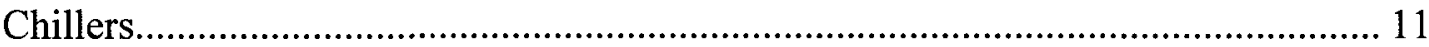

1.3.3 Simulation Based Studies of Absorption Chiller Performance ......................... 15

1.3.4 Experimental Studies of Absorption Chiller Performance ................................ 20

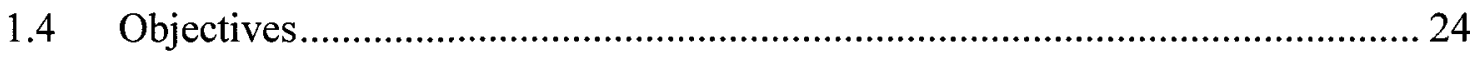

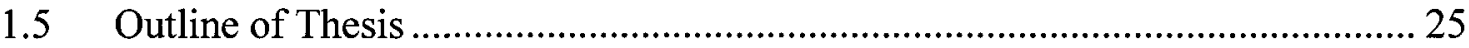

2.0 Modelling Solar Cooling Systems..................................................................26

2.1 Typical Equipment of a Residential Solar Air Conditioning System Based on an

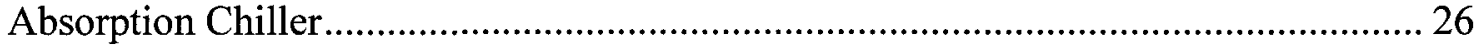

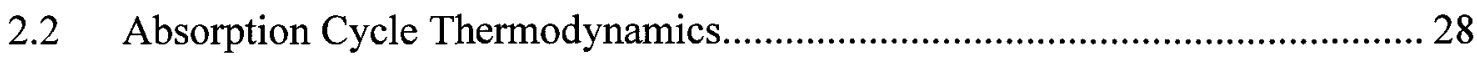

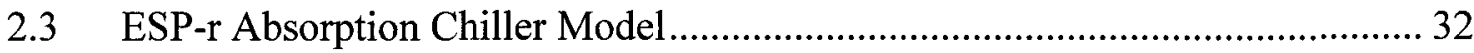

3.0 Design and Commissioning of an Experiment........................................................38 
3.1 Absorption Chiller Laboratory Design.............................................................. 38

4.0 Instrumentation and Uncertainty Analysis.......................................................49

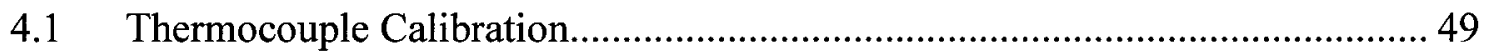

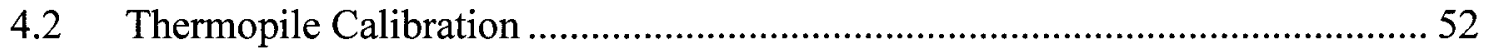

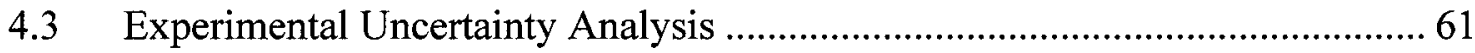

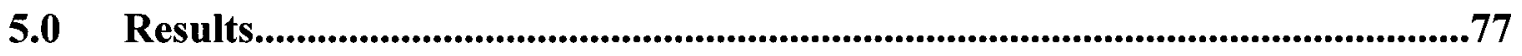

5.1 Sample Absorption Chiller Performance Experiment........................................ 77

5.2 Derived Parameters of an Absorption Chiller Performance Experiment........... 82

5.3 Absorption Chiller Performance Data ......................................................... 86

5.4 Absorption Chiller Transient Performance During Start-up ........................... 102

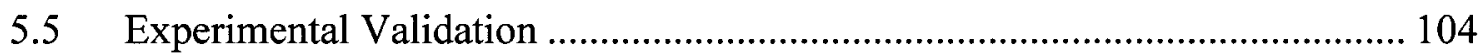

6.0 Conclusions and Future Work...................................................................107

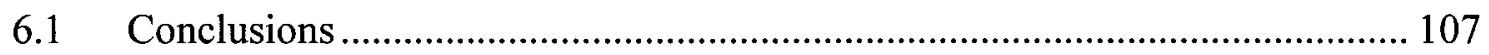

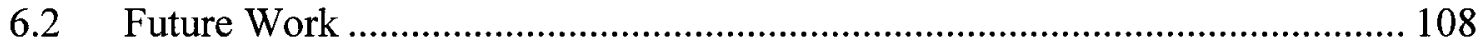

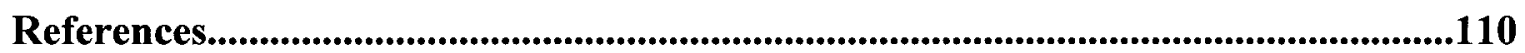




\section{List of Tables}

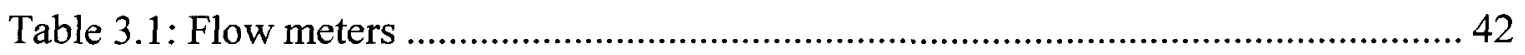

Table 3.2: Experimentally measured quantities............................................................ 43

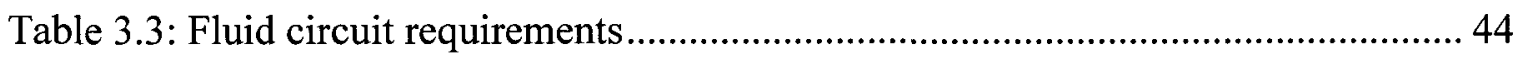

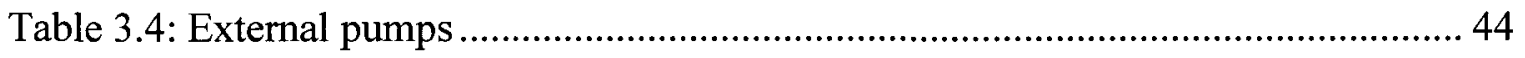

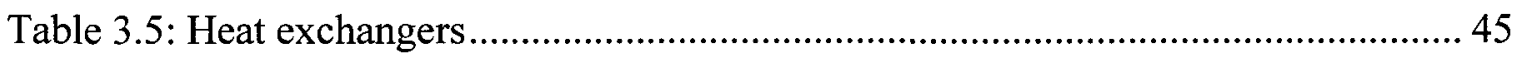

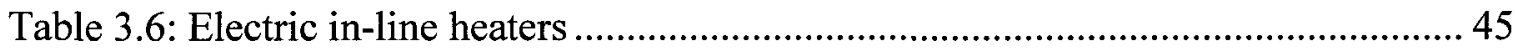

Table 4.1: Thermocouple calibration equations.............................................................. 51

Table 4.2: Summary of thermopile junction number selection calculation ....................... 54

Table 4.3: Interpolation procedure bias error estimation summary ……...........................69

Table 4.4: Thermopile EMF measurement bias error calculation summary ..................... 73

Table 4.5: Data acquisition system bias error conversion from $\mathrm{mV}$ to ${ }^{\circ} \mathrm{C} \ldots \ldots \ldots \ldots \ldots \ldots \ldots \ldots . .73$

Table 4.6: Thermocouple bias error summary …………............................................... 75

Table 5.1: Experimental grid: Boundary conditions for which absorption chiller

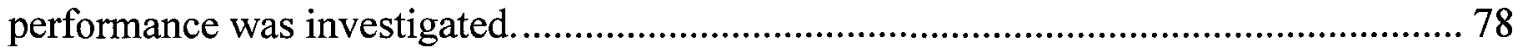

Table 5.2: Specific heat and density functions for water............................................... 84

Table 5.3: Absorption chiller performance dependence on generator flow rate.............. 101 


\section{List of Figures}

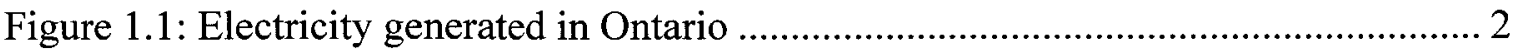

Figure 2.1: Typical residential solar air conditioning system based on an absorption

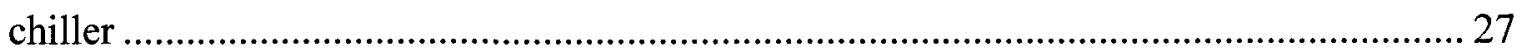

Figure 2.2: Idealized absorption cycle temperature - entropy diagram .......................... 28

Figure 2.3: Solar thermal driven absorption air conditioning system............................. 29

Figure 2.4: Absorption cycle refrigerant temperature - entropy diagram ......................... 30

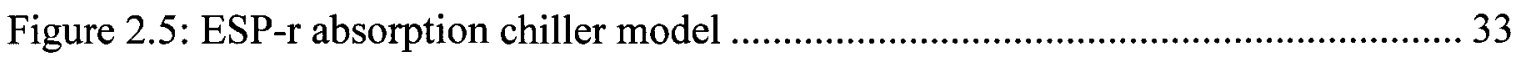

Figure 3.1: Absorption chiller test facility design schematic ............................................ 39

Figure 3.2: Absorption chiller test facility: inlet piping to chiller .................................... 46

Figure 3.3: Absorption chiller test facility: Yazaki WFC-SC10 ....................................... 47

Figure 3.4: Absorption chiller test facility: pumps and structural support ....................... 47

Figure 4.1: Thermocouple calibration equipment....................................................... 50

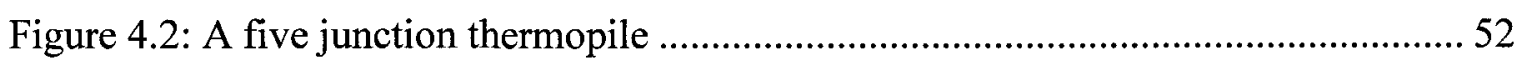

Figure 4.3: One half of a constructed thermopile assembly ............................................ 54

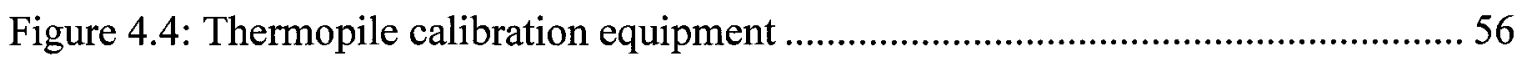

Figure 4.5: Thermopile calibration for cold junction range of approximately $7-20^{\circ} \mathrm{C} \ldots . .58$

Figure 5.1: Thermal data from absorption chiller performance Test \#7............................. 81

Figure 5.2: Flow rate data from absorption chiller performance Test $\# 7$..........................8 82

Figure 5.3: Instantaneous heat transfer rates to the evaporator and generator for boundary

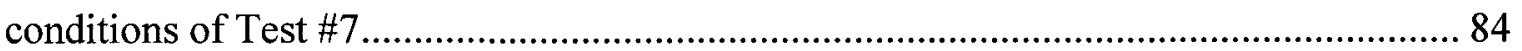

Figure 5.4: Instantaneous absorption chiller COP for boundary conditions of Test $\# 7$... 85 
Figure 5.5: Generator heat transfer rates for Test \#1 - 4. Condenser/Absorber inlet temperature: $27^{\circ} \mathrm{C}$. Generator flow: $85 \mathrm{~L} / \mathrm{min}$. Evaporator flow: $82 \mathrm{~L} / \mathrm{min}$ 88 Figure 5.6: Evaporator heat transfer rates for Test \#1 - 4. Condenser/Absorber inlet temperature: $27^{\circ} \mathrm{C}$. Generator flow: $85 \mathrm{~L} / \mathrm{min}$. Evaporator flow: $82 \mathrm{~L} / \mathrm{min}$ 89 Figure 5.7: Generator heat transfer rates for Test \#5 - 11. Condenser/Absorber inlet temperature: $29^{\circ} \mathrm{C}$. Generator flow: $85 \mathrm{~L} / \mathrm{min}$. Evaporator flow: $82 \mathrm{~L} / \mathrm{min}$ 90 Figure 5.8: Evaporator heat transfer rates for Test \#5 - 11. Condenser/Absorber inlet temperature: $29^{\circ} \mathrm{C}$. Generator flow: $85 \mathrm{~L} / \mathrm{min}$. Evaporator flow: $82 \mathrm{~L} / \mathrm{min}$ 91 Figure 5.9: Generator heat transfer rates for Test \#12 - 16. Condenser/Absorber inlet temperature: $30^{\circ} \mathrm{C}$ : Generator flow: $85 \mathrm{~L} / \mathrm{min}$. Evaporator flow: $82 \mathrm{~L} / \mathrm{min}$ 92 Figure 5.10: Evaporator heat transfer rates for Test \#12 - 16. Condenser/Absorber inlet temperature: $30^{\circ} \mathrm{C}$ : Generator flow: $85 \mathrm{~L} / \mathrm{min}$. Evaporator flow: $82 \mathrm{~L} / \mathrm{min}$ 93 Figure 5.11: Generator heat transfer rates for Test \#17 - 21. Condenser/Absorber inlet temperature: $32^{\circ} \mathrm{C}$ : Generator flow: $85 \mathrm{~L} / \mathrm{min}$. Evaporator flow: $82 \mathrm{~L} / \mathrm{min}$ 94

Figure 5.12: Evaporator heat transfer rates for Test \#17 - 21. Condenser/Absorber inlet temperature: $32^{\circ} \mathrm{C}$ : Generator flow: $85 \mathrm{~L} / \mathrm{min}$. Evaporator flow: $82 \mathrm{~L} / \mathrm{min}$ 95

Figure 5.13: COP for Test \#1 - 4. Condenser/Absorber inlet temperature: $27^{\circ} \mathrm{C}$.

Generator flow: $85 \mathrm{~L} / \mathrm{min}$. Evaporator flow: $82 \mathrm{~L} / \mathrm{min}$. 96

Figure 5.14: COP for Test \#5 - 11. Condenser/Absorber inlet temperature: $29^{\circ} \mathrm{C}$

Generator flow: $85 \mathrm{~L} / \mathrm{min}$. Evaporator flow: $82 \mathrm{~L} / \mathrm{min}$ 97

Figure 5.15 COP: for Test \#12 - 16. Condenser/Absorber inlet temperature: $30^{\circ} \mathrm{C}$ :

Generator flow: $85 \mathrm{~L} / \mathrm{min}$. Evaporator flow: $82 \mathrm{~L} / \mathrm{min}$ 98 
Figure 5.16 COP: for Test $\# 17-21$. Condenser/Absorber inlet temperature: $32^{\circ} \mathrm{C}$ :

Generator flow: $85 \mathrm{~L} / \mathrm{min}$. Evaporator flow: $82 \mathrm{~L} / \mathrm{min}$.

Figure 5.17: Transient absorption chiller performance during start-up. 


\section{Nomenclature}

\begin{tabular}{|c|c|c|}
\hline $\mathrm{T}$ & temperature & ${ }^{\circ} \mathrm{C}$ \\
\hline$\hat{\mathrm{T}}$ & temperature predicted by platinum RTD calibration data & ${ }^{\circ} \mathrm{C}$ \\
\hline$\Delta \mathrm{T}$ & temperature difference & ${ }^{\circ} \mathrm{C}$ \\
\hline$\dot{m}$ & mass flow rate & $\mathrm{kg} / \mathrm{s}$ \\
\hline$\dot{q}$ & heat transfer rate & $\mathrm{kW}$ \\
\hline$\rho$ & density & $\mathrm{kg} / \mathrm{m}^{3}$ \\
\hline$c_{p}$ & specific heat & $\mathrm{kJ} / \mathrm{kgK}$ \\
\hline$\dot{q}_{\text {pump }}$ & heat added by absorption chiller solution pump & $\mathrm{kW}$ \\
\hline COP & thermal coefficient of performance & \\
\hline$B_{i}$ & sensor bias error & \\
\hline$B_{j}$ & sensor bias error contributing element & \\
\hline$B$ & bias error & \\
\hline$S_{i}$ & sensor precision error & \\
\hline$S$ & $\begin{array}{l}\text { precision error of an instantaneous quantity/standard } \\
\text { deviation }\end{array}$ & \\
\hline $\bar{S}$ & precision error of an average quantity & \\
\hline$\theta_{l}$ & sensitivity parameter & \\
\hline$N$ & number of measurements & \\
\hline$r$ & any element of a derived quantity & \\
\hline$P_{i}$ & derived quantity & \\
\hline
\end{tabular}




\begin{tabular}{|c|c|}
\hline$U_{95}$ & $95 \%$ uncertainty margin \\
\hline $\bar{U}_{95}$ & $95 \%$ uncertainty margin of average quantity \\
\hline EMF & voltage generated by thermopile \\
\hline emf & voltage generated by thermocouple \\
\hline $\mathrm{R}$ & resistance measured from platinum RTD standard \\
\hline$\hat{\mathrm{R}}$ & $\begin{array}{l}\text { resistance of platinum RTD predicted by thermocouple } \\
\text { calibration data }\end{array}$ \\
\hline $\mathrm{C}^{2}$ & Pearson correlation coefficient squared \\
\hline$\dot{v}$ & volumetric flow rate \\
\hline$t$ & student $\mathrm{t}$ statistic \\
\hline $\mathrm{COP}$ & coefficient of performance \\
\hline$x_{t}$ & the first component of an ordered pair from a larger set \\
\hline$y_{t}$ & the second component of an ordered pair from a larger set \\
\hline $\bar{x}$ & the average of the first components of an ordered pair set \\
\hline $\bar{y}$ & $\begin{array}{l}\text { the average of the second components of an ordered pair } \\
\text { set }\end{array}$ \\
\hline W & power \\
\hline $\mathrm{C}$ & condenser/absorber \\
\hline G & generator \\
\hline $\mathrm{E}$ & evaporator \\
\hline
\end{tabular}

\section{Subscripts}

C condenser/absorber 


$\begin{array}{ll}\text { CI } & \text { condenser/absorber inlet } \\ \text { CO } & \text { condenser/absorber outlet } \\ \text { GI } & \text { generator } \\ \text { GO } & \text { generator inlet } \\ \text { E } & \text { evaporator } \\ \text { EI } & \text { evaporator inlet } \\ \text { EO } & \text { evaporator outlet } \\ 1 & \text { warm temperature thermopile junctions } \\ 2 & \text { cold temperature thermopile junctions } \\ \text { set } & \text { constant temperature bath set point } \\ \text { ref } & \text { cold junction reference temperature }\end{array}$




\section{List of Appendices}

Appendix A: Thermocouple Calibration Uncertainty Analysis.

Appendix B: Thermocouple Cold Junction Compensation Analysis.............................124

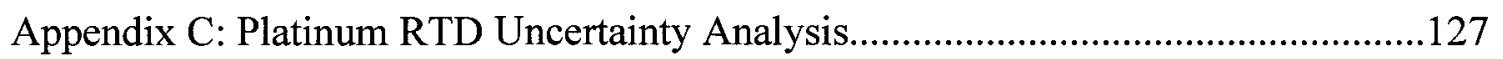

Appendix D: Thermopile Calibration...................................................................130

Appendix E: Thermopile Conversion from $\mathrm{mV}$ to ${ }^{\circ} \mathrm{C}$ Matlab Syntax...........................133

Appendix F: Uncertainty Margin Calculation Matlab Syntax...................................135

Appendix G: Absorption Chiller Performance Data................................................138 


\subsection{Introduction}

\subsection{Motivation}

Residential air conditioning usage in Ontario in recent years has had an increasing trend. From 1990 - 2007 the air conditioning stock in Ontario increased from 1.6 million to 3.6 million units according to Natural Resources Canada (NRCan) (2007). There are problems associated with air conditioning use. Henning (2009) indicated the electricity demand of current electrically driven air conditioners contributes substantially to power demand peaks during the cooling season. Such a demand peak is illustrated by data provided in a report by the Independent Electricity Systems Operator (IESO) (2009) in Figure 1.1. In this figure, Ontario hourly generator output to meet all power demand in industrial, commercial and residential sectors for one day in the cooling season is shown. It can be observed that coal and gas are burned in Ontario to meet the peak demand during the cooling season. Coal and gas power generation is problematic because coal and gas are finite resources and have high greenhouse gas intensities compared to other energy sources used in Ontario. In Ontario, nuclear and hydro are the other major sources of energy used for power generation. 
Hourly Ontario Generator Output for Aug. 102009

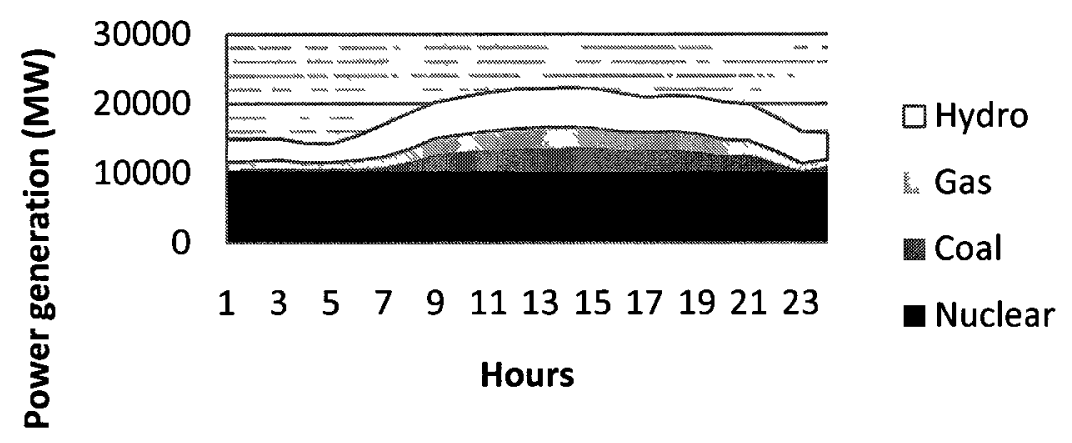

Figure 1.1: Electricity generated in Ontario IESO (2009)

If the energy required for residential air conditioning could be gathered at the site of the cooling load, the contribution to the demand peak from the central electrical grid from residential air conditioning would be reduced. A potential energy source that can be gathered at the site of the cooling load is solar energy. Henning (2009) remarked that it is logical to use solar energy for air conditioning since solar energy is usually most available on days when cooling loads are highest.

\subsection{Potential for Solar Thermal Air Conditioning in Canada}

Solar energy may be gathered at the site of the cooling load by photovoltaic cells or solar thermal collectors. Henning (2009) indicated that using solar thermal collectors to gather solar energy to drive a thermally activated cooling cycle is more widespread than using technology driven by photovoltaic cells. This is because solar thermal collectors may be used to contribute substantially to heating demands in geographic regions that experience both heating and cooling seasons. 
Solar thermal collectors heat water which can be used to hydronically activate a thermodynamic cooling cycle in a solar thermal air conditioning system. Chillers based on thermodynamic cooling cycles suitable for solar thermal air conditioning applications are currently commercially available with several companies manufacturing these devices. Mugnier (2006) identified solar thermal chiller manufacturer names and market shares as: Yazaki 40\%, EAW 22\%, Sonnenklima 4\%, Rotartica 8\%, Thermax 6\%, Broad $6 \%$, Pink $2 \%$, Climatewell $2 \%$, Others $10 \%$.

The solar thermal chiller manufacturers listed were all based outside of North America. Operating solar thermal air conditioning facilities are also mainly located outside of North America. A survey completed by the International Energy Agency (IEA) (2009) identified 290 existing solar thermal air conditioning systems operating worldwide. Only 4 of the 290 surveyed solar thermal air conditioning systems were located in North America; 3 in the United States and 1 in Mexico. Since there are few solar thermal air conditioning systems operating in North America, the potential of solar thermal air conditioning in Canada has received little attention from researchers to date and is still unknown. Researchers outside of North America have begun to assess the potential of solar thermal air conditioning technology for their respective geographic regions. In the following discussion the current research literature from worldwide sources is reviewed. 


\subsection{Literature Review}

Worldwide solar thermal air conditioning systems were identified by an IEA Task 38 survey (2009). Of the surveyed installations, there were several thermodynamic cycles which formed the basis of the solar thermal air conditioning systems. Of the solar thermal air conditioning systems identified by the survey, $84 \%$ used absorption, $11 \%$ used adsorption and $6.2 \%$ used desiccant cooling cycles. Some of the installations surveyed used hybrid systems based on two or more of the mentioned thermodynamic cycles so the preceding percentages do not add to $100 \%$.

Absorption and adsorption cycles have the same components as the conventional vapour compression refrigeration cycle with the exception of the compressor. In the absorption cycle, the function of the compressor is replaced by processes which involve dissolving the refrigerant vapour in a solution with a liquid sorbent. The solution is then pumped to a higher pressure level where it is boiled. In the adsorption cycle the function of the compressor is replaced by processes which involve dissolving the refrigerant vapour in a solid sorbent bed which is then heated. Desiccant cooling cycles rely on directly dehumidifying the conditioned air stream with a solid or liquid desiccant.

For solar thermal air conditioning applications, technology based on the absorption cycle is currently more developed than technology based on desiccant cooling cycles. Absorption cycle chillers may be purchased; desiccant cooling technology is commercially available but only at the system component level. Not a single desiccant cooling system manufacturer was given by the IEA (2009) survey. Desiccant cooling 
systems must be designed and assembled ad hoc from commercially available system components.

There are manufacturers of adsorption chillers. Adsorption chillers, however, face some technological challenges compared to absorption chillers. Demir et al. (2008) identified problems with current adsorption cooling technology which are the discontinuous cooling effect, low coefficient of performance (COP) and vacuum chamber which necessitates a large and heavy structure. The COP is defined as the ratio of refrigeration effect to the energy supplied to drive any type of chiller based on a thermodynamic refrigeration cycle. The COP of adsorption chillers and absorption chillers have been compared. Nunez et al. (2007) compared the COP of a SorTech adsorption chiller to Yazaki and Nishiyodo absorption chillers. The researchers found the SorTech adsorption chiller to have the lowest COP at all operating conditions out of the three chillers studied. The highest COP achieved by the Yazaki, Nishiyodo and SorTech chillers for all the conditions reported was $0.72,0.66$, and 0.62 respectively.

This research will focus on solar thermal air conditioning systems based on absorption chillers (solar-absorption $\mathrm{A} / \mathrm{C}$ systems). The absorption cycle is currently the most developed and widespread thermodynamic cycle used in solar thermal air conditioning applications. This research will also focus on residential applications of solar-absorption A/C systems. According to the IEA (2009) survey, only solar-absorption A/C systems with cooling capacities of $40 \mathrm{~kW}$ or less were used in residential applications. Since the focus of this research is residential solar-absorption A/C systems, 
the remainder of the literature review will concentrate on articles relevant to solarabsorption $\mathrm{A} / \mathrm{C}$ systems with cooling capacities of $40 \mathrm{~kW}$ or less.

\subsubsection{Simulation Based Studies of Solar Air Conditioning Systems Based on Absorption Chillers}

Studies have been performed where researchers used building performance simulation to assess the potential of complete solar-absorption $\mathrm{A} / \mathrm{C}$ systems with cooling capacities of $40 \mathrm{~kW}$ or less. According to Clarke (2001), building performance simulation relies on mathematical models of building system components constructed to represent each energy flow path and their interactions. These models can be used to make predictions of how building systems will perform. Building performance simulation is an attempt to emulate reality. The following researchers used building performance simulation to assess the potential of solar-absorption $\mathrm{A} / \mathrm{C}$ systems for their respective climate regions.

May et al. (2009) simulated the performance of a solar-absorption A/C system with a $10 \mathrm{~kW}$ cooling capacity operating in Tunis and Gabes. The researchers investigated the optimum operating conditions of the absorption chiller studied which avoided salt crystallization. Salt crystallization occurs in an absorption chiller when the absorbent/refrigerant solution decreases in temperature which causes the solution solubility limit to decrease as well. If the solubility limit decreases sufficiently, salt will crystallize causing wear to the absorption chiller. The researchers found that a cooling medium of $35^{\circ} \mathrm{C}$, evaporator medium of $11^{\circ} \mathrm{C}$ and generator medium of $90^{\circ} \mathrm{C}$ avoided salt crystallization and yielded an absorption chiller COP of 0.66 . The absorption chiller 
model used for building performance simulation, however, was calibrated using manufacturer's data with unreported uncertainty.

Oliveti et al. (2009) simulated the performance of a solar-absorption A/C system with a $35 \mathrm{~kW}$ cooling capacity operating in Italy. The study was concerned with investigating the benefits of using a cold storage tank in a solar-absorption $\mathrm{A} / \mathrm{C}$ system. The researchers found significant improvements to the absorption chiller and global COP when a cold storage tank was employed. The global COP is defined as the ratio of refrigeration effect to the energy required to operate the entire solar-absorption $\mathrm{A} / \mathrm{C}$ system. The absorption chiller and global COP increased from 0.42 and 0.11 to 0.71 and 0.51 , respectively, with the addition of cold storage. The absorption chiller model used, however, was calibrated with manufacturer's data whose uncertainty was not reported.

Lecuona et al. (2009) simulated the performance of a solar-absorption $\mathrm{A} / \mathrm{C}$ system to estimate the hot water temperature at the generator inlet of the absorption chiller that would yield optimum system performance. The simulations performed in this study clearly demonstrate that an optimum generator inlet temperature exists because the absorption chiller COP increases with generator inlet temperature, however, solar collector efficiency decreases. The determination of optimum operating conditions, such as generator inlet temperature, of solar-absorption $\mathrm{A} / \mathrm{C}$ systems is an area where building performance simulation may be useful. The researchers found this optimum temperature varied with ambient temperature and system design. This result supported the argument that the performance of solar-absorption $\mathrm{A} / \mathrm{C}$ systems varies with local climatic 
conditions. The absorption chiller models used for simulation of the solar-absorption $\mathrm{A} / \mathrm{C}$ system were, however, calibrated against manufacturer's data for two absorption chillers with $4.5 \mathrm{~kW}$ and $10 \mathrm{~kW}$ cooling capacities. The uncertainty of the manufacturer's data was not reported.

Mazloumi et al. (2008) simulated the performance of a solar-absorption $\mathrm{A} / \mathrm{C}$ system with a cooling capacity of $17.5 \mathrm{~kW}$ in Iran. In this climate the ambient dry bulb temperature varied between $27^{\circ} \mathrm{C}$ and $46^{\circ} \mathrm{C}$ while the wet bulb temperature varied between $20^{\circ} \mathrm{C}$ and $25^{\circ} \mathrm{C}$. The simulation results showed that a parabolic trough collector area of $57.6 \mathrm{~m}^{2}$ was adequate to supply the absorption chiller with energy. The researchers also found the mass flow rate of water to the collectors had negligible impact on system performance. The absorption chiller model used for simulation was, however, not calibrated with experimentally obtained performance data.

Mateus and Oliveira (2008) simulated the performance of a solar-absorption A/C system for locations in Portugal, Germany and Italy. This study was primarily concerned with the economics of solar-absorption $\mathrm{A} / \mathrm{C}$ systems. This study found that while it was possible for solar-absorption $\mathrm{A} / \mathrm{C}$ systems to contribute to space cooling demands, the economic benefits varied widely from region to region. The price of water, gas and electricity as well as government financial support were identified as important factors contributing to the economic performance of solar-absorption $\mathrm{A} / \mathrm{C}$ systems. This study did not identify important climatic conditions which contribute to performance dependencies of solar-absorption $\mathrm{A} / \mathrm{C}$ systems on geographic location. The absorption 
chiller model used in the simulation was calibrated with manufacturer's data but the uncertainty of the data was not reported.

Balghouthi et al. (2005) simulated the performance of a solar-absorption A/C system with a $10 \mathrm{~kW}$ cooling capacity in Tunisia. The purpose of this study was to size and select components of the solar-absorption $\mathrm{A} / \mathrm{C}$ system auxiliary to the absorption chiller such as solar collectors, heat exchangers and storage tanks. The simulated solarabsorption $\mathrm{A} / \mathrm{C}$ system was eventually constructed with the help of the simulation results. For the climate investigated, the authors determine from simulation that $30 \mathrm{~m}^{2}$ of flat plate solar thermal collectors tilted $35^{\circ}$ to the horizontal along with a $1000 \mathrm{~L}$ hot water storage tank are optimized for a solar-absorption $\mathrm{A} / \mathrm{C}$ system with a $10 \mathrm{~kW}$ cooling capacity. The authors do not provide details of climatic conditions or of the overall system performance. The authors did not mention how the model of the absorption chiller was calibrated so uncertainty in the simulation results was unclear.

Assilzadeh et al. (2005) performed simulations to determine optimum characteristics of components for a solar-absorption $\mathrm{A} / \mathrm{C}$ system with a $3.5 \mathrm{~kW}$ cooling capacity for the climate of Malaysia. The authors determined the optimum system to have a collector area of $35 \mathrm{~m}^{2}$ and a hot water storage tank volume of $800 \mathrm{~L}$. The absorption chiller simulation model used was calibrated with manufacturer's data but the uncertainty of the data was not reported.

Florides et al. (2002) simulated the performance of a solar-absorption A/C system 
with an $18 \mathrm{~kW}$ cooling capacity operating in Cyprus. The goal of the simulation was to optimize the design of the components of the solar-absorption $\mathrm{A} / \mathrm{C}$ system for the given absorption chiller. Based on the simulation results, the system was constructed with a $600 \mathrm{~L}$ hot water storage tank, and $15 \mathrm{~m}^{2}$ of compound parabolic trough solar collectors tilted $30^{\circ}$ to the horizontal. The system was optimized based on simulation results for a house with an annual cooling load at $25^{\circ} \mathrm{C}$ of $17600 \mathrm{kWh}$ with peak load of $10.3 \mathrm{~kW}$ and heating load at $21^{\circ} \mathrm{C}$ of $3530 \mathrm{kWh}$ with a peak load of $5.5 \mathrm{~kW}$. The absorption chiller model used for building performance simulation was calibrated with manufacturer's data but the uncertainty of the data was not reported.

$\mathrm{Li}$ and Summathy (2001) simulated the performance of a solar-absorption $\mathrm{A} / \mathrm{C}$ system operating in Hong Kong. The researchers were investigating optimal hot water storage tank characteristics which were independent of absorption chiller cooling capacity. The researchers were interested in the effect on system performance caused by the addition of a partition in the hot water tank which prevented mixing between the warmest water at the top of the tank and the water in the rest of the tank when solar insolation was low. The simulations showed that using the hot water tank with a partition allowed the solar absorption $\mathrm{A} / \mathrm{C}$ system to operate for approximately an extra hour for the day studied. The simulation was based on an absorption chiller model that was calibrated with manufacturer's data but the uncertainty of the data was not reported.

It was clear from the literature reviewed that research using building performance simulation to assess the potential of solar-absorption $\mathrm{A} / \mathrm{C}$ systems was not being 
performed in North America. None of the studies mentioned contained simulation results based on climatic conditions of a Canadian setting. The performance of a solarabsorption $\mathrm{A} / \mathrm{C}$ system is highly dependent on many local climatic conditions such as the average solar insolation value, the ambient temperature and humidity. The results of the previously mentioned studies were only relevant to their respective climatic regions. Consequently, it was unclear whether or not solar-absorption $\mathrm{A} / \mathrm{C}$ systems were viable for locations in Canada. Building performance simulation would be useful in evaluating the potential of solar-absorption $\mathrm{A} / \mathrm{C}$ systems for a Canadian residential environment.

The models of the solar-absorption $\mathrm{A} / \mathrm{C}$ systems from the previously mentioned studies could be emulated to provide insight into the performance of these systems in a Canadian environment. The insight would be limited, however, because the systems that have been simulated relied on models of absorption chillers that required improvements to their calibration. The absorption chiller models that have been used for building performance simulation were either not calibrated or calibrated against data from manufacturers with unreported uncertainty.

\subsubsection{Experimental Studies of Solar Air Conditioning Systems Based on Absorption} Chillers

Several experimental studies focused on observing the performance of operating solar-absorption $\mathrm{A} / \mathrm{C}$ systems have been performed. Available absorption chiller performance data in those studies were relevant to assessing the potential of solarabsorption A/C systems for Canadian residential housing. An absorption chiller model for 
building performance simulation could be calibrated from reliable experimental data. The calibrated absorption chiller model could be used to simulate how a solar-absorption $\mathrm{A} / \mathrm{C}$ system would perform for a Canadian residential housing application. The following researchers have experimentally investigated solar-absorption A/C systems.

Agyenim et al. (2010) investigated the performance of a solar-absorption A/C system with a $4.5 \mathrm{~kW}$ cooling capacity operating in Wales during the summer. The researchers found that the absorption chiller operated with an average COP of 0.48 for an average peak solar insolation of $812 \mathrm{~W} / \mathrm{m}^{2}$. The authors presented absorption chiller performance data for a few specific operating conditions, however, the instrumentation that acquired this performance data was not described. Details concerning the uncertainty of this data were not reported.

Marc et al. (2010) investigated experimentally the performance of a solarabsorption A/C system with a $10 \mathrm{~kW}$ cooling capacity operating in France. The goal of the study was to show that the system could cool four classrooms without any backup cooling. The goal of the study was achieved. The authors presented some performance data for the absorption chiller of the solar-absorption A/C system. Details concerning the facility's instrumentation were, however, not mentioned along with the uncertainty of the data presented.

Asdrubali et al. (2009) experimentally investigated the performance of a solarabsorption $\mathrm{A} / \mathrm{C}$ system with a $4.5 \mathrm{~kW}$ cooling capacity operating in Italy. The system was 
only recently constructed at the time this experimental investigation was conducted so data presented by the authors was only preliminary. The uncertainty of the given data was not reported.

Helm et al. (2009) experimentally investigated the performance of a solarabsorption $\mathrm{A} / \mathrm{C}$ system with a cooling capacity of $10 \mathrm{~kW}$ operating in Germany. The solar-absorption $\mathrm{A} / \mathrm{C}$ system was novel because it employed a dry cooling tower and latent heat storage instead of a wet cooling tower. The system provides $10 \mathrm{~kW}$ of cooling capacity driven by $14 \mathrm{~kW}$ of heat input for evaporator, generator and condenser inlet temperatures of $18^{\circ} \mathrm{C}, 90^{\circ} \mathrm{C}$ and $28^{\circ} \mathrm{C}$. The uncertainty associated with this data was not reported.

Jung and Cagni (2009) experimentally investigated the performance of a solarabsorption $\mathrm{A} / \mathrm{C}$ system with a cooling capacity of $10 \mathrm{~kW}$ operating in Italy. The system components were described, however, no real data were presented regarding the performance of any component of this installation.

Ali et al. (2008) experimentally investigated the performance of a solarabsorption A/C system in Germany over a five year operational period. The solarabsorption $\mathrm{A} / \mathrm{C}$ system employed an absorption chiller with a $35 \mathrm{~kW}$ cooling capacity. Over the five years studied, the solar-absorption $\mathrm{A} / \mathrm{C}$ system was able to supply $60 \%$ of the space cooling load required in $\mathrm{kWh}$. Data indicated that the absorption chiller COP varied from 0.37 to 0.81 with local solar insolation and ambient temperature, however, 
there was no indication of the experimental uncertainty associated with the data presented.

Hidalgo et al. (2008) experimentally investigated the performance of a solarabsorption $\mathrm{A} / \mathrm{C}$ system with a $35 \mathrm{~kW}$ cooling capacity operating in Spain. The authors presented performance data of the absorption chiller that were collected over the summer of 2004. According to the data, the solar-absorption A/C system was able to supply $56 \%$ of the space cooling demand required in $\mathrm{kWh}$. The instrumentation of this facility was not described and there was no indication of the experimental uncertainty associated with data presented.

Pongtornkulpanich et al. (2008) investigated the performance of a solarabsorption $\mathrm{A} / \mathrm{C}$ system with a $35 \mathrm{~kW}$ cooling capacity operating in Thailand. The solarabsorption $\mathrm{A} / \mathrm{C}$ system was able to supply $81 \%$ of the building's yearly space cooling load in $\mathrm{kWh}$. The researchers presented system performance data for a typical clear sky and overcast day, however, details concerning the instrumentation and uncertainty of this data were not reported.

The results of the mentioned experimental investigations have limited ability to assess the potential of solar-absorption $\mathrm{A} / \mathrm{C}$ systems for a Canadian residential application. Solar-absorption A/C system performance is highly dependent on local climatic conditions such as ambient temperature, humidity and solar insolation. The studied solar-absorption $\mathrm{A} / \mathrm{C}$ systems would behave differently in a Canadian 
environment due to differences in climatic conditions between a Canadian location and the locations where the respective solar-absorption $\mathrm{A} / \mathrm{C}$ systems were studied.

The mentioned experimental investigations do provide absorption chiller performance data. The performance data of the absorption chiller alone depends only on the boundary conditions at the absorption chiller. Absorption chiller performance data are relevant to the study of solar-absorption $\mathrm{A} / \mathrm{C}$ systems for the climatic conditions of any location. Unfortunately, the uncertainty of the absorption chiller performance data produced by the mentioned experimental investigations was unclear in all cases. The absorption chiller performance data presented in these experimental investigations was unsuitable to calibrate an absorption chiller model for building performance simulation.

\subsubsection{Simulation Based Studies of Absorption Chiller Performance}

There have been efforts dedicated to developing absorption chiller models based on the thermodynamics of the constituent components of the absorption chiller. It is possible to use these models for building performance simulation of solar-absorption $\mathrm{A} / \mathrm{C}$ systems. Absorption chiller performance results from such models have been presented in the following studies.

Arnavat et al. (2010) compared two modelling methods of absorption chillers. Both methods relied on writing energy balance equations for the absorption chiller condenser, absorber, generator and evaporator. In the first modelling method the energy balance equations were complemented with thermophysical data for the refrigerant and absorbent. In the second modelling method the energy balance equations were 
complemented with empirical data of absorption chiller performance given by manufacturers. The absorption chiller model predictions and their results were validated against experimental data from Safarik (2007). The validation showed that the experimental data and model predictions differed in their predictions of heat input to the generator by as much as $5 \mathrm{~kW}$ for both modelling methods. This is a significant amount considering the maximum generator heat input was shown to be approximately $20 \mathrm{~kW}$ for the absorption chiller studied by the validation data. The experimental uncertainty of the data was not reported by Safarik (2007).

Marcos et al. (2009) simulated the performance of a water/lithium-bromide absorption chiller with the goal of determining the solution concentration which optimized absorption chiller COP. The absorption chiller model used was based on energy balance equations written for the absorber, condenser, evaporator and generator of the absorption chiller. Researchers discovered the solution concentration should be incremented by $6.7 \%-8.5 \%$ for condenser temperatures of $25^{\circ} \mathrm{C}, 30^{\circ} \mathrm{C}$ and $35^{\circ} \mathrm{C}$. Details concerning how the absorption chiller model was calibrated were not mentioned.

Kohlenbach and Ziegler (2008a and 2008b) developed a mathematical model of an absorption chiller based on a thermodynamic analysis of the absorber, generator, condenser and evaporator. Simulated results were compared against manufacturer's data for an absorption chiller with a $10 \mathrm{~kW}$ cooling capacity. The simulated results and experimental data differed in their predictions of water temperature exiting the absorber, evaporator and generator by at least $1^{\circ} \mathrm{C}$ in all cases; this amount results in an error of 
temperature difference between water entering and exiting the absorber of approximately $15 \%$.

Zambrano et al. (2008) developed a model for an entire solar-absorption A/C system which included a model development for an absorption chiller. The system model developed was based on a solar-absorption $\mathrm{A} / \mathrm{C}$ system with a $35 \mathrm{~kW}$ cooling capacity. The absorption chiller model was based on an energy balance applied to the evaporator and generator of the absorption chiller. The absorption chiller model was validated against the solar-absorption $\mathrm{A} / \mathrm{C}$ system's performance data. The model predictions and performance data differ by over $2^{\circ} \mathrm{C}$ in the prediction of the evaporator outlet temperature for some cases. Considering that the temperature difference between evaporator inlet and outlet was approximately $5^{\circ} \mathrm{C}$ the discrepancy is quite significant. The instrumentation used to acquire the data, however, was not described. The uncertainty of the experimental performance data was not reported.

Kim and Ferreira (2008) developed a mathematical model for an absorption chiller based on energy balance equations written for the absorption chiller's constituent components complemented with thermophysical properties of the absorbent/refrigerant working pair. Model predictions were validated against manufacturer's performance data for two absorption chillers with a $15 \mathrm{~kW}$ and a $35 \mathrm{~kW}$ cooling capacity. Differences of up to $5 \mathrm{~kW}$ in the absorption chiller's cooling capacity were observed between the model predictions and manufacturer's data. The uncertainty of the manufacturer's data was also not reported. 
Witte et al. (2007) validated two separate models of a $15 \mathrm{~kW}$ absorption chiller against experimental performance data. Experimental performance data was provided by the absorption chiller manufacturer and the Institute of Air Conditioning and Refrigeration in Dresden, Germany. The first model validated relied on a data file that contained absorption chiller performance data for a variety of operating conditions in addition to the nominal operating condition. The absorption chiller performance data file was called by the model to estimate the absorption chiller performance for any operating condition. The second model validated was developed by considering energy balance equations for the absorption chiller absorber, condenser, evaporator and generator. Both models showed differences in predicted cooling capacities of roughly $3 \mathrm{~kW}$ compared to the validation data. The uncertainty associated with the validation data was not reported.

Kim and Park (2007) simulated the performance of an absorption chiller with a $10.5 \mathrm{~kW}$ cooling capacity. The simulation model was based on solving governing equations simultaneously for the different constituent components of an absorption chiller. The different constituent components of the absorption chiller were modeled with a lumped parameter approach. Results were presented by the authors, however, the results were not validated against experimental data.

Fathi et al. (2004) developed a mathematical model of an absorption chiller based on energy balances written for the absorber, condenser, evaporator and generator. The model also took into account irreversibilities due to heat transfer, friction and eddies. The results of the mathematical model were not validated against experimental data. 
Atmaca and Yigit (2003) simulated the performance of an absorption chiller with a cooling capacity of $10.5 \mathrm{~kW}$. The simulation results were based on a simple mathematical model for the absorption chiller where the generator, absorber, condenser and evaporator were modeled as heat exchangers. Model predictions of absorption chiller performance were validated against simulation results of Ileri (1995). The absorption chiller studied by Ileri (1995), however, had a cooling capacity of $100 \mathrm{~kW}$ which was oversized to validate the simulation results of Atmaca and Yigit (2003).

Florides et al. (2003) developed a mathematical model of an absorption chiller. The absorption chiller model was based on energy balance equations written for the absorber, condenser, evaporator and generator. Results from the absorption chiller model were validated against experimental performance data from an absorption chiller developed for this research with a cooling capacity of $1 \mathrm{~kW}$. For validation, the researchers compared model predictions versus measured overall heat transfer coefficients of the various heat exchangers internal to the absorption chiller. Significant differences were observed between predicted and experimental results. For example, the model predicted a heat transfer coefficient of $625 \mathrm{~W} / \mathrm{m}^{2} \mathrm{~K}$ versus a measured value of 400 $\mathrm{W} / \mathrm{m}^{2} \mathrm{~K}$ for the absorber heat exchanger at one set of conditions studied. An uncertainty analysis of the experimental data was also not reported.

Chua et al. (2002) developed a model for an ammonia-water absorption chiller. The model was based on energy balance equations written for the absorption chiller components such as the absorber, condenser, generator and evaporator. The model also 
accounted for internal irreversibilities within the absorption chiller components. Model predictions were presented, however, they were not validated against empirical data.

The absorption chiller models developed in the studies mentioned do provide insight into the performance of these devices. The models are capable of predicting thermodynamic performance trends of absorption chillers. The models are consistent in showing that the quantities that define absorption chiller performance, the generator and evaporator heat transfer rate along with the $\mathrm{COP}$, increase with increasing temperature of fluid delivered to the generator and evaporator. An increase in the temperature of the fluid which enters the condenser or absorber will result in a decrease in the absorption chiller's performance quantities.

The applicability of the developed absorption chiller models to building performance simulation of solar-absorption $\mathrm{A} / \mathrm{C}$ systems is limited. In all of the studies which developed and validated models against empirical performance data, significant differences were observed between validation data and performance predicted by models. In addition to these discrepancies, the uncertainty of the validation data were unreported.

\subsubsection{Experimental Studies of Absorption Chiller Performance}

If models of absorption chillers are to be useful for building performance simulation of solar-absorption $\mathrm{A} / \mathrm{C}$ systems, the models will have to be calibrated against reliable experimental data. Absorption chiller models will also require calibration data over a wide range of operating boundary conditions if they are to be useful for building performance simulation of solar-absorption $\mathrm{A} / \mathrm{C}$ systems. In practice, an absorption 
chiller operating as part of a solar-absorption $\mathrm{A} / \mathrm{C}$ system would be exposed to a broad range of boundary conditions due to local climatic conditions, system control and system hardware characteristics. The following studies investigated experimentally the performance of absorption chillers.

Melograno et al. (2009) described the development of an experimental test facility capable of collecting performance data from absorption chillers with cooling capacities up to $20 \mathrm{~kW}$. The authors presented absorption chiller performance data for six different operating boundary conditions in this study. Details concerning the instrumentation that was used to acquire data were not reported. An uncertainty analysis of the experimental data was not presented.

Adao et al. (2008) studied the performance of a prototype absorption chiller with a cooling capacity of $8 \mathrm{~kW}$ in Portugal. The authors presented absorption chiller performance data for one set of operating boundary conditions. The generator inlet temperature was above $95^{\circ} \mathrm{C}$, the evaporator inlet temperature was above $17^{\circ} \mathrm{C}$, the condenser and absorber were cooled with air at a temperature of $28^{\circ} \mathrm{C}$. The absorption chiller operated with approximately $14 \mathrm{~kW}$ of heat input to provide a cooling capacity of approximately $7 \mathrm{~kW}$. The instrumentation that was used to acquire the data was not reported. An uncertainty analysis of the experimental data was not present.

Aphornratana and Sriveerakul (2007) experimentally investigated the performance of an absorption chiller with a cooling capacity of $2 \mathrm{~kW}$. Data indicating the 
performance of the absorption chiller was presented by the authors for a range of generator, condenser, absorber and evaporator operating conditions. The data indicate the absorption chiller's cooling capacity, generator heat input and COP increase with increasing generator and evaporator inlet temperature. The data also indicate the absorption chiller's cooling capacity, generator heat input and COP decrease with increasing condenser and absorber inlet temperature. The dependency on the absorption chiller's performance to externally pumped flow was not investigated nor was there an uncertainty analysis presented.

Izquierdo et al. (2005) investigated the performance of an absorption chiller with a $4.5 \mathrm{~kW}$ cooling capacity as part of a solar-absorption $\mathrm{A} / \mathrm{C}$ system. For the facility developed in this research, air was blown over fan coils and fin/tube heat exchangers to simulate the cooling water and refrigeration load. Performance of the absorption chiller was given as a function of ambient dry bulb temperature only which varied from $23^{\circ} \mathrm{C}$ to $42^{\circ} \mathrm{C}$. It was found that the absorption chiller's COP decreased with increasing ambient dry bulb temperature from approximately 0.6 at $23^{\circ} \mathrm{C}$ to 0.3 at $42^{\circ} \mathrm{C}$. An uncertainty analysis of the performance data acquired was not reported.

Absorption chiller performance data were available over a wide range of operating conditions in the previously mentioned experimental investigations. These particular investigations, however, did not include a detailed uncertainty analysis of the absorption chiller performance data. Since the uncertainty of the absorption chiller performance data was unclear, the data were unsuitable to calibrate an absorption chiller 
model for building performance simulation.

The most reliable experimental absorption chiller performance data were available in the experimental investigation of Asdrubali and Grignaffini (2005). These researchers experimentally investigated the performance of an absorption chiller at different operating conditions. The experimental results were used to extrapolate absorption chiller performance at conditions not measured to validate a mathematical model of an absorption chiller. An uncertainty analysis was given. The uncertainty margins of the absorption chiller COP data were determined to be $\pm 6 \%$. These uncertainty margins are likely overly optimistic as the temperature sensors used for the derivation of the COP were not submerged in the flow streams but were instead embedded in cavities and immersed in oil. The researchers only provided absorption chiller performance data for seven sets of operating boundary conditions. To calibrate an absorption chiller model for building performance simulation of solar-absorption $\mathrm{A} / \mathrm{C}$ systems, data from a larger variety of boundary conditions is required.

Experimental data which constituted a performance map of an absorption chiller were presented in the experimental investigation of Vega et al. (2006). The uncertainty associated with the absorption chiller performance data presented by the authors was high. The experimentally determined cooling capacity and energy supplied to the absorption chiller had uncertainty margins of $\pm 18-20 \%$. Absorption chiller experimental performance data with lower uncertainty margins are needed to calibrate an absorption chiller model for building performance simulation of solar-absorption $\mathrm{A} / \mathrm{C}$ systems. 
Reliable experimental absorption chiller performance data covering a wide enough range of operating conditions to calibrate a model for solar-absorption $\mathrm{A} / \mathrm{C}$ system simulation are not currently available in literature. The absorption chiller performance data in literature does identify variables of interest that affect absorption chiller performance. The thermal conditions and flow rates of the fluid entering the generator, evaporator, condenser and absorber are identified as variables that will vary in actual solar-absorption $\mathrm{A} / \mathrm{C}$ systems that affect absorption chiller performance.

\subsection{Objectives}

The overall goal of this research was to assess the performance of solarabsorption $\mathrm{A} / \mathrm{C}$ systems for Canadian residential housing by using building performance simulation. In order to meet the overall goal of this research, the particular goals of this thesis were defined to improve existing building performance simulation models of absorption chillers. For this thesis the following goals were completed:

1) An absorption chiller was acquired and commissioned at Carleton University. A test facility was designed and assembled to experimentally characterize the absorption chiller's performance under different steady-state operating boundary conditions.

2) The absorption chiller test facility was used to gather performance data for a variety of operating boundary conditions. The gathered performance data can be used in the future as part of a data set to calibrate a building performance simulation model of an absorption chiller. 


\subsection{Outline of Thesis}

This thesis describes the experimental design and operation of an absorption chiller test facility which was used to gather absorption chiller performance data. The next chapter describes the thermodynamics of absorption chillers and an existing absorption chiller model used for building performance simulation. Following this, details of the design of the absorption chiller test facility are provided. The instrumentation of the absorption chiller test facility is then described followed by an uncertainty analysis of the performance data to be gathered. Finally, absorption chiller performance data is presented along with uncertainty margins for a range of operating boundary conditions. 


\subsection{Modelling Solar Cooling Systems}

The preceding chapter identified the need to assess the potential of solarabsorption A/C systems for Canadian residential housing. This chapter describes the working principle of solar-absorption $\mathrm{A} / \mathrm{C}$ systems. The thermodynamics of the absorption cycle are explained in this chapter as well as an absorption chiller model for building performance simulation.

\subsection{Typical Equipment of a Residential Solar Air Conditioning System Based on an Absorption Chiller}

The equipment of a typical solar-absorption A/C system is illustrated in Figure 2.1 for a residential application. By using mathematical models of the components in Figure 2.1 , it is possible to simulate how solar-absorption $\mathrm{A} / \mathrm{C}$ systems perform. Beausoleil-Morrison (2009) indicated that all of the components in Figure 2.1 have established models for building performance simulation except the absorption chiller. 


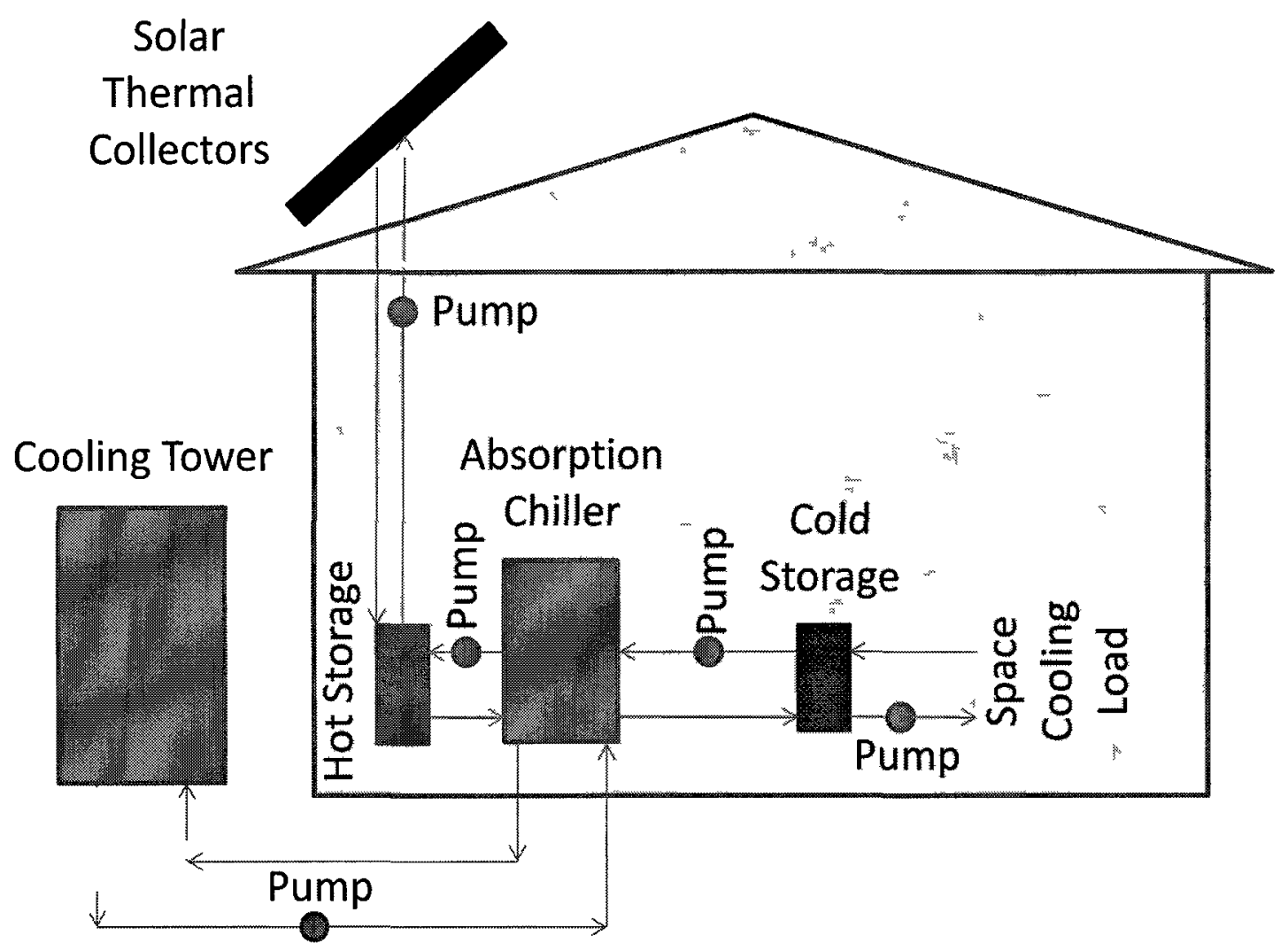

Figure 2.1: Typical residential solar air conditioning system based on an absorption chiller

In Figure 2.1, solar thermal collectors gather the sun's energy to heat water. The solar heated water is circulated to a hot storage tank. The stored hot water can be used to activate the absorption chiller on demand. The absorption chiller, when activated, chills a stream of water which is circulated to a cold storage tank. Pumps are used to circulate water. The stored chilled cold water can be circulated for space cooling on demand. A cooling tower is required to reject all the heat being transferred to the absorption chiller to the environment. The absorption chiller receives heat transferred from the solar thermal collectors and the space cooling load. 


\subsection{Absorption Cycle Thermodynamics}

Idealized Carnot cycles can be used to help explain the basic principle of operation of an absorption refrigeration cycle as illustrated in Figure 2.2. The absorption refrigeration cycle can be idealized as a combination of two Carnot cycles: a Carnot power cycle and a Carnot refrigeration cycle. The power cycle receives heat $\left(\dot{q}_{G}\right)$ from a high temperature $(\mathrm{H})$ thermal reservoir and expels heat $\left(\dot{q}_{C}\right)$ to an intermediate temperature (M) thermal reservoir. The power generated (W) is used to run a refrigeration cycle that removes heat $\left(\dot{q}_{E}\right)$ from a low temperature (L) thermal reservoir and expels heat $\left(\dot{q}_{C}{ }^{\prime}\right)$ to the same intermediate temperature thermal reservoir as the power cycle.

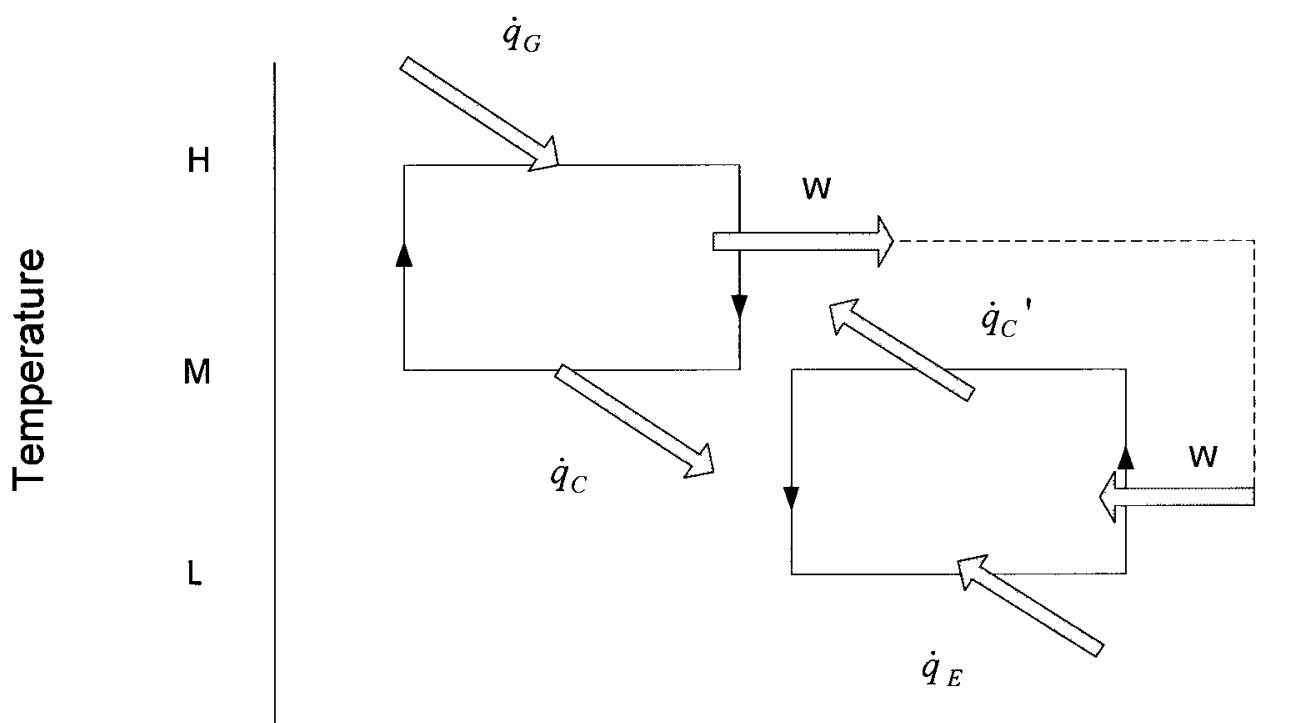

\section{Entropy}

Figure 2.2: Idealized absorption cycle temperature - entropy diagram. Adapted from Herold et. al (1996) 
The idealized Carnot cycles shown in Figure 2.2 demonstrate that three thermal reservoirs are necessary in a heat driven thermodynamic refrigeration cycle. Figure 2.3 illustrates the components that form an actual single-effect absorption cycle. The dashed lines in Figure 2.3 represent the fluid circuits which function as the high, intermediate and low temperature thermal reservoirs that are required by the thermodynamics of the absorption chiller. The description by Henning (2007) of Figure 2.3 has been adapted for the following discussion.

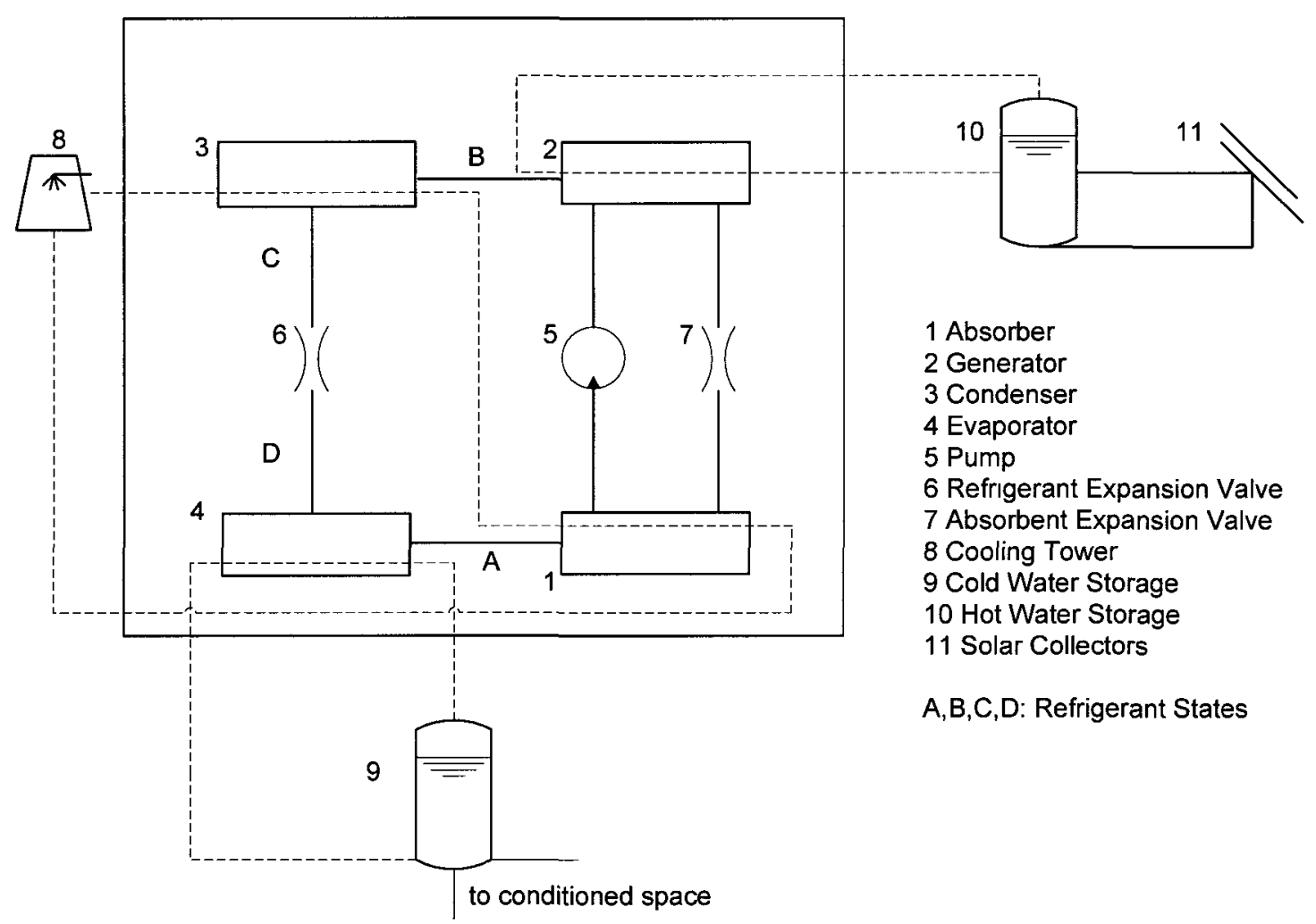

Figure 2.3: Solar thermal driven absorption air conditioning system. Adapted from Henning (2007) 
The internal components of a single-effect absorption chiller are illustrated in Figure 2.3 along with the other external components of a typical solar-absorption $\mathrm{A} / \mathrm{C}$ system. The refrigerant states shown in Figure 2.3 can be represented on the temperatureentropy diagram shown in Figure 2.4. The useful cooling effect of an absorption chiller is produced by the evaporation of a refrigerant at a cold temperature in the evaporator (4) in the process from state A to B. In a conventional vapour compression refrigeration cycle, the refrigerant vapor exiting the evaporator is compressed using mechanical work to a higher pressure level with a compressor. The compressor of a conventional vapour compression refrigeration cycle is replaced by a generator (2), absorber (1), pump (5) and absorbent expansion valve (7) in the absorption cycle illustrated in Figure 2.3.

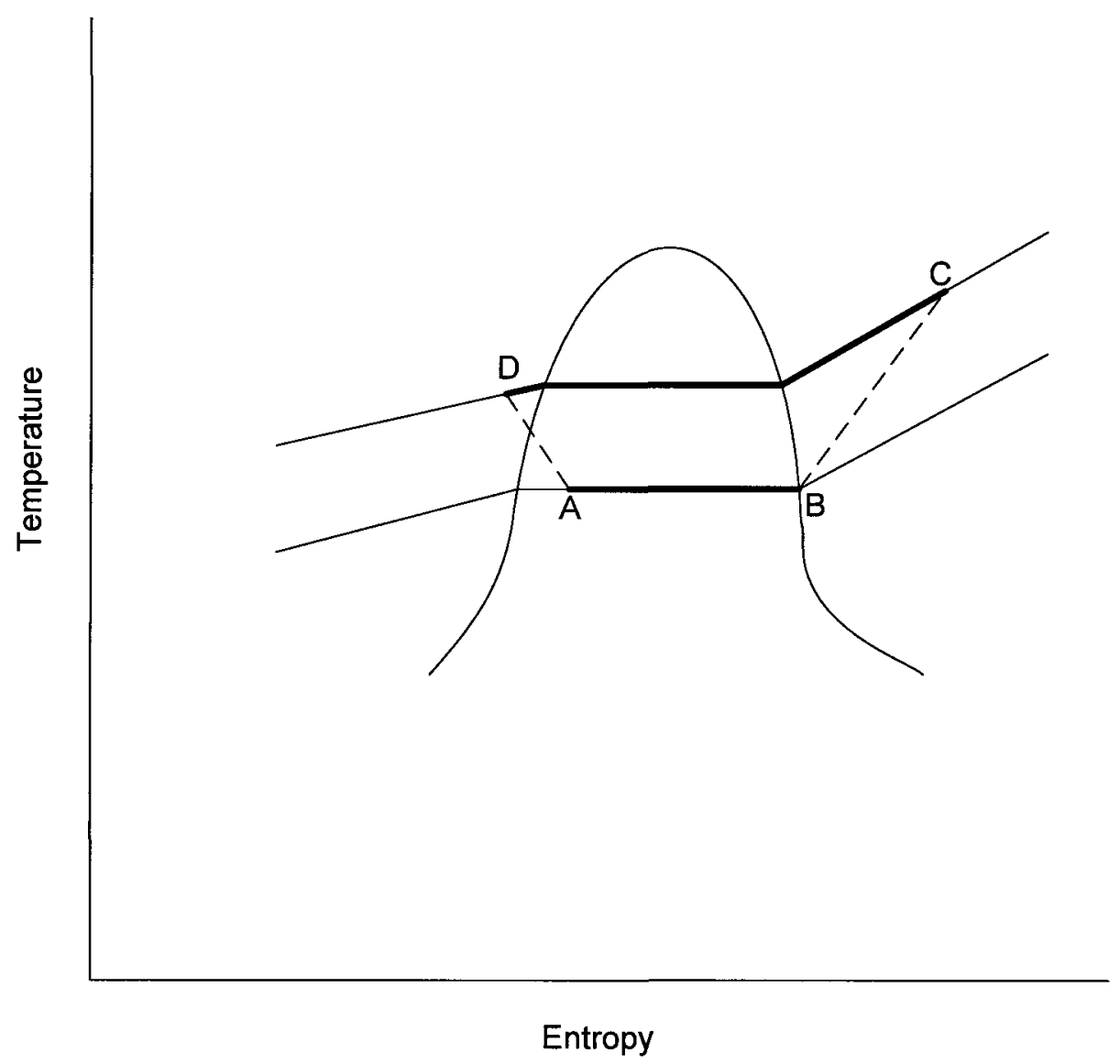

Figure 2.4: Absorption cycle refrigerant temperature - entropy diagram 
In the processes from state $\mathrm{B}$ to $\mathrm{C}$, refrigerant vapour exiting the evaporator is absorbed by a liquid sorbent in the absorber. It is known that for a liquid, a small change in volume will result in a large change in pressure; comparatively for a gas to achieve the same change in pressure a substantially greater change in volume is required. By considering that work $=\int_{V_{1}}^{V_{2}}$ Pressure $x d$ Volume it can be seen that it requires far less work to compress a liquid between the same two pressure levels compared to a gas. Consequently, only a small pump is required to supply the mechanical work needed to compress the refrigerant/absorbent solution to a high pressure after leaving the absorber in the absorption cycle. The high pressure solution then enters the generator where refrigerant vapor is driven out of solution by water heated from solar thermal collectors (11) at a high temperature stored in the hot storage tank (10).

After exiting the generator, the refrigerant vapour undergoes similar processes as it would in a conventional vapor compression cycle. In the process from state $\mathrm{C}$ to $\mathrm{D}$ in the condenser (3), refrigerant vapour exchanges heat with fluid circulated from a cooling tower (8) at an intermediate temperature. After exiting the condenser, the refrigerant is expanded through a valve (6) to the lower evaporator pressure completing the cycle in the process from state $\mathrm{D}$ to $\mathrm{A}$. An expansion valve is also needed between the generator and absorber. This valve expands concentrated absorbent solution in the generator to the lower pressure in the absorber.

A cooling tower is needed to remove the heat of absorption that is produced in the absorber. Absorption is an exothermic reaction. The heat released during absorption is 
due to two components: the latent heat due to refrigerant vapour condensation and the heat of solution released when the now liquid refrigerant dissolves into the absorbent.

It is possible to simulate how absorption chillers perform based on the models of the constituent components illustrated in Figure 2.3. An approach more practical to building performance simulation, however, is to calibrate a coherent absorption chiller model based on experimental performance data. When calibrated, the absorption chiller model predictions approach the accuracy of the experimental performance data.

\subsection{ESP-r Absorption Chiller Model}

ESP-r is a computer program used for building performance simulation. According to Clarke (2001), "ESP-r employs a finite volume approach to the conservation of energy, mass, electrical power, etc. Essentially, the building and its HVAC system are discretised and equations are established for each region to represent the conservation of energy, mass and momentum." The existing absorption chiller model used for building performance simulation in ESP-r was described by Beausoleil-Morrison (2004). The model illustrated in Figure 2.5 depicts this absorption chiller model discussed by Beausoleil-Morrison (2004). The absorption chiller model consists of three control volumes (CV). Each control volume consists of two fluid streams which come into thermal contact in a heat exchanger. This model does not explicitly model the thermodynamics of the individual processes that constitute an absorption chiller but rather relies on experimental calibration. 


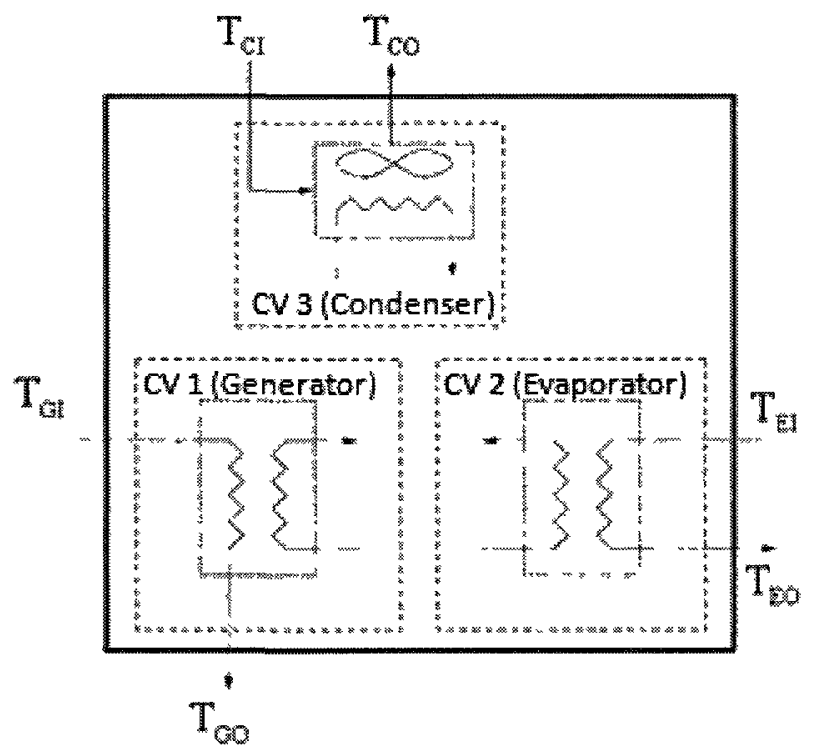

Figure 2.5: ESP-r absorption chiller model. Adapted from Beausoleil-Morrison (2004)

The generator equation relevant to the model illustrated in Figure 2.5 is discussed below. The expression is derived by using the First Law of Thermodynamics for a control volume at steady-state. Equation 2.1 is an energy balance on Control Volume 1. Equation 2.2, the generator equation, is found by rearranging equation 2.1 . It is assumed in this analysis that the control volumes have no heat capacity other than that of the externally circulated fluid streams.

$$
\begin{gathered}
\left(\dot{m} c_{p}\right)_{\mathrm{G}}\left(\mathrm{T}_{\mathrm{GI}}-\mathrm{T}_{\mathrm{GO}}\right)=\dot{q}_{G} \\
\mathrm{~T}_{\mathrm{GO}}=\mathrm{T}_{\mathrm{GI}}-\frac{\dot{q}_{G}}{\left(\dot{m} c_{p}\right)_{\mathrm{G}}}
\end{gathered}
$$

In the above equations $\dot{q}_{G}$ represents the heat transferred across the generator heat exchanger which is used to drive the absorption cycle in $\mathrm{kW}$. The terms $\mathrm{T}_{\mathrm{GI}}$ and $\mathrm{T}_{\mathrm{GO}}$ represent the externally circulated fluid temperature at the inlet and outlet of the 
generator in ${ }^{\circ} \mathrm{C}$. The term $\dot{m}$ represents the mass flow rate of the externally circulated fluid in $\mathrm{kg} / \mathrm{s}$ and $c_{p}$ represents the specific heat capacity of the externally circulated fluid in $\mathrm{kJ} / \mathrm{kgK}$.

An analysis similar to the generator equation of Control Volume 1 is needed to derive the evaporator equation of Control Volume 2 which follows. Equation 2.3 is an energy balance on Control Volume 2.

$$
\left(\dot{m} c_{p}\right)_{\mathrm{E}}\left(\mathrm{T}_{\mathrm{EI}}-\mathrm{T}_{\mathrm{EO}}\right)=\dot{q}_{E}
$$

Equation 2.3 may be re-expressed by using the definition of COP given in equation 2.4 . In this definition of COP, the pumping power required to circulate solution within the absorption chiller is neglected as it is negligible in comparison to $\dot{q}_{G}$.

$$
\mathrm{COP}=\frac{\dot{q}_{E}}{\dot{q}_{G}}
$$

By substituting equation 2.4 into equation 2.3, the energy balance of Control Volume 2 may be re-expressed as:

$$
\left(\dot{m} c_{p}\right)_{\mathrm{E}}\left(\mathrm{T}_{\mathrm{EI}}-\mathrm{T}_{\mathrm{EO}}\right)=\operatorname{COP} \dot{q}_{G}
$$

By substituting equation 2.1 into equation 2.5, the energy balance of Control Volume 2 may be re-expressed as:

$$
\left(\dot{m} c_{p}\right)_{\mathrm{E}}\left(\mathrm{T}_{\mathrm{EI}}-\mathrm{T}_{\mathrm{EO}}\right)=\operatorname{COP}\left(\dot{m} c_{p}\right)_{\mathrm{G}}\left(\mathrm{T}_{\mathrm{GI}}-\mathrm{T}_{\mathrm{GO}}\right)
$$


Equation 2.6 may be rearranged to yield the evaporator equation for Control Volume 2 given as follows:

$$
\mathrm{T}_{\mathrm{EO}}-\mathrm{COP} \cdot \frac{\left(\dot{m} c_{p}\right)_{\mathrm{G}}}{\left(\dot{m} c_{p}\right)_{\mathrm{E}}} \cdot \mathrm{T}_{\mathrm{GO}}=-\mathrm{COP} \cdot \frac{\left(\dot{m} c_{p}\right)_{\mathrm{G}}}{\left(\dot{m} c_{p}\right)_{\mathrm{E}}} \cdot \mathrm{T}_{\mathrm{GI}}+\mathrm{T}_{\mathrm{EI}}
$$

The term $\dot{q}_{E}$ in the above equations represents the heat transferred across the evaporator heat exchanger which is the useful cooling effect of the absorption cycle in $\mathrm{kW}$. The terms $T_{E I}$ and $T_{E O}$ represent the externally circulated fluid temperature at the inlet and outlet of the evaporator in ${ }^{\circ} \mathrm{C}$. The COP represents the absorption chiller's thermal coefficient of performance and is given by the following formula if the pumping power is neglected.

$$
\mathrm{COP}=\frac{\left(\dot{m} c_{p}\right)_{\mathrm{E}}\left(\mathrm{T}_{\mathrm{EI}}-\mathrm{T}_{\mathrm{EO}}\right)}{\left(\dot{m} c_{p}\right)_{\mathrm{G}}\left(\mathrm{T}_{\mathrm{GI}}-\mathrm{T}_{\mathrm{GO}}\right)}
$$

The condenser equation is found by the First Law of Thermodynamics written for the entire system illustrated in Figure 2.5. Equation 2.9 is an energy balance for the entire system illustrated in Figure 2.5 .

$$
\dot{q}_{E}+\dot{q}_{G}+\dot{q}_{p u m p}=\dot{q}_{C}=\left(\dot{m} c_{p}\right)_{\mathrm{C}}\left(\mathrm{T}_{\mathrm{CO}}-\mathrm{T}_{\mathrm{Cl}}\right)
$$

By substituting equation 2.4 into equation 2.9 , the energy balance for the entire system may be re-expressed as:

$$
\mathrm{COP} \dot{q}_{G}+\dot{q}_{G}+\dot{q}_{p u m p}=\left(\dot{m} c_{p}\right)_{\mathrm{C}}\left(\mathrm{T}_{\mathrm{CO}}-\mathrm{T}_{\mathrm{CI}}\right)
$$


Equation 2.10 may be re-expressed by using the definition of COP given in equation 2.8

as:

$$
\frac{\left(\dot{m} c_{p}\right)_{\mathrm{E}}\left(\mathrm{T}_{\mathrm{EI}}-\mathrm{T}_{\mathrm{EO}}\right)}{\left(\dot{m} c_{p}\right)_{\mathrm{G}}\left(\mathrm{T}_{\mathrm{GI}}-\mathrm{T}_{\mathrm{GO}}\right)} \dot{q}_{G}+\dot{q}_{G}+\dot{q}_{p u m p}=\left(\dot{m} c_{p}\right)_{\mathrm{C}}\left(\mathrm{T}_{\mathrm{CO}}-\mathrm{T}_{\mathrm{CI}}\right)
$$

By substituting equation 2.1, equation 2.11 may be re-expressed as:

$$
\begin{aligned}
& \frac{\left(\dot{m} c_{p}\right)_{\mathrm{E}}\left(\mathrm{T}_{\mathrm{EI}}-\mathrm{T}_{\mathrm{EO}}\right)}{\left(\dot{m} c_{p}\right)_{\mathrm{G}}\left(\mathrm{T}_{\mathrm{GI}}-\mathrm{T}_{\mathrm{GO}}\right)}\left(\dot{m} c_{p}\right)_{\mathrm{G}}\left(\mathrm{T}_{\mathrm{GI}}-\mathrm{T}_{\mathrm{GO}}\right)+ \\
& \left(\dot{m} c_{p}\right)_{\mathrm{G}}\left(\mathrm{T}_{\mathrm{GI}}-\mathrm{T}_{\mathrm{GO}}\right)+\dot{q}_{p u m p}=\left(\dot{m} c_{p}\right)_{\mathrm{C}}\left(\mathrm{T}_{\mathrm{CO}}-\mathrm{T}_{\mathrm{CI}}\right)
\end{aligned}
$$

Equation 2.12 may be rearranged to yield equation 2.13, the condenser equation.

$$
\begin{array}{r}
\mathrm{T}_{\mathrm{CO}}+\frac{\left(\dot{m} c_{p}\right)_{\mathrm{G}}}{\left(\dot{m} c_{p}\right)_{\mathrm{C}}} \cdot \mathrm{T}_{\mathrm{GO}}+\frac{\left(\dot{m} c_{p}\right)_{\mathrm{E}}}{\left(\dot{m} c_{p}\right)_{\mathrm{C}}} \cdot \mathrm{T}_{\mathrm{EO}}= \\
\frac{\dot{q}_{p u m p}}{\left(\dot{m} c_{p}\right)_{\mathrm{C}}}+\mathrm{T}_{\mathrm{CI}}+\frac{\left(\dot{m} c_{p}\right)_{\mathrm{G}}}{\left(\dot{m} c_{p}\right)_{\mathrm{C}}} \cdot \mathrm{T}_{\mathrm{GI}}+\frac{\left(\dot{m} c_{p}\right)_{\mathrm{E}}}{\left(\dot{m} c_{p}\right)_{\mathrm{C}}} \cdot \mathrm{T}_{\mathrm{EI}}
\end{array}
$$

In the above equation $\dot{q}_{\text {pump }}$ represents heat gains from the pump used to circulate solution inside the absorption chiller in $\mathrm{kW}$. The term $\dot{q}_{C}$ represents the heat removed from the absorption chiller by fluid circulated through the condenser circuit in $\mathrm{kW}$. The terms $T_{C O}$ and $T_{C I}$ represent the externally circulated fluid temperature at the condenser outlet and inlet in ${ }^{\circ} \mathrm{C}$. The condenser node in Figure 2.5 actually represents both the condenser and absorber; these components are often connected serially in the same fluid circuit in an actual absorption chiller. 
The preceding equations were intended to be complemented with experimentally determined COP and $\dot{q}_{G}$ functions. It was expected these functions would depend on the following boundary conditions:

$$
\begin{aligned}
& \mathrm{COP}=f\left(\dot{m}_{\mathrm{G}}, \dot{m}_{\mathrm{E}}, \dot{m}_{\mathrm{C}}, \mathrm{T}_{\mathrm{G}}, \mathrm{T}_{\mathrm{E}}, \mathrm{T}_{\mathrm{C}}\right) \\
& \dot{q}_{\mathrm{G}}=f\left(\dot{m}_{\mathrm{G}}, \dot{m}_{\mathrm{E}}, \dot{m}_{\mathrm{C}}, \mathrm{T}_{\mathrm{G}}, \mathrm{T}_{\mathrm{E}}, \mathrm{T}_{\mathrm{C}}\right)
\end{aligned}
$$

Beausoleil-Morrison (2004) indicated that reliable experimental data describing the dependence of absorption chiller COP and $\dot{q}_{G}$ on boundary conditions are required to calibrate equations 2.14 and 2.15. For calibration, experimental COP and $\dot{q}_{G}$ data are required for various combinations of boundary conditions $\left(\dot{m}_{\mathrm{G}}, \dot{m}_{\mathrm{E}}, \dot{m}_{\mathrm{C}}, \mathrm{T}_{\mathrm{G}}, \mathrm{T}_{\mathrm{E}}, \mathrm{T}_{\mathrm{C}}\right)$. To acquire data to calibrate the COP and $\dot{q}_{G}$ functions, an absorption chiller test facility was developed in this research which is the subject of the next chapter. 


\subsection{Design and Commissioning of an Experiment}

The preceding chapter described how absorption chillers are modelled with thermodynamics and for building performance simulation in ESP-r. The current ESP-r absorption chiller model described in the previous chapter is not properly calibrated due to insufficient experimental performance data. This chapter describes the design and hardware of an absorption chiller test facility capable of gathering sufficient experimental performance data to calibrate the ESP-r model.

\subsection{Absorption Chiller Laboratory Design}

For performance assessment, a Yazaki water-fired absorption chiller for solar cooling applications with a nominal cooling capacity of $35 \mathrm{~kW}$ (WFC-SC10) was acquired. The refrigerant/absorbent pair of this absorption chiller was water/lithiumbromide.

It was important to test the performance of this absorption chiller operating with a variety of boundary conditions since these boundary conditions vary in operating solarabsorption $\mathrm{A} / \mathrm{C}$ systems. In practice, weather, solar collector characteristics, storage medium and system control affect the temperature and flow rate of the fluid delivered to the condenser, absorber, evaporator and generator. The temperatures of the externally pumped fluid streams which circulate through the absorption chiller influence the absorption chiller's performance directly. The flow rates of these streams may also affect the absorption chiller's performance. The test facility was required to characterize the 
performance of the absorption chiller for a range of flow rates and temperatures entering the generator, evaporator, condenser and absorber. This acquired performance data would be relevant to a solar-absorption $\mathrm{A} / \mathrm{C}$ system scenario.

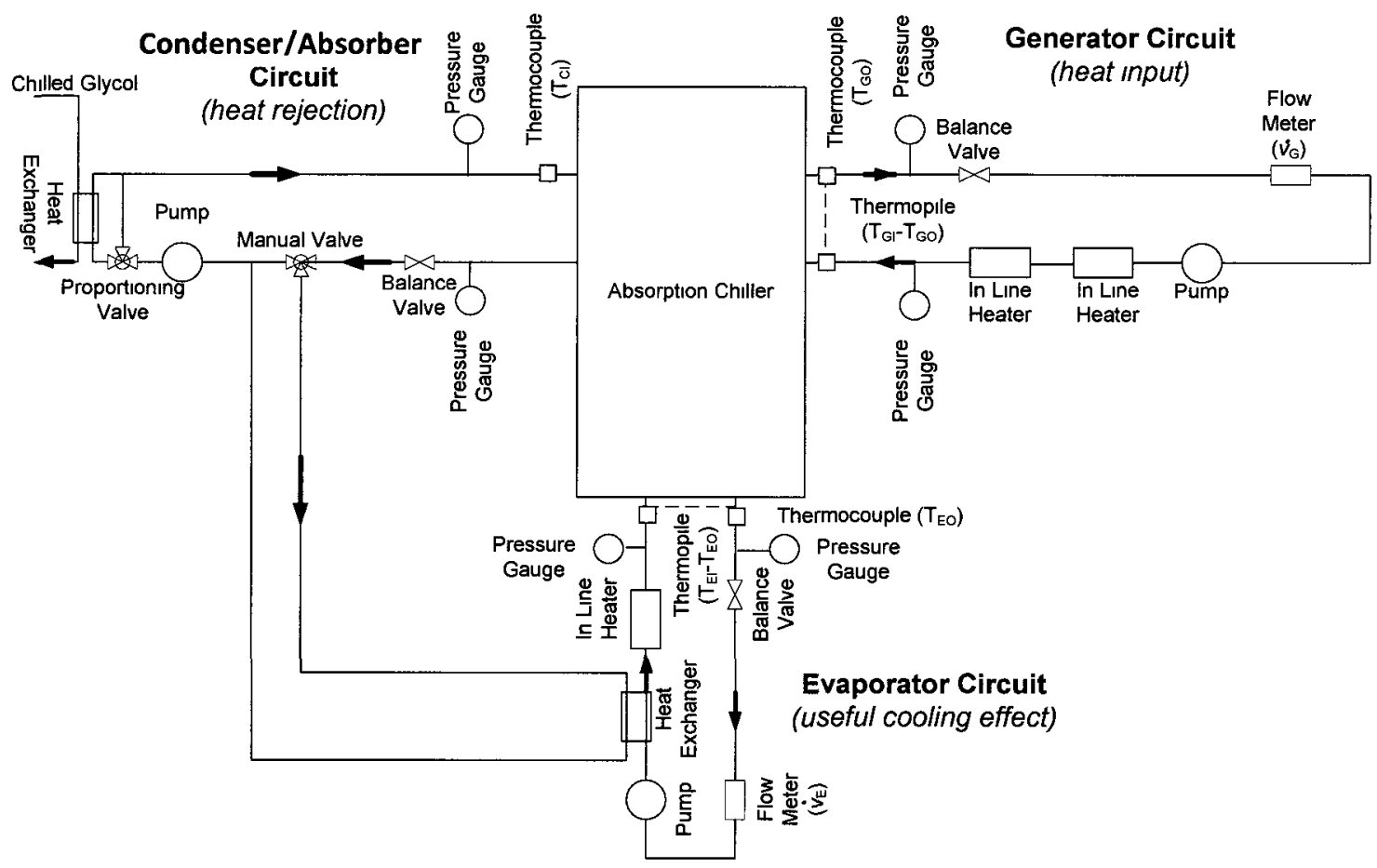

Figure 3.1: Absorption chiller test facility design schematic

A schematic of the absorption chiller test facility designed, assembled and commissioned for this research is illustrated in Figure 3.1. The generator circuit provided the heat input to drive the absorption cycle. The evaporator circuit was where the useful cooling effect occurred. The condenser/absorber circuit rejected the heat being transferred to the absorption chiller by the evaporator and generator circuits to the externally chilled glycol stream. 
The design of the test facility shown in Figure 3.1 was based on the residential solar-absorption A/C system shown in Figure 2.1. The goal of the test facility, however, was to characterize the performance of the absorption chiller operating under steady-state boundary conditions. To do this, the test facility included instrumentation not required in a typical solar-absorption $\mathrm{A} / \mathrm{C}$ system. The test facility also included additional measures to ensure boundary conditions at the absorption chiller could be held at steady-state. The functions of the solar thermal collectors, storage tanks, cooling tower and space cooling load were performed using other hardware in the test facility to carefully control the boundary conditions.

In the evaporator circuit, an electrical in-line heater substituted for the building's space cooling load. This heater was modulated to control the evaporator inlet temperature. Electrical in-line heaters in the generator circuit substituted for the solar thermal collectors. These heaters were modulated to control the generator inlet temperature. The PID controllers, not shown in Figure 3.1, executed the control algorithm to maintain set water temperatures to the inlets of the chiller for these electrical in-line heaters. The manufacturer of the PID controllers and heaters indicated the controller, as tuned at the factory, would be able to maintain a set heater temperature to $\pm 0.5^{\circ} \mathrm{C}$. The thermocouples that provided control signals to the PID controller were not used for data acquisition so their accuracy was irrelevant so long as the heaters could provide steady thermal boundary conditions at the absorption chiller inlets. 
A PID controller was also used to control the temperature to the condenser/absorber inlet. This PID controller modulated a proportioning valve to maintain a set condenser/absorber inlet temperature. The proportioning valve controlled the temperature by modulating flow to the heat exchanger between the condenser/absorber circuit and externally chilled glycol. A cooling tower was not employed as a heat sink in the condenser/absorber circuit. Outlet condenser/absorber flow from the absorption chiller, instead, exchanged heat with an externally chilled glycol stream supplied by other chillers for re-cooling.

The outlet flow from the condenser/absorber and evaporator also both passed through a heat exchanger. This heat exchanger decreased the cooling burden on the externally chilled glycol stream. This heat exchanger also warmed the flow to the evaporator inlet which reduced the load required by the electrical in-line heater. The amount of flow that exchanged heat between the condenser/absorber and evaporator circuits was controlled by a manual valve. This heat exchanger was also used to manually control the inlet temperature to the evaporator.

Fixed speed pumps circulated water in all circuits. Flow control was achieved using balance valves at chiller outlets in all circuits. Flow rate data in the evaporator (E) and generator $(\mathrm{G})$ circuits were collected by oval gear flow meters. The flow meters that were used are listed in Table 3.1. Pressure gauges were also used to ensure that the flow rates in all three circuits were within the manufacturer's operational limits. The gauges 
were dry with a dial reading scale from 0-100 psi manufactured by Bii Canada. The accuracy of the gauges is unknown but they were not used for data acquisition.

\begin{tabular}{|c|c|c|c|c|}
\hline Circuit & Flow Meter & Manufacturer & Range (L/min) & Accuracy \\
\hline G & BM40AARP2R1BVAA & Brooks & $15-135$ & $1 \%$ reading \\
\hline E & BM10AARP2R1BVAA & Brooks & $10-100$ & $1 \%$ reading \\
\hline
\end{tabular}

Table 3.1: Flow meters

Thermal data were gathered by thermocouples and thermopiles submerged in the fluid streams. Thermopiles were located to monitor the temperature differences across the chiller inlet and outlet in the evaporator $\left(\mathrm{T}_{\mathrm{EI}}-\mathrm{T}_{\mathrm{EO}}\right)$ and generator circuits $\left(\mathrm{T}_{\mathrm{GI}}-\mathrm{T}_{\mathrm{GO}}\right)$. Thermocouples were located to monitor the temperature at the absorption chiller outlet in the generator $\left(\mathrm{T}_{\mathrm{GO}}\right)$ and evaporator $\left(\mathrm{T}_{\mathrm{EO}}\right)$ circuits. In the condenser/absorber circuit, a thermocouple was located at the absorption chiller inlet $\left(\mathrm{T}_{\mathrm{CI}}\right)$.

Not shown in Figure 3.1 is the data acquisition system that logged the thermal and flow rate data. The data acquisition system employed National Instruments compact field point hardware. Labview was used to create the software environment which logged data from sensors during experiments. Table 3.2 indicates the experimental quantities of interest and how they were measured. 


\begin{tabular}{|c|c|c|}
\hline $\begin{array}{l}\text { Measured } \\
\text { Quantity }\end{array}$ & Instrument & Description \\
\hline $\mathbf{T}_{G O}$ & $\begin{array}{c}\text { Type T } \\
\text { Thermocouple }\end{array}$ & $\begin{array}{c}\text { Generator Outlet } \\
\text { Temperature } \\
T_{G O}\end{array}$ \\
\hline$\Delta \mathrm{T}_{G}$ & $\begin{array}{c}\text { Type T } \\
\text { Thermopile }\end{array}$ & $\begin{array}{c}\text { Generator } \\
\text { Temperature } \\
\text { Difference } \\
\mathrm{T}_{\mathrm{GI}}-\mathrm{T}_{\mathrm{GO}}\end{array}$ \\
\hline$\dot{\boldsymbol{v}}_{G}$ & $\begin{array}{l}\text { Oval Gear } \\
\text { Flowmeter }\end{array}$ & $\begin{array}{c}\text { Generator } \\
\text { Volumetric Flow } \\
\text { Rate } \\
\dot{v}_{G}\end{array}$ \\
\hline $\mathrm{T}_{E O}$ & $\begin{array}{c}\text { Type } \mathrm{T} \\
\text { Thermocouple }\end{array}$ & $\begin{array}{c}\text { Evaporator Outlet } \\
\text { Temperature } \\
\mathrm{T}_{\mathrm{EO}}\end{array}$ \\
\hline$\Delta \mathrm{T}_{E}$ & $\begin{array}{c}\text { Type T } \\
\text { Thermopile }\end{array}$ & $\begin{array}{c}\text { Evaporator } \\
\text { Temperature } \\
\text { Difference } \\
\mathrm{T}_{\mathrm{EI}}-\mathrm{T}_{\mathrm{EO}}\end{array}$ \\
\hline$\dot{v}_{E}$ & $\begin{array}{l}\text { Oval Gear } \\
\text { Flowmeter }\end{array}$ & $\begin{array}{c}\text { Evaporator } \\
\text { Volumetric Flow } \\
\text { Rate } \\
\dot{v}_{E}\end{array}$ \\
\hline $\mathrm{T}_{C I}$ & $\begin{array}{c}\text { Type } \mathrm{T} \\
\text { Thermocouple }\end{array}$ & $\begin{array}{c}\text { Condenser/Absorber } \\
\text { Inlet Temperature } \\
\mathrm{T}_{\mathrm{CI}}\end{array}$ \\
\hline
\end{tabular}

Table 3.2: Experimentally measured quantities

To measure the quantities in Table 3.2, the absorption chiller had to operate within a range of operating boundary conditions specified by the manufacturer. The 
chiller required thermal contact from three externally pumped fluid circuits: a generator (G), an evaporator (E) and a condenser/absorber (C) circuit. Table 3.3 lists the chiller's requirements from these three external circuits. The flow rates in Table 3.3 were met in the test assembly by using the pumps listed in Table 3.4.

\begin{tabular}{|c|c|c|}
\hline Circuit & $\begin{array}{c}\text { Temperature } \\
\left({ }^{\circ} \mathrm{C}\right)\end{array}$ & $\begin{array}{c}\text { Flow Rate } \\
(\mathrm{L} / \mathrm{min})\end{array}$ \\
\hline $\mathrm{G}$ & $70-95$ & $49-170$ \\
\hline $\mathrm{E}$ & $7-20$ & $72-110$ \\
\hline $\mathrm{C}$ & $25-31$ & $306-356$ \\
\hline
\end{tabular}

Table 3.3: Fluid circuit requirements specified by the manufacturer

\begin{tabular}{|c|c|c|c|}
\hline Circuit & Pump & Manufacturer & Power (kW) \\
\hline G & CR 3-5 & Grundfos & 0.56 \\
\hline E & CR 3-5 & Grundfos & 0.56 \\
\hline C & SSV32 1/1 & Gould & 3.73 \\
\hline
\end{tabular}

Table 3.4: External pumps

From Table 3.4, approximately $4.85 \mathrm{~kW}$ of pumping power from external pumps was needed to supply the absorption chiller with water at the flow rates required for operation. The amount of $4.85 \mathrm{~kW}$ was determined from the summation of the external pumps' motor ratings. This amount of pumping power was significant relative to the thermal energy required by the absorption chiller's generator. This amount of pumping power should not be taken as representative of what would be required by a solarabsorption $\mathrm{A} / \mathrm{C}$ system. Many of the flow components used in the absorption chiller test facility would not be needed in a solar-absorption A/C system. Some of these flow components created large resistances which necessitated the use of more powerful 
pumps. The pumping power required for an actual solar-absorption $\mathrm{A} / \mathrm{C}$ system would require less than the $4.85 \mathrm{~kW}$ used for the absorption chiller test facility.

The temperature ranges of the streams which supplied the absorption chiller for operation were met by using electrical in-line heaters and heat exchangers. The heat exchangers selected are listed in Table 3.5. The electrical in-line heaters selected are listed in Table 3.6. Note the heating requirement of the generator circuit necessitated the use of two electrical in-line heaters operating in series. The heater with the smaller capacity was located at the generator inlet to achieve more precise control.

\begin{tabular}{|c|c|c|c|}
\hline Circuit & $\begin{array}{c}\text { Heat } \\
\text { Exchanger }\end{array}$ & Manufacturer & $\begin{array}{c}\text { Capacity } \\
(\mathrm{kW})\end{array}$ \\
\hline E/C & M110-50 & SEC Heat Exchangers & 35 \\
\hline $\mathrm{C}$ & M110-70 & SEC Heat Exchangers & 70 \\
\hline
\end{tabular}

Table 3.5: Heat exchangers

\begin{tabular}{|c|c|c|c|}
\hline Circuit & Heater & Manufacturer & $\begin{array}{c}\text { Capacity } \\
(\mathrm{kW})\end{array}$ \\
\hline $\mathrm{G}$ & $\begin{array}{c}\text { CRES-ILB-48- } \\
\text { 0220-K-3P }\end{array}$ & $\begin{array}{c}\text { Infinity } \\
\text { Fluids }\end{array}$ & 22 \\
\hline $\mathrm{G}$ & $\begin{array}{c}\text { CRES-IBL-48- } \\
0180-K-3 P\end{array}$ & $\begin{array}{c}\text { Infinity } \\
\text { Fluids }\end{array}$ & 18 \\
\hline $\mathrm{E}$ & $\begin{array}{c}\text { CRES-ILB-48- } \\
0300-\mathrm{K}-3 \mathrm{P}\end{array}$ & $\begin{array}{c}\text { Infinity } \\
\text { Fluids }\end{array}$ & 30 \\
\hline
\end{tabular}

Table 3.6: Electric in-line heaters

The schematic in Figure 3.1 called for two heat exchangers in the external fluid circuits. A M110-50 brazed plate heat exchanger operated with a manual bypass valve between the evaporator and condenser/absorber circuits. A M110-70 brazed plate heat exchanger operated between the condenser/absorber circuit and the externally chilled 
glycol line. The external chilled glycol line provided a flow of $98 \mathrm{~L} / \mathrm{min}$ at $7^{\circ} \mathrm{C}$. The heat exchangers were sized to exchange the loads listed in Table 3.6. Flow conditions used for heat exchanger sizing were in the ranges listed in Table 3.3.

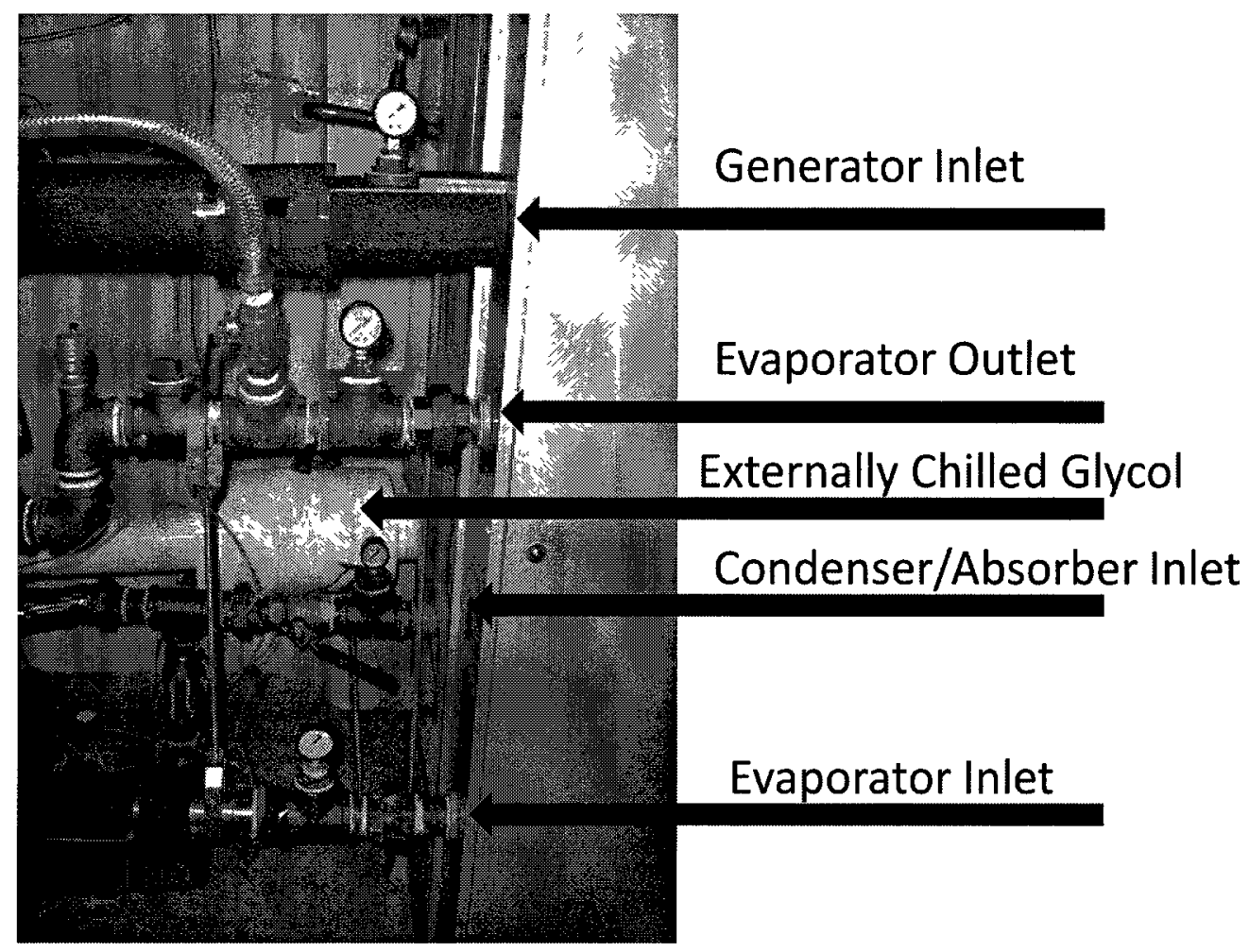

Figure 3.2: Absorption chiller test facility: inlet piping to chiller 


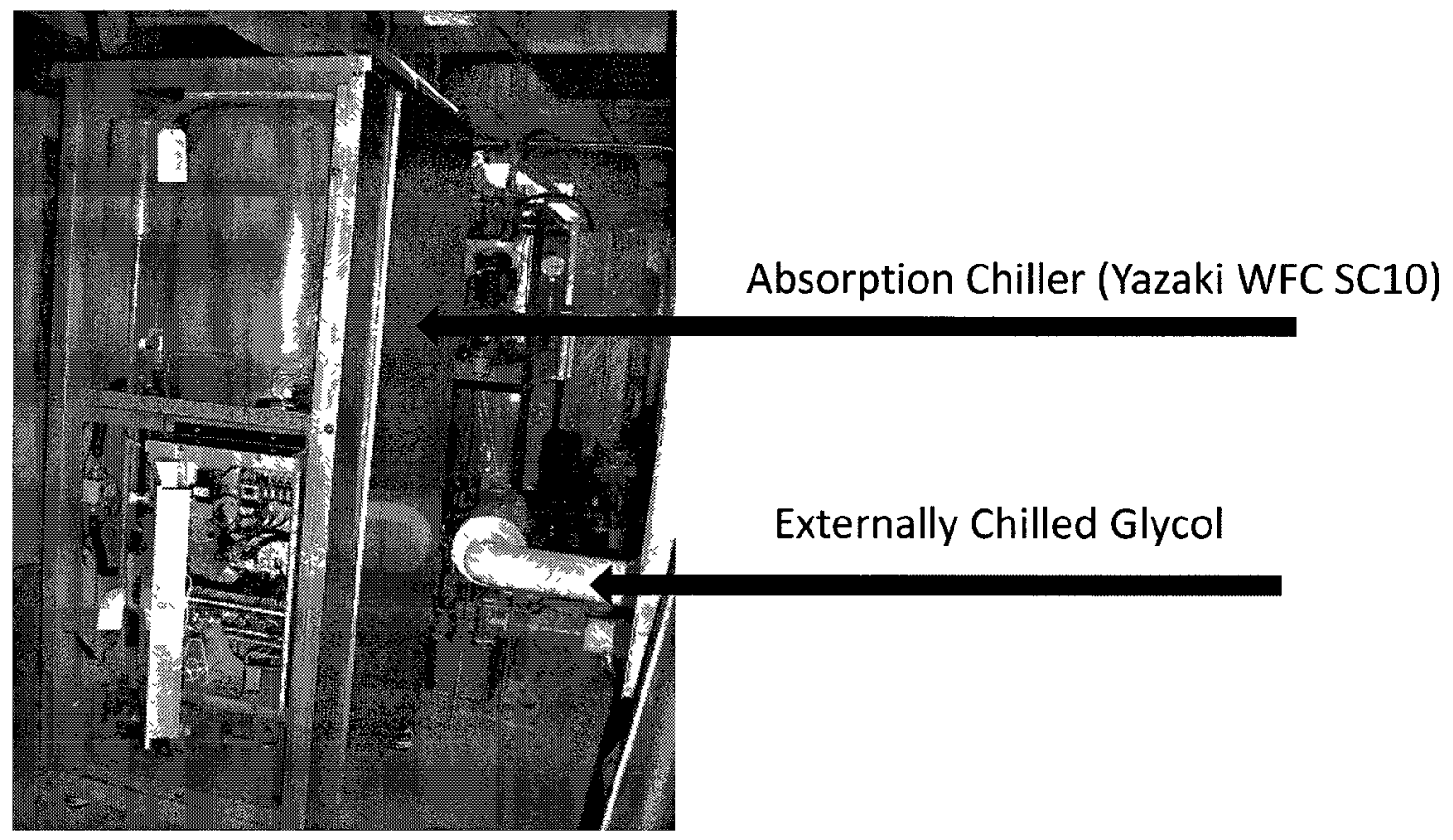

Figure 3.3: Absorption chiller test facility: Yazaki WFC-SC10

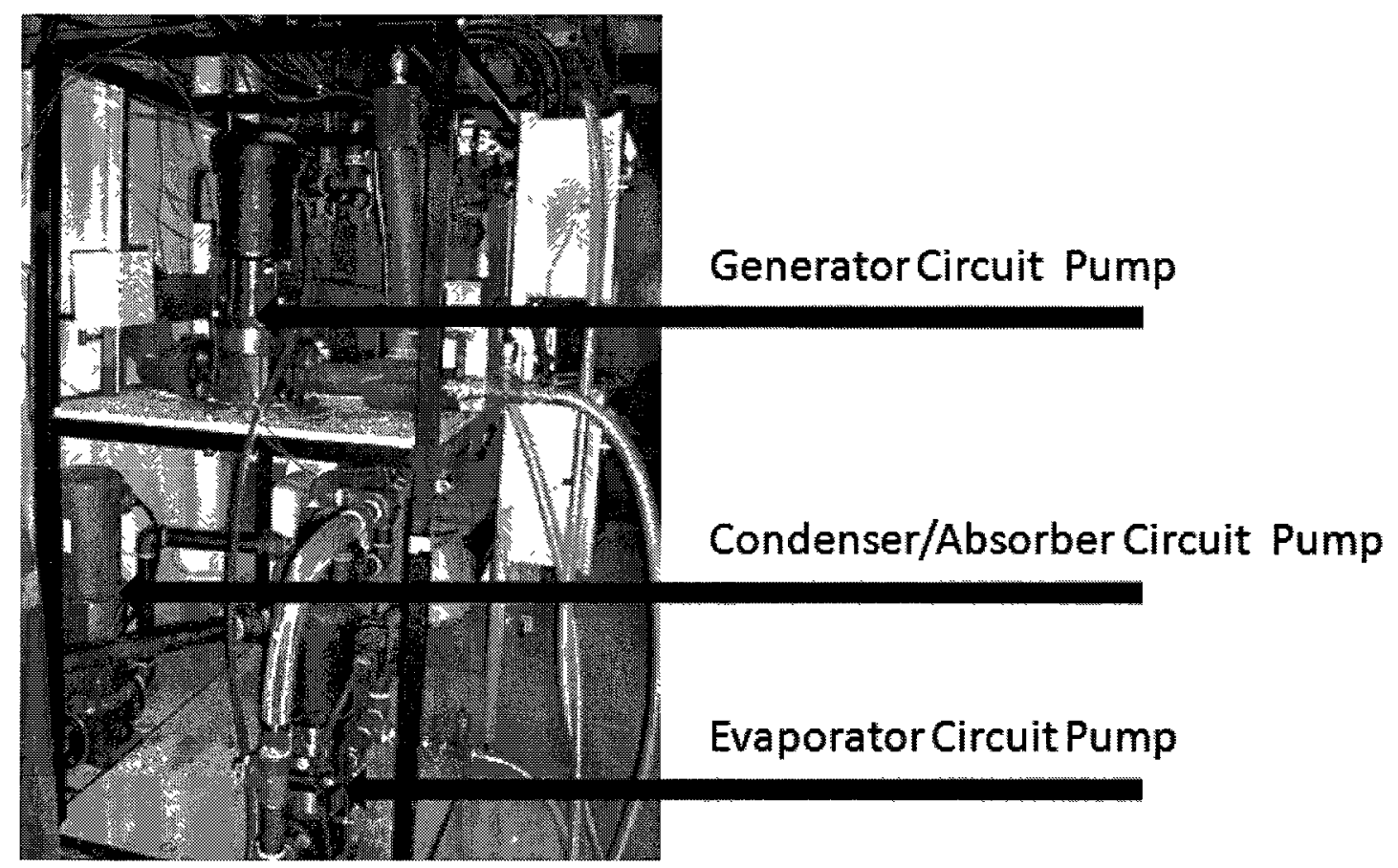

Figure 3.4: Absorption chiller test facility: pumps and structural support 
This chapter described the design and hardware of the absorption chiller test facility developed for this research. Several photographs of the facility as built are shown in Figures 3.2, 3.3 and 3.4. This facility has been constructed to control absorption chiller boundary conditions over a range of operating boundary conditions. This facility was designed, built and commissioned mainly by the M.A.Sc. candidate. The following chapter will detail how this facility has been instrumented along with an experimental uncertainty analysis of the data which this facility is capable of producing. 


\subsection{Instrumentation and Uncertainty Analysis}

The previous chapter described the design of a test facility capable of characterizing the performance of an absorption chiller. The absorption chiller test facility was required to produce performance data over a broader range of operating conditions with higher accuracy than data that are available in the literature. This chapter describes the instrumentation calibration and uncertainty analysis which was relevant to the data gathered from the absorption chiller test facility. More reliable performance data will result in an absorption chiller model with a better calibration to better represent how these devices actually perform in solar-absorption $\mathrm{A} / \mathrm{C}$ systems.

\subsection{Thermocouple Calibration}

In order to achieve performance data with a high reliability, calibrated thermocouples were selected as instruments to measure flow temperature in the absorption chiller test facility. The thermocouples used for absorption chiller performance experiments needed to be calibrated against a standard to achieve a smaller measurement bias error. The calibration procedure required a constant temperature bath, a platinum resistance temperature detector (RTD) probe/thermometer along with a thermocouple (to be calibrated) connected to the data acquisition system. 


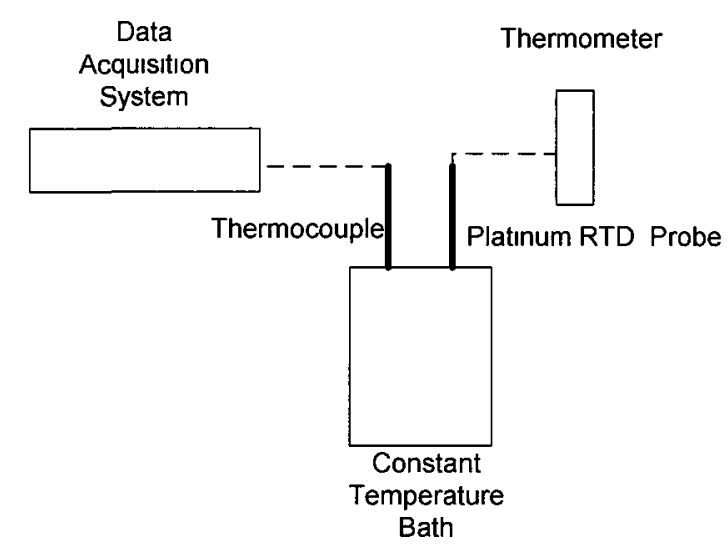

Figure 4.1: Thermocouple calibration equipment

The calibration equipment is illustrated schematically in Figure 4.1. For calibration, the constant temperature bath was set to a specific temperature and both the thermocouple and RTD probe were submerged in the same constant temperature bath. The constant temperature bath contained a PID controller, heating element, cooling element and magnetic stir rod to ensure the entire bath was at a uniform temperature. For a logging period of approximately 2 minutes, RTD resistance values were logged on the thermometer. During the logging period, the signal of the thermocouple was logged with the data acquisition system. Both the thermocouple signal and RTD resistances were logged every second. The logged RTD resistances $(\Omega)$ and thermocouple signals $(\mathrm{mV})$ were then averaged over the logging period to yield an ordered pair. The standard deviation of the logged RTD resistances and thermocouple signals were also noted; it was on the order of a tenth of a percent indicating steady-state conditions. This procedure was repeated for different temperatures to span the thermal regions of interest. 
The result of thermocouple calibration were regression equations to convert the thermocouple signal (in $\mathrm{mV}$ ) to RTD resistances (in $\Omega$ ). Data from the thermocouple calibration procedure and regression analysis are summarized in Appendix A. The regression equations fit to the calibration data for the thermocouples used in each of the fluid circuits of the absorption chiller test facility are given in Table 4.1. In Table 4.1, the term R denotes the resistance measured by the platinum RTD in $\Omega$ and emf denotes the electrical signal of a thermocouple in $\mathrm{mV}$.

\begin{tabular}{|c|cc|}
\hline Fluid Circuit & \multicolumn{2}{|c|}{ Regression Equation Fit to Calibration Data } \\
\hline Condenser/Absorber & $\mathrm{R} \approx 9.676 \mathrm{emf}+108.64$ & $(4.1)$ \\
\hline Evaporator & $\mathrm{R} \approx 9.999 \mathrm{emf}+108.70$ \\
\hline Generator & $\mathrm{R} \approx 8.668 \mathrm{emf}+109.87$ & $(4.2)$ \\
\hline
\end{tabular}

Table 4.1: Thermocouple calibration equations

The thermal regions of interest for calibration of the different fluid circuits roughly corresponded to the operational temperature ranges of the absorption chiller given in Table 3.3. To convert RTD resistance to temperature, polynomial curves were fit to data supplied by the RTD's manufacturer. A summary of this data and curve fit procedure can be found in Appendix C. The polynomial that was obtained by curve fitting used to convert resistance $(\mathrm{R})$ to temperature $(\mathrm{T})$ for the thermocouples used in all three fluid circuits was derived as:

$$
\mathrm{T} \approx 0.001 \mathrm{R}^{2}+2.309 \mathrm{R}-240.843
$$

During absorption chiller performance experiments, thermocouple signals in $\mathrm{mV}$ were logged. After each experiment concluded the thermocouple signals in $\mathrm{mV}$ were converted 
to RTD resistances in $\Omega$ using equations 4.1 to 4.3 and then to temperatures in ${ }^{\circ} \mathrm{C}$ using equation 4.4 .

\subsection{Thermopile Calibration}

Thermocouples were used to measure temperatures but thermopiles were used to measure temperature differences in the absorption chiller test facility. Thermopiles were located to measure flow temperature differences across the evaporator and generator inlets and outlets. A thermopile is a multi-junction thermocouple which can be used as a temperature difference sensor whose theory is described in detail in Figlioa and Beasley (2006). A five junction thermopile was selected for these experiments whose wiring is show below in Figure 4.2.

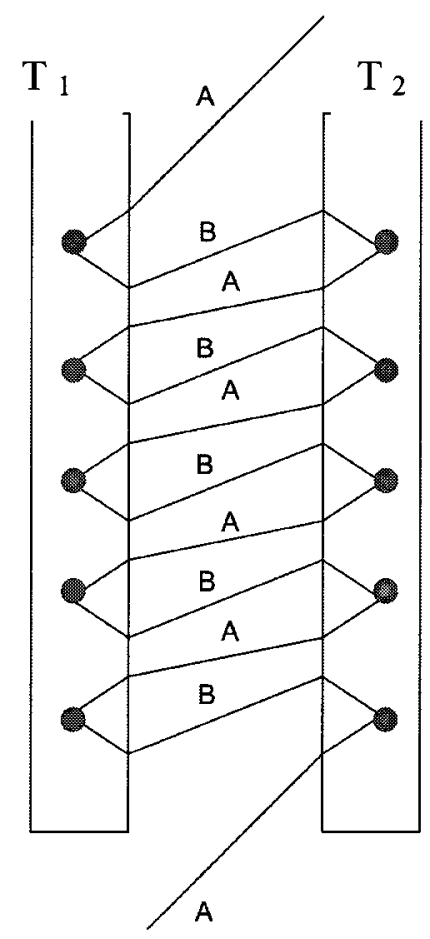

Figure 4.2: A five junction thermopile. Adapted from Figlioa and Beasley (2006) 
Thermopile beads consist of junctions between two dissimilar metals: material A and B. A five junction thermopile consists of ten individual thermopile beads: five at the same temperature $T_{1}$, the warm junctions, and the other five at another temperature $T_{2}$, the cold junctions. The beads are wired in such a way that an EMF is produced whenever there is a difference in temperature between $T_{1}$ and $T_{2}$. The strength of the EMF depends on the temperatures $T_{1}$ and $T_{2}$.

To select a sufficient number of junctions for the thermopile to produce a strong enough signal, the signal strength of a thermopile was estimated based on the signals generated by thermocouples. The EMF generated by a single junction thermopile was estimated as the difference between the signals of a thermocouple at $T_{1}$ and a thermocouple at $T_{2}$. To estimate the signal strength of a thermopile with more than one junction, the EMF of a single junction thermopile was multiplied by the number of junctions of the multi-junction thermopile.

The thermopiles used in this research were constructed from Type $T$ thermocouple wire. The thermopiles used in this research had to produce a strong enough signal compared to the uncertainty of the data acquisition system. The uncertainty of the data acquisition system was given as $\pm 0.008 \mathrm{mV}$ by the manufacturer. The thermopile signal had to be strong enough while measuring a temperature difference of $2^{\circ} \mathrm{C}$ with the cold junctions at $7^{\circ} \mathrm{C}$. These conditions were expected to produce the weakest thermopile signal to be encountered during absorption chiller performance tests. The following table 
is a summary of the estimation method used to select the number of thermopile junctions to measure temperature differences in this research.

\begin{tabular}{|l|c|}
\hline Expected Thermocouple Signal at $9^{\circ} \mathrm{C}$ & $0.352 \mathrm{mV}$ \\
\hline Expected Thermocouple Signal at $7^{\circ} \mathrm{C}$ & $0.273 \mathrm{mV}$ \\
\hline Signal Difference & $0.079 \mathrm{mV}$ \\
\hline $5 \times$ Signal Difference & $0.395 \mathrm{mV}$ \\
\hline Data Acquisition System Error & $0.008 \mathrm{mV}$ \\
\hline$\%$ Error & $2 \%$ \\
\hline
\end{tabular}

Table 4.2: Summary of thermopile junction number selection calculation

The thermocouple signal strengths in Table 4.2 were taken from the thermocouple table in Omega (2006). The signal difference is the difference between the thermocouple signals at $9^{\circ} \mathrm{C}$ and $7^{\circ} \mathrm{C}$. By selecting a five junction thermopile the signal was strong enough such that the $\pm 0.008 \mathrm{mV}$ error of the data acquisition system would be only $2 \%$ of the five junction thermopile signal strength.

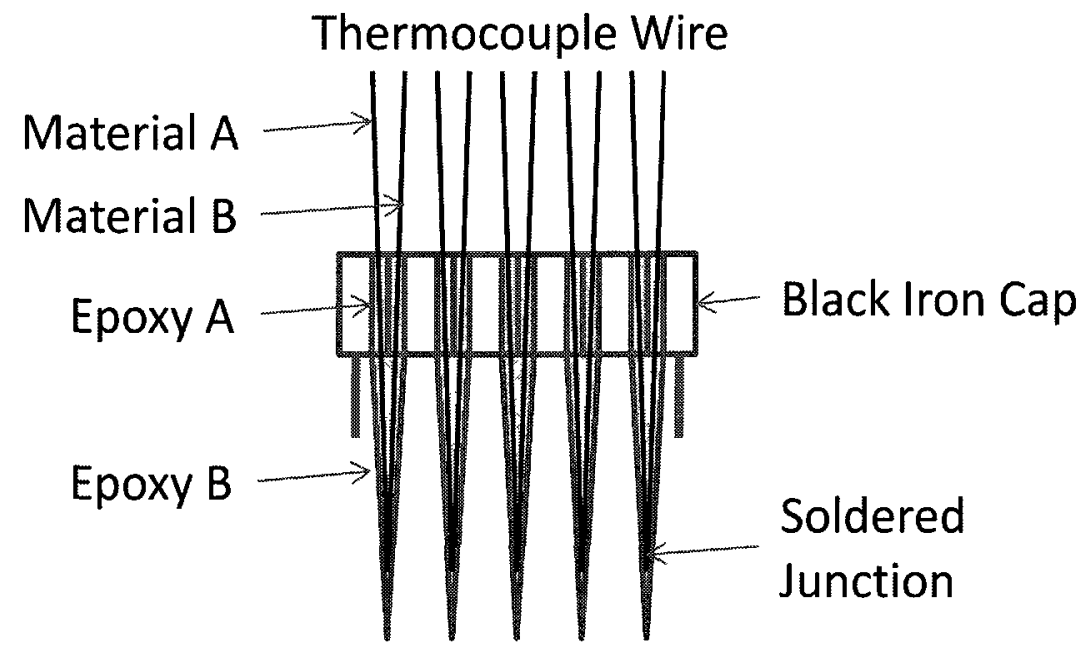

Figure 4.3: One half of a constructed thermopile assembly 
A schematic of half a five junction thermopile assembly is shown in Figure 4.3 which was constructed for the absorption chiller test facility. The other half (not shown) of the constructed thermopile assembly is nearly identical except the order of material A and $\mathrm{B}$ is reversed. Figure 4.3 illustrates how the thermopile junctions were submerged in the flow streams of the absorption chiller test facility. Thermocouple wire was passed through holes drilled out of a black iron cap. The gap between the thermocouple wire and the black iron cap was sealed with epoxy A. Epoxy A (commercially known as J.B. Weld) was selected to be water proof and insulate electrically. The junctions between material $\mathrm{A}$ and $\mathrm{B}$ to be submerged were soldered together to ensure electrical conductivity. To prevent electrical contact between different soldered junctions, epoxy B was used as electrical insulation. Epoxy B (commercially known as Arctic Silver 5) was selected to be electrically insulative, thermally conductive and water resistant.

In total, three thermopile assemblies were constructed for this research. One to be submerged in the generator circuit and another to be submerged in the evaporator circuit. The third thermopile was used for calibration. These thermopiles were all cut from the same strand of thermocouple wire. Since all three thermopiles were constructed with the same thermocouple wire the calibration results from one of these thermopiles were applicable to the others.

To improve their bias error, the thermopiles used in this research had to be calibrated against a standard. The goal of calibrating the thermopiles was to accurately determine the relationship between the strength of the EMF generated and the 
temperature difference between $T_{1}$ and $T_{2}$ for a range of temperatures $T_{2}$. For calibration, two constant temperature baths were required where the warm and cold thermopile junctions were submerged in either bath. The calibration procedure required a method of accurately measuring the water temperature of both constant temperature baths simultaneously.

Two platinum RTD probes logging resistances $(\Omega)$ into one dual channel thermometer were selected to measure the water temperature of the constant temperature baths. The EMF generated by the thermopile being calibrated was logged by the data acquisition system. Figure 4.4 shows a schematic of the equipment needed for thermopile calibration.

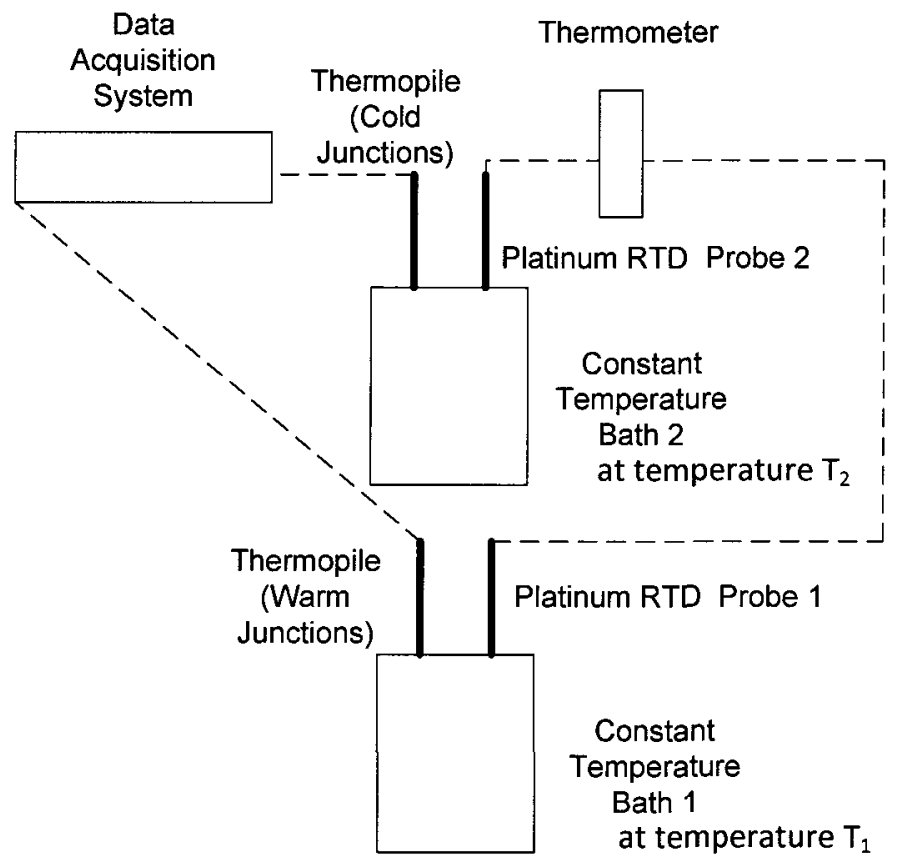

Figure 4.4: Thermopile calibration equipment 
During calibration, the warm junctions were submerged in the first bath at temperature $T_{1}$ along with a first platinum RTD probe. The cold junctions were submerged in the second bath at temperature $T_{2}$ along with a second platinum RTD probe. For one pair of $T_{1}$ and $T_{2}$, the thermopile EMF generated and RTD resistance values were logged every second for a logging period of approximately 5 minutes. The thermopile EMF signal and RTD resistance values were then averaged over the logging period. The standard deviation of all quantities was recorded but was noted as being quite low, in the fractions of a percent indicating steady-state conditions.

For this calibration procedure, $T_{1}$ and $T_{2}$ would be set to the same temperature initially and data would be logged. After this initial data were logged, $T_{1}$ was increased and held at a different temperature while $T_{2}$ was held constant. Data were then logged for these new conditions. Data were then logged for other increments of $T_{1}$ for the same constant $T_{2}$ until a large enough temperature difference $\left(T_{1}-T_{2}\right)$ range was spanned. Separate regression equations were derived for each value of cold junction temperature $\mathrm{T}_{2}$ that was examined. These equations related the measured EMF in $\mathrm{mV}$ of the thermopile to the RTD resistance in $\Omega$ of the probe submerged at $T_{1}$ for a given RTD resistance in $\Omega$ of the probe submerged at $T_{2}$.

Separate regression equations for each value of cold junction temperature $T_{2}$ that was examined were created to span the range of temperatures expected during absorption chiller performance assessment experiments. The temperature ranges expected roughly corresponded to the operational temperature ranges of the absorption chiller given in 
Table 3.3. The regression equations along with the calibration data they represent are illustrated in Figure 4.5 for the cold junction temperature range of $7-20^{\circ} \mathrm{C}$. A similar figure was produced from the data that were used to calibrate the thermopile in the generator circuit. The entire set of thermopile calibration data is available in Appendix D. Also shown in Figure 4.5 are error bars which represent $95 \%$ uncertainty margins of the average quantities graphed. Because the standard deviation of the averaged quantities graphed was small, the $95 \%$ uncertainty margins shown on Figure 4.5 are dominated by bias error. The only bias error that was large enough to appear visually on Figure 4.5 was the read error of the data acquisition system which was given as $\pm 0.008 \mathrm{mV}$ by the manufacturer. A detailed description of uncertainty margins and experimental error is deferred to Section 4.3.

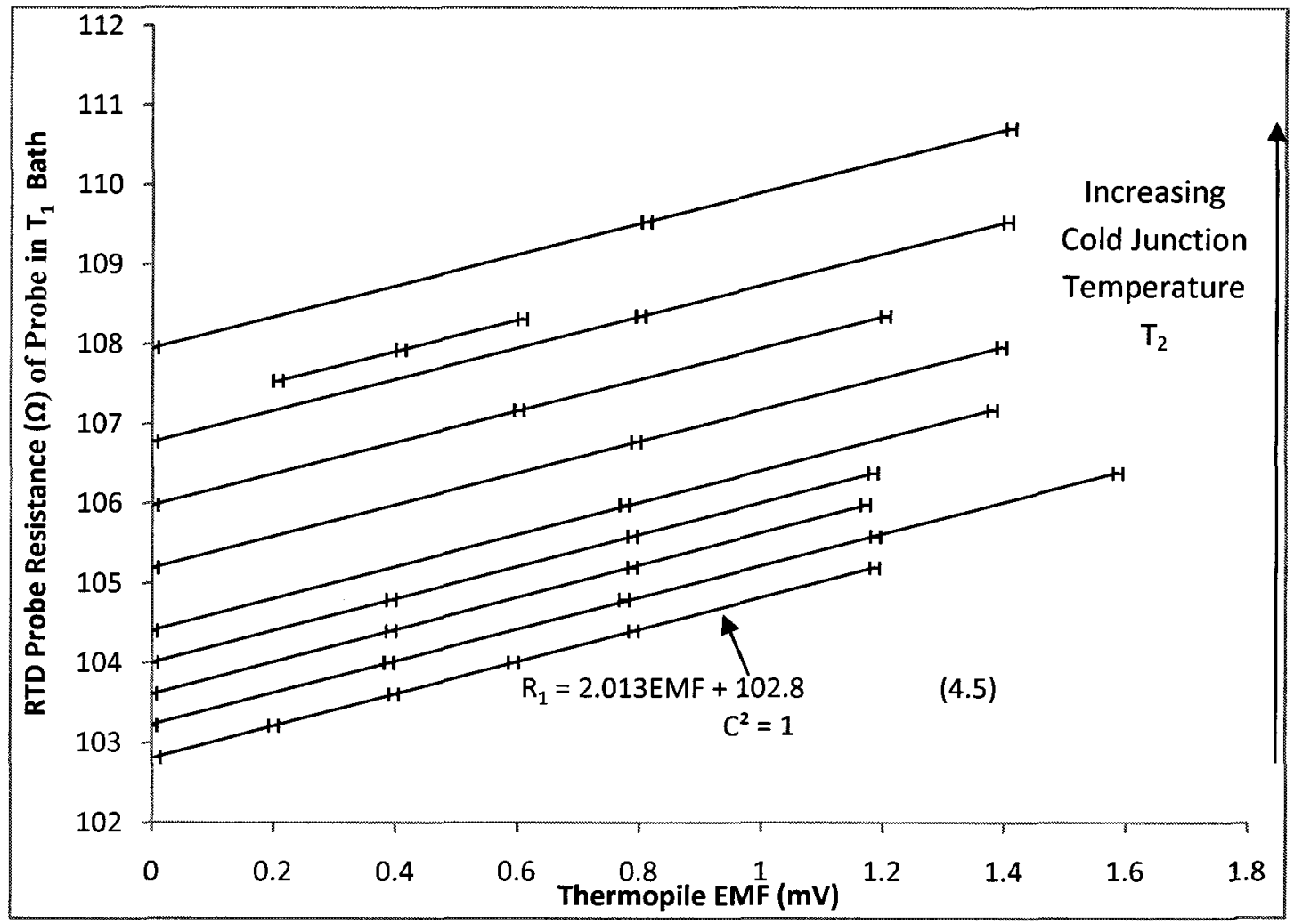

Figure 4.5: Thermopile calibration for cold junction range of approximately $7-20^{\circ} \mathrm{C}$ 
The lines on the previous figure represent the separate regression equations of each cold junction temperature $T_{2}$ that was examined in calibration for the cold junction range of approximately $7-20^{\circ} \mathrm{C}$. Equation 4.5 displayed on Figure 4.5 is one regression equation that was derived from thermopile calibration data. This equation and all other constant regression equations behaved linearly. The correlation coefficient, $\mathrm{C}^{2}$, for equation 4.5 is also shown on Figure 4.5. The equation to determine $\mathrm{C}^{2}$ for any two variables is given below in equation 4.6.

$$
\mathrm{C}^{2}=\left(\frac{\sum\left(x_{i}-\bar{x}\right)\left(y_{\imath}-\bar{y}\right)}{\sqrt{\Sigma\left(x_{\imath}-\bar{x}\right)^{2} \Sigma\left(y_{l}-\bar{y}\right)^{2}}}\right)^{2}
$$

In equation 4.6, $x_{t}$ and $y_{t}$ represent individual components of an ordered pair $\left(x_{l}, y_{l}\right)$ from a larger set of ordered pairs. $\bar{x}$ and $\bar{y}$ represent the average values of each of the ordered pair components from the larger set. The correlation coefficient, $\mathrm{C}^{2}$, is an indication of how linear the relationship is between the two components of the ordered pair set. A $\mathrm{C}^{2}$ value of unity indicates that the relationship is linear. In the context of the thermopile calibration data discussed in this section, $x_{t}$ and $y_{l}$ represent instantaneous thermopile EMF generated in $\mathrm{mV}$ and the resistance of the RTD in $\Omega$ measured during calibration.

The separate regression equations derived for each value of cold junction temperature examined had to be complemented with equations to convert units of RTD resistance in $\Omega$ to temperature in ${ }^{\circ} \mathrm{C}$. Equation 4.4 converted RTD resistance values $R_{2}$ to temperature $T_{2}$ for the probe measuring the cold junction temperature. The RTD probe that was used to measure the cold junction temperature was the same probe used during 
thermocouple calibration described in Section 4.1. For the probe measuring the warm junction temperature $T_{1}$, to convert RTD resistance values a different equation was employed. The following polynomial was fit to manufacturer's data of the RTD probe measuring the warm junction temperature $T_{1}$. The term $R_{1}$ in the following equation represents the temperature of the warm junction measured by the RTD in $\Omega$. Details regarding this polynomial fitting procedure are available in Appendix $\mathrm{C}$.

$$
\mathrm{T}_{1} \approx 0.001 \mathrm{R}_{1}{ }^{2}+2.309 \mathrm{R}_{1}-240.863
$$

Equations 4.4 and 4.7 along with the separate regression equations for each cold junction temperature examined during calibration were part of a data conversion process. This process was performed after each absorption chiller performance assessment experiment had concluded. During the experiments, only thermopile EMF (mV) was logged. Conversion from logged thermopile EMF $(\mathrm{mV})$ to temperature difference $\left({ }^{\circ} \mathrm{C}\right)$ was accomplished with a Matlab function. The Matlab function syntax is reported in Appendix E.

The Matlab function used an interpolation procedure described as follows. Based on the measured cold junction temperature $\mathrm{T}_{2}$, the appropriate known upper and lower bounding regression equations from the calibration were selected. When the measured cold junction temperature was within the range of $7-20^{\circ} \mathrm{C}$ the appropriate known upper and lower bounding regression equations were selected from those illustrated in Figure 4.5. The upper and lower bounding regression equations selected were each used to calculate an upper and lower bounding warm junction temperature measured in $\Omega$ of 
RTD resistance based on the measured EMF in $\mathrm{mV}$. A weighted average based on the upper and lower bounding warm junction temperatures measured in $\Omega$ of RTD resistance was used to calculate the actual warm junction temperature measured in $\Omega$. This weighted average was appropriate to the measured cold junction temperature in $\Omega$ of RTD resistance. The difference between the warm and cold junction temperatures was then converted to units of temperature in ${ }^{\circ} \mathrm{C}$ from RTD resistances in $\Omega$ using equations 4.4 and 4.7. The Matlab function that performed the previously described interpolation procedure was the end result of thermopile calibration.

By calibrating the thermocouples and themopiles the uncertainty of their measurements was reduced. Reduced uncertainty in these thermocouples and thermopiles measurements translated into reduced uncertainty of the absorption chiller performance parameters derived from these individual measurements. This is treated in the next section.

\subsection{Experimental Uncertainty Analysis}

An analysis was performed which propagated the uncertainty of individual measurements to the absorption chiller performance quantities derived from them. The individual measurements from the absorption chiller test facility were used to compute the following derived absorption chiller performance quantities.

$$
C O P=\frac{\left(\dot{m} c_{p} \Delta \mathrm{T}\right)_{E}}{\left(\dot{m} c_{p} \Delta \mathrm{T}\right)_{G}}
$$




$$
\begin{gathered}
\dot{q}_{E}=\left(\dot{m} c_{p} \Delta \mathrm{T}\right)_{E} \\
\dot{q}_{G}=\left(\dot{m} c_{p} \Delta \mathrm{T}\right)_{G}
\end{gathered}
$$

In the above equations, COP represents the absorption chiller's thermal coefficient of performance. The terms $\dot{q}_{E}$ and $\dot{q}_{G}$ represent the heat transferred to the evaporator and generator in $\mathrm{kW}$. The term $c_{p}$ represents the specific heat capacity of the externally pumped fluid in $\mathrm{kJ} / \mathrm{kgK}$. The term $\Delta \mathrm{T}$ represents the temperature difference between the entering and exiting externally pumped fluid in the evaporator or generator in ${ }^{\circ} \mathrm{C}$. The term $\dot{m}$ represents the mass flow rate of the externally pumped fluid in the evaporator or generator in $\mathrm{kg} / \mathrm{s}$.

The experimental uncertainty of the derived performance quantities was calculated by considering the bias and precision errors of the individual measurements using the standard American Society of Mechanical Engineers measurement uncertainty methods outlined by Moffat (1988). There are two kinds of error to be considered in an uncertainty analysis. The precision error $S_{l}$ of a sensor is the random error that is observed during experimentation from measurement to measurement. The bias error of a particular sensor $B_{l}$ corresponds to a repeatable uncertainty that is known to be inherent to a sensor. A sensor may be subjected to different sources of individual bias error. Independent, individual sources of sensor bias $B_{J}$ may be combined into an overall sensor bias by the root mean square method given by the following equation.

$$
B_{\imath}=\sqrt{\sum_{j} B_{j}^{2}}
$$


Uncertainties in individual sensor measurements may be propagated to quantities derived from the individual measurements by use of sensitivity parameters. For a derived quantity $r$ that depends on some other parameters $P_{1}$ :

$$
r=f\left(P_{1}, P_{2}, \ldots P_{l}\right)
$$

The sensitivity parameters $\theta_{l}$ are found by:

$$
\theta_{\imath}=\frac{\partial r}{\partial P_{\imath}}
$$

For COP the sensitivity parameters are:

$$
\begin{aligned}
& \frac{\partial \mathrm{COP}}{\partial \Delta \mathrm{T}_{\mathrm{E}}}=\frac{\left(\dot{m} c_{p}\right)_{\mathrm{E}}}{\left(\dot{m} c_{p} \Delta \mathrm{T}\right)_{\mathrm{G}}} \\
& \frac{\partial \mathrm{COP}}{\partial \dot{m}_{\mathrm{E}}}=\frac{\left(c_{p} \Delta \mathrm{T}\right)_{\mathrm{E}}}{\left(\dot{m} c_{p} \Delta \mathrm{T}\right)_{\mathrm{G}}} \\
& \frac{\partial \mathrm{COP}}{\partial c_{p \mathrm{E}}}=\frac{(\dot{m} \Delta \mathrm{T})_{\mathrm{E}}}{\left(\dot{m} c_{p} \Delta \mathrm{T}\right)_{\mathrm{G}}} \\
& \frac{\partial \mathrm{COP}}{\partial \Delta \mathrm{T}_{\mathrm{G}}}=-\frac{\left(\dot{m} c_{p} \Delta \mathrm{T}\right)_{\mathrm{E}}}{\left(\dot{m} c_{p} \Delta \mathrm{T}^{2}\right)_{\mathrm{G}}} \\
& \frac{\partial \mathrm{COP}}{\partial \dot{m}_{\mathrm{G}}}=-\frac{\left(\dot{m} c_{p} \Delta \mathrm{T}\right)_{\mathrm{E}}}{\left(\dot{m}^{2} c_{p} \Delta \mathrm{T}\right)_{\mathrm{G}}} \\
& \frac{\partial \mathrm{COP}}{\partial c_{p \mathrm{G}}}=-\frac{\left(\dot{m} c_{p} \Delta \mathrm{T}\right)_{\mathrm{E}}}{\left(\dot{m} c_{p}^{2} \Delta \mathrm{T}\right)_{\mathrm{G}}}
\end{aligned}
$$

For $\dot{q}_{G}$ the sensitivity parameters are:

$$
\frac{\partial \dot{q}_{\mathrm{G}}}{\partial \Delta \mathrm{T}_{\mathrm{G}}}=\left(\dot{m} c_{p}\right)_{\mathrm{G}}
$$




$$
\begin{aligned}
& \frac{\partial \dot{q}_{\mathrm{G}}}{\partial \dot{m}_{\mathrm{G}}}=\left(c_{p} \Delta \mathrm{T}\right)_{\mathrm{G}} \\
& \frac{\partial \dot{q}_{\mathrm{G}}}{\partial c_{p \mathrm{G}}}=(\dot{m} \Delta \mathrm{T})_{\mathrm{G}}
\end{aligned}
$$

For $\dot{q}_{E}$ the sensitivity parameters are:

$$
\begin{aligned}
& \frac{\partial \dot{q}_{\mathrm{E}}}{\partial \Delta \mathrm{T}_{\mathrm{E}}}=\left(\dot{m} c_{p}\right)_{\mathrm{E}} \\
& \frac{\partial \dot{q}_{\mathrm{E}}}{\partial \dot{m}_{\mathrm{E}}}=\left(c_{p} \Delta \mathrm{T}\right)_{\mathrm{E}} \\
& \frac{\partial \dot{q}_{\mathrm{E}}}{\partial c_{p \mathrm{E}}}=(\dot{m} \Delta \mathrm{T})_{\mathrm{E}}
\end{aligned}
$$

The overall bias $B$ and precision $S$ error of a derived quantity may be found from the individual measurements' bias $B_{l}$ and precision $S_{l}$ errors by:

$$
\begin{aligned}
& B=\sqrt{\sum_{l}\left(\theta_{l} B_{l}\right)^{2}} \\
& S=\sqrt{\sum_{l}\left(\theta_{l} S_{l}\right)^{2}}
\end{aligned}
$$

The bias and precision errors may be combined along with a student $t$ statistic to yield an overall $95 \%$ uncertainty margin $U_{95}$ given by:

$$
U_{95}=\sqrt{t S^{2}+B^{2}}
$$

An alternative method of calculating a derived quantity's precision error by propagation of the individual measurements' precision error with sensitivity parameters may be used. In the alternative method, instantaneous derived quantities for each set of instantaneous individual measurements are calculated. The precision error of a derived 
quantity, using this alternative method, is found by taking the standard deviation of the instantaneous derived quantities. In the uncertainty analysis of this thesis, the precision errors of the derived quantities were calculated using this alternative method.

For this research, average derived quantities were reported rather than instantaneous values. Moffat (1988) gives the precision error on an average quantity as:

$$
\bar{S}=\frac{S}{\sqrt{N}}
$$

In the equation above, $S$ represents the standard deviation of the instantaneous derived quantity. The term $\bar{S}$ represents the precision error of the average quantity. $N$ is the number of instantaneous derived quantity measurements. The overall $95 \%$ uncertainty level of the average derived quantity $\bar{U}_{95}$ may be found by combining the overall bias and precision errors using the following equation:

$$
\bar{U}_{95}=\sqrt{t \bar{S}^{2}+B^{2}}
$$

The uncertainty analysis described in this section allows for the uncertainty margins of the derived absorption chiller performance quantities to be calculated from the bias and precision errors of the individual measurements.

The manufacturer of the oval gear flow meters, Brooks, calibrated the flow meters in a facility where fluid flow was collected and counted in a container during a known time interval. Rojas (2009a and 2009b) performed the flow meter calibration and provided signed certificates of calibration for each flow meter. The calibration certificates 
indicated a bias better than $\pm 1 \%$ of flow meter reading. This bias was applied to all flow rate measurements in the absorption chiller performance experiments. This bias was given by the calibration certificates of both flow meters used. The data acquisition system was able to log the flow meters' signals without any additional bias error. This is because the flow meters' signals were square pulse trains of voltage whose frequency was proportional to the flow rate. The number of pulses per litre was the quantity determined during the flow meters' manufacturer's calibration procedure. The data acquisition system simply had to count the number of pulses within a specified time interval. There was a small amount of error attributed to the fact that only an integer number of pulses could be counted within a fixed time interval; this error manifested itself as a precision error.

The bias attributed to the thermopiles was computed from several individual sources. Uncertainty associated with the data acquisition system contributed a large source of bias to the thermopiles. The data acquisition system had an uncertainty of $\pm 0.008 \mathrm{mV}$. This bias was given by the manufacturer National Instruments. From the calibration of Section 4.2 , the relationship between thermopile signal $(\mathrm{mV})$ and temperature difference $\left({ }^{\circ} \mathrm{C}\right)$ was known so it became possible to estimate this uncertainty in units of temperature difference $\left({ }^{\circ} \mathrm{C}\right)$. In order to convert the bias error of $\pm 0.008 \mathrm{mV}$ to a bias in temperature difference $\left({ }^{\circ} \mathrm{C}\right)$, sensitivity parameters were needed. The following analysis was needed to derive the sensitivity parameter so that the data acquisition system read error could be converted from $\mathrm{mV}$ to ${ }^{\circ} \mathrm{C}$. Recall that the sensitivity parameter was found by taking the first derivative as follows. 


$$
\frac{\partial \Delta \mathrm{T}}{\partial \mathrm{EMF}}=\frac{\partial\left(\mathrm{T}_{1}-\mathrm{T}_{2}\right)}{\partial \mathrm{EMF}}=\frac{\partial \mathrm{T}_{1}}{\partial \mathrm{EMF}}
$$

Because the cold junction temperature $\mathrm{T}_{2}$ was directly measured with an RTD, only the warm junction temperature $T_{1}$ depended on the measured thermopile EMF. The term $T_{2}$ was independent of EMF. Consequently, the derivative of $T_{2}$ with respect to EMF was zero. The result was that the sensitivity parameter of $\Delta \mathrm{T}$ with respect to $\mathrm{EMF}$ was equal to the sensitivity parameter of $T_{1}$ with respect to EMF which is given in equation 4.32 .

$$
\frac{\partial \mathrm{T}_{1}}{\partial \mathrm{EMF}}=\frac{\partial \mathrm{T}_{1}}{\partial \mathrm{R}_{1}} \frac{\partial \mathrm{R}_{1}}{\partial \mathrm{EMF}}
$$

The derivative of $T_{1}$ with respect to EMF was found as the product of two elementary derivatives on the right hand side of equation 4.32. The derivative of $T_{1}$ with respect to $R_{1}$ was found in Appendix $C$ and is repeated below.

$$
\frac{\partial \mathrm{T}_{1}}{\partial \mathrm{R}_{1}}=2.55
$$

The derivative of $R_{1}$ with respect to EMF was found from the separate regression equations derived for each cold junction temperature examined during thermopile calibration. Multiple regression equations were derived as a result of thermopile calibration. The regression equation that propagated the most error was used in the computation of the sensitivity parameter of $\Delta \mathrm{T}$ with respect to $\mathrm{EMF}$ for this uncertainty analysis. The regression equation that propagated the most error had the largest slope which is shown on Figure 4.5 and is repeated below.

$$
\mathrm{R}_{1}=2.013 \mathrm{EMF}+102.81
$$




$$
\frac{\partial \mathrm{R}_{1}}{\partial \mathrm{EMF}}=2.013
$$

Therefore the sensitivity parameter was computed as:

$$
\frac{\partial \Delta \mathrm{T}}{\partial \mathrm{EMF}}=5.13 \frac{{ }^{\circ} \mathrm{C}}{\mathrm{mV}}
$$

The bias of the data acquisition system read error was then converted from $\mathrm{mV}$ to ${ }^{\circ} \mathrm{C}$ :

$$
B_{l}=5.13 \frac{{ }^{\circ} \mathrm{C}}{\mathrm{mV}} \times 0.008 \mathrm{mV}=0.04^{\circ} \mathrm{C}
$$

This source of bias affected the thermopile measurements twice. This bias first affected the separate regression equations that were derived from thermopile calibration in Section 4.2. In Table 4.4 this source of bias is listed as the data acquisition system read error during calibration. Every measurement of thermopile signals in $\mathrm{mV}$ during experiments was also subjected to this bias. In Table 4.4 this source of bias is listed as the data acquisition system read error during experiment.

Another source of bias to the thermopiles was caused by the interpolation procedure utilized by the Matlab function of Appendix E. The interpolation procedure propagated error associated with the separate regression equations it employed obtained from calibration in Section 4.2. To estimate the amount of bias from this source, the interpolation procedure was first used to evaluate the warm junction temperature measured in units of RTD resistance $(\Omega)$. The warm junction temperature $(\Omega)$ was calculated from a cold junction temperature $(\Omega)$ and an EMF $(\mathrm{mV})$. The calculated warm junction temperature results $(\Omega)$ were then compared against known values $(\Omega)$ from calibration. 
For comparison, the interpolation procedure was required to interpolate a warm junction temperature $(\Omega)$ between two regression equations that were $0.8 \Omega\left(2^{\circ} \mathrm{C}\right)$ apart; the most difficult interpolation required. In total six known values used for calibration were available from Appendix D to be compared against calculated values from the interpolation procedure. Availability was limited to these six known values since only they were available to be interpolated by regression equations $0.8 \Omega\left(2^{\circ} \mathrm{C}\right)$ apart. A summary of the analysis is given below in Table 4.3.

\begin{tabular}{|c|c|c|c|c|c|}
\hline $\begin{array}{l}\text { Known Cold } \\
\text { Junction RTD } \\
\text { Resistance } \\
\text { From } \\
\text { Calibration } \\
(\Omega)\end{array}$ & $\begin{array}{l}\text { EMF } \\
(\mathrm{mV})\end{array}$ & $\begin{array}{l}\text { Known Warm } \\
\text { Junction RTD } \\
\text { Resistance } \\
\text { From } \\
\text { Calibration }(\Omega)\end{array}$ & $\begin{array}{l}\text { Calculated } \\
\text { Warm Junction } \\
\text { RTD } \\
\text { Resistance }(\Omega)\end{array}$ & $\begin{array}{l}\text { Error } \\
(\Omega)\end{array}$ & $\begin{array}{l}\text { Error } \\
\left({ }^{\circ} \mathrm{C}\right)\end{array}$ \\
\hline 103.208 & 0.390 & 104.005 & 103.995 & 0.010 & 0.025 \\
\hline 103.209 & 0.775 & 104.794 & 104.774 & 0.020 & 0.050 \\
\hline 103.603 & 0.393 & 104.400 & 104.389 & 0.011 & 0.029 \\
\hline 103.603 & 0.789 & 105.194 & 105.181 & 0.013 & 0.034 \\
\hline 103.998 & 0.393 & 104.793 & 104.791 & 0.002 & 0.005 \\
\hline 103.998 & 0.789 & 105.587 & 105.589 & 0.002 & 0.005 \\
\hline & & & Maximum: & 0.020 & 0.050 \\
\hline
\end{tabular}

Table 4.3: Interpolation procedure bias error estimation summary

In Table 4.3, the error $(\Omega)$ was found as the absolute value of the difference between the calculated warm junction RTD resistance from the interpolation procedure and the known value of the warm junction RTD resistance from calibration. To convert the error units from $\Omega$ to ${ }^{\circ} \mathrm{C}$ a factor of 2.55 is used; the sensitivity parameter given in Appendix C. The maximum error between the results calculated by the interpolation procedure and the known values from calibration was assigned as the bias introduced by 
the interpolation procedure to the thermopiles in Table 4.4. The analysis showed that the interpolation procedure contributed a bias of approximately $0.05^{\circ} \mathrm{C}$ to the thermopiles.

Uncertainty associated with the measurement of the cold junction temperature propagated into negligible uncertainty to the temperature difference calculated from measured thermopile EMF and cold junction temperature. This was because the separate regression equations for the cold junction temperatures examined during calibration of Section 4.2 were nearly parallel. The following analysis revealed how these nearly parallel equations guarded against uncertainty associated with measurements of cold junction temperature.

$$
\mathrm{R}_{1}=\frac{\partial \mathrm{R}_{1}}{\partial \mathrm{EMF}} \mathrm{EMF}+\mathrm{R}_{2}
$$

Equation 4.38 is the general form of the regression equations that were derived from calibration in Section 4.2. The term $R_{1}$ represents the warm junction RTD temperature measured in $\Omega$. The term $\mathrm{R}_{2}$ represents the cold junction RTD temperature measured in $\Omega$. The term EMF represents the thermopile signal in $\mathrm{mV}$. The regression equations were linear and could be expressed in slope/y-intercept form. Although the temperature of the cold junction was measured with a different RTD, the two RTDs behaved almost identically. The similarities between the two RTDs can be observed in Appendix C. For only this discussion the RTDs were regarded as identical. If the RTDs were regarded as identical, the $y$-intercept of a given regression equation in the form of equation 4.38 should equal to the measured cold junction temperature in $\Omega$ of RTD resistance. 
To investigate what effect the error associated with cold junction temperature measurements had on the calculated temperature difference, a sensitivity parameter was needed. The sensitivity parameter of the temperature difference measured in units of RTD resistance $(\Omega)$ with respect to cold junction temperature $(\Omega)$ was found by first bringing $\mathrm{R}_{2}$ to the left side of equation 4.38 . Equation 4.38 was then differentiated with respect to $R_{2}$. The result is shown below in equation 4.39. Recall EMF and $R_{2}$ were independent variables.

$$
\frac{\partial\left(\mathrm{R}_{1}-\mathrm{R}_{2}\right)}{\partial \mathrm{R}_{2}}=\frac{\partial\left(\frac{\partial \mathrm{R}_{1}}{\partial \mathrm{EMF}}\right)}{\partial \mathrm{R}_{2}} \mathrm{EMF}
$$

The terms on the left side of equation 4.39 have units of temperature measured in $\Omega$ of RTD resistance. To convert the units of the left side of equation 4.39 from $\Omega$ to ${ }^{\circ} \mathrm{C}$, the polynomials derived in Appendix $\mathrm{C}$ were required. Although these polynomials were quadratic, the coefficients of the quadratic terms were small compared to the linear and constant coefficients. The quadratic functions of Appendix $\mathrm{C}$ behaved in a highly linear manner. For the purpose of this discussion the quadratic terms of these polynomials were neglected. The linear approximation of both quadratics of Appendix $\mathrm{C}$ used for this discussion is given below in equation 4.40 .

$$
\mathrm{T} \approx 2.309 \mathrm{R}-240.8
$$

Equation 4.40 was used to convert units of the left hand side of equation 4.39 from $\Omega$ to ${ }^{\circ} \mathrm{C}$ for this discussion. The result of converting the units of the left hand side of equation 4.39 is shown in equation 4.41 . 


$$
\frac{\partial \Delta \mathrm{T}}{\partial \mathrm{T}_{2}}=\frac{\partial\left(\mathrm{T}_{1}-\mathrm{T}_{2}\right)}{\partial \mathrm{T}_{2}} \approx \frac{\partial\left(\frac{\partial \mathrm{R}_{1}}{\partial \mathrm{EMF}}\right)}{\partial \mathrm{R}_{2}} \mathrm{EMF}
$$

The derivative on the right hand side of equation 4.41 is the rate of change of the slope of the regression equations derived from calibration in Section 4.2 with respect to their $y-$ intercepts. Since the regression equations' slopes are nearly parallel, the derivative on the right hand side of equation 4.41 is very small. Consequently, $\Delta \mathrm{T}$ was insensitive to errors in cold junction temperature measurement so long as the measured EMF in $\mathrm{mV}$ on the right side of equation 4.41 was also small. The largest EMF observed in this research was near $1.4 \mathrm{mV}$. It was concluded from this analysis that since the sensitivity parameter of the temperature difference $\left({ }^{\circ} \mathrm{C}\right)$ with respect to cold junction temperature $\left({ }^{\circ} \mathrm{C}\right)$ was small, errors associated with the cold junction temperature measurement could be neglected.

Each of the RTDs that were used to calibrate the thermopiles were themselves calibrated to an uncertainty of $\pm 0.02^{\circ} \mathrm{C}$; this introduced a source of bias to the thermopiles. A summary of the contributing bias sources to the thermopiles used for the absorption chiller performance assessment experiments is given in Table 4.4. The individual sources of bias error are combined by the root mean square method at the bottom of the table to give the total thermopile bias. 


\begin{tabular}{|c|c|}
\hline & $B_{J}\left( \pm^{\circ} \mathrm{C}\right)$ \\
\hline $\begin{array}{c}\text { Data Acquisition System } \\
\text { Read Error During } \\
\text { Calibration }\end{array}$ & 0.04 \\
\hline $\begin{array}{c}\text { Data Acquisition System } \\
\text { Read Error During } \\
\text { Experiment }\end{array}$ & 0.04 \\
\hline RTD 1 & 0.02 \\
\hline RTD 2 & 0.02 \\
\hline Interpolation Procedure & 0.05 \\
\hline Total $=\sqrt{\sum_{J} B_{J}^{2}}$ & 0.08 \\
\hline
\end{tabular}

Table 4.4: Thermopile EMF measurement bias error calculation summary

An analysis similar to that of Table 4.4 was also needed for the thermocouples used in the absorption chiller test facility. To determine what effect the $\pm 0.008 \mathrm{mV}$ data acquisition system uncertainty had on the thermocouples, an analysis similar to that required for the thermopiles was performed. The conversion is performed below in Table 4.5 for the thermocouples used in the condenser/absorber, generator and evaporator circuits. The sensitivity parameters needed to convert the data acquisition system uncertainty in $\mathrm{mV}$ to temperature in ${ }^{\circ} \mathrm{C}$ used in Table 4.5 can be found in Appendices A and C.

\begin{tabular}{|l|l|l|l|l|}
\hline $\begin{array}{l}\text { Thermocouple } \\
\text { Location }\end{array}$ & $\begin{array}{c}\frac{\partial \mathrm{R}}{\partial \mathrm{emf}} \\
(\Omega / \mathrm{mV})\end{array}$ & $\begin{array}{c}\frac{\partial \mathrm{T}}{\partial \mathrm{R}} \\
\left({ }^{\circ} \mathrm{C} / \Omega\right)\end{array}$ & $\begin{array}{c}\frac{\partial \mathrm{T}}{\partial \mathrm{emf}} \\
\left({ }^{\circ} \mathrm{C} / \mathrm{mV}\right)\end{array}$ & $\begin{array}{c}B_{J} \\
\left( \pm{ }^{\circ} \mathrm{C}\right)\end{array}$ \\
\hline Generator & 8.668 & 2.55 & 22.10 & 0.18 \\
\hline Condenser/Absorber & 9.667 & 2.55 & 24.67 & 0.20 \\
\hline Evaporator & 9.999 & 2.55 & 25.50 & 0.20 \\
\hline
\end{tabular}

Table 4.5: Data acquisition system bias error conversion from $\mathrm{mV}$ to ${ }^{\circ} \mathrm{C}$ 
In Table 4.5, R represents the reading of the thermocouple measured in $\Omega$ of RTD resistance. The term $\mathrm{T}$ represents the temperature of the thermocouple measured in ${ }^{\circ} \mathrm{C}$. emf represents the thermocouple signal measured in $\mathrm{mV}$. The term $B_{J}$ is obtained by multiplying the sensitivity parameter in the preceding column by $\pm 0.008 \mathrm{mV}$. The term $B_{J}$ in Table 4.5 represents the bias contribution associated with the data acquisition system read error in ${ }^{\circ} \mathrm{C}$. The data acquisition system read error affected the thermocouple measurements during experiments and during calibration as well. The data acquisition system read error during experiments is displayed explicitly as a source of bias in Table 4.6. The data acquisition system read error during calibration has been considered as a constituent component of the regression equation source of bias and the cold junction compensation source of bias listed in Table 4.6.

The regression equations of Appendices $\mathrm{A}$ and $\mathrm{C}$, that were used to convert the thermocouple signal from $\mathrm{mV}$ to temperature in ${ }^{\circ} \mathrm{C}$ contributed bias. The source of bias associated with the use of regression equations assessed in Appendix A and C is listed in Table 4.6. The method of thermocouple cold junction compensation used in this research is discussed in Appendix B also introduced bias to the thermocouples. The source of bias associated with cold junction compensation is assessed in Appendix B and is listed in Table 4.6. A summary of the different bias sources along with their combination into a total thermocouple bias is given in Table 4.6 


\begin{tabular}{|c|c|c|c|}
\hline Bias Source & \multicolumn{3}{|c|}{ Thermocouple Location } \\
\hline & $\begin{array}{c}\text { Generator } \\
B_{j}\left( \pm^{\circ} \mathrm{C}\right)\end{array}$ & $\begin{array}{c}\text { Condenser/Absorber } \\
B_{j}\left( \pm^{\circ} \mathrm{C}\right)\end{array}$ & $\begin{array}{c}\text { Evaporator } \\
B_{j}\left( \pm^{\circ} \mathrm{C}\right)\end{array}$ \\
\hline $\begin{array}{c}\text { Data Acquisition } \\
\text { System Read Error } \\
\text { During Experiments }\end{array}$ & 0.18 & 0.20 & 0.20 \\
\hline $\begin{array}{c}\text { Regression } \\
\text { Equations }\end{array}$ & 0.25 & 0.21 & 0.28 \\
\hline $\begin{array}{c}\text { Cold Junction } \\
\text { Compensation }\end{array}$ & 0.41 & 0.38 & 0.42 \\
\hline Total $=\sqrt{\sum_{J} B_{J}^{2}}$ & 0.51 & 0.46 & 0.54 \\
\hline
\end{tabular}

Table 4.6: Thermocouple bias error summary

Table 4.6 summarizes the sources which contributed to the overall bias of the thermocouples used in this experiment. The individual sources are combined into a total thermocouple bias at the bottom of the table. The instrument bias errors calculated in this section were combined with the precision errors observed during absorption chiller performance assessment experiments using a Matlab function. This Matlab function was written to compute the average $95 \%$ uncertainty margins of the derived quantities with syntax given in Appendix F.

Calibration of temperature sensors was performed to decrease their bias error. Lower bias error in the individual measurements of temperature sensors translated to more reliable absorption chiller performance data. A sensitivity analysis reveals the impact that errors in individual measurements have on derived absorption chiller performance quantities. Because the derived absorption chiller performance quantities (shown in equations 4.8 to 4.10 ) are products of individual measurements, a percentage 
error in one of the individual measurements translates into the same percentage error with the performance quantity derived from it. If the lowest temperature difference expected is $2^{\circ} \mathrm{C}$, a $0.08^{\circ} \mathrm{C}$ (from Table 4.4) error in measurement from the thermopile could result in an error of $4 \%$ on absorption chiller performance quantities derived from the temperature difference measured. A $1 \%$ error in measurement of a flow rate would cause a $1 \%$ error in an absorption chiller performance quantity derived from it. Individual sensor measurements along with derived absorption chiller performance quantities gathered from experiments in the test facility is the subject of the following chapter. 


\subsection{Results}

The instrumentation of the absorption chiller test facility was the subject of the previous chapter. The instrumentation was used to acquire thermal and flow rate data during experiments to characterize the absorption chiller's performance. The subject of this chapter is the data that have been gathered from the absorption chiller test facility.

\subsection{Sample Absorption Chiller Performance Experiment}

The test facility was capable of gathering performance data of the acquired absorption chiller over a range of operating boundary conditions. The boundary conditions for which absorption chiller performance data have been gathered are listed in Table 5.1. The boundary condition values listed in Table 5.1 are nominal values of boundary conditions for which absorption chiller performance data were desired. An individual Test \# was assigned to each combination of boundary conditions examined. The actual values of the boundary conditions achieved during experiment that corresponded to the nominal values listed in Table 5.1 can be found in Appendix G. Significant differences between nominal values and actual values achieved during experiment occurred due to difficulties with controlling the variables during experiments. For example, the nominal condenser/absorber inlet temperature of Test $\# 14$ was $30^{\circ} \mathrm{C}$ while the value achieved during experiment was $29.78^{\circ} \mathrm{C}$. Some of the control difficulties were caused by steady state error due to the PID constants selected for control, poor calibration of thermocouples used for PID control signals and difficulties making small adjustments to flow rates with balance valves. 


\begin{tabular}{|l|c|c|c|c|c|c|}
\hline Test \# & $\begin{array}{c}\text { Generator } \\
\text { Inlet Temp. } \\
\left({ }^{\circ} \mathrm{C}\right)\end{array}$ & $\begin{array}{c}\text { Evaporator } \\
\text { Inlet Temp. } \\
\left({ }^{\circ} \mathrm{C}\right)\end{array}$ & $\begin{array}{c}\text { Condenser/ } \\
\text { Absorber } \\
\text { Inlet } \\
\text { Temp. } \\
\left({ }^{\circ} \mathrm{C}\right)\end{array}$ & $\begin{array}{c}\text { Generator } \\
\text { Flow Rate } \\
(\mathrm{L} / \mathrm{min})\end{array}$ & $\begin{array}{c}\text { Evaporator } \\
\text { Flow Rate } \\
(\mathrm{L} / \mathrm{min})\end{array}$ & $\begin{array}{c}\text { Duration } \\
(\mathrm{min})\end{array}$ \\
\hline 1 & 82 & 13 & 27 & 85 & 82 & 9 \\
\hline 2 & 82 & 15 & 27 & 85 & 82 & 9 \\
\hline 3 & 75 & 15 & 27 & 85 & 82 & 8 \\
\hline 4 & 75 & 19 & 27 & 85 & 82 & 9 \\
\hline 5 & 80 & 11 & 29 & 85 & 82 & 9 \\
\hline 6 & 80 & 15 & 29 & 85 & 82 & 9 \\
\hline 7 & 84 & 15 & 29 & 85 & 82 & 8 \\
\hline 8 & 75 & 16 & 29 & 85 & 82 & 9 \\
\hline 9 & 75 & 20 & 29 & 85 & 82 & 9 \\
\hline 10 & 77 & 20 & 29 & 85 & 82 & 9 \\
\hline 11 & 73 & 22 & 29 & 85 & 82 & 9 \\
\hline 12 & 74 & 15 & 30 & 85 & 82 & 9 \\
\hline 13 & 86 & 15 & 30 & 85 & 82 & 17 \\
\hline 14 & 80 & 17 & 30 & 85 & 82 & 9 \\
\hline 15 & 84 & 19 & 30 & 85 & 82 & 9 \\
\hline 16 & 80 & 19 & 30 & 85 & 82 & 9 \\
\hline 17 & 81 & 18 & 32 & 85 & 82 & 9 \\
\hline 18 & 74 & 18 & 32 & 85 & 82 & 9 \\
\hline 19 & 75 & 19 & 32 & 85 & 82 & 9 \\
\hline 20 & 77 & 22 & 32 & 85 & 82 & 9 \\
\hline 21 & 75 & 22 & 32 & 85 & 82 & 9 \\
\hline 22 & 75 & 19 & 32 & 67 & 82 & 9 \\
\hline 23 & 75 & 15 & 26 & 85 & 82 & 9 \\
\hline & 75 & 19 & 29 & & \\
\hline
\end{tabular}

Table 5.1: Experimental grid: Boundary conditions for which absorption chiller performance was investigated.

In Table 5.1, the boundary conditions were selected to explore the performance of the absorption chiller over the range of operating conditions feasible in the absorption chiller test facility. An upper limit on the generator temperature was imposed by the heaters which could only generate enough heat to warm the generator inlet flow stream to $86^{\circ} \mathrm{C}$. The external pump which supplied the generator with flow was also undersized and only capable of supplying a maximum flow rate of approximately $85 \mathrm{~L} / \mathrm{min}$. The 
lowest generator flow rate selected was the lowest flow rate that could be safely maintained by restricting the flow stream with the balance valve used for flow control in the generator circuit. Excessive restriction of the flow stream using the balance valves would cause cavitation on the low pressure side of the restriction.

The range of thermal boundary conditions explored was also constrained by the operational range of the absorption chiller given in Table 3.3. The lowest temperatures selected for the generator inlet were chosen to ensure the inlet temperature would be greater than the lower limit of the operational range given in Table 3.3. The lowest temperatures selected for evaporator were chosen to ensure the outlet temperature would be greater than the lower limit of the operational range given in Table 3.3.

The boundary conditions of Tests \#1-21 were selected to explore the dependence of the absorption chiller performance on thermal boundary conditions. The dependence of absorption chiller performance on externally pumped generator flow rate was examined by the boundary conditions selected for Test \#19 and Test \#22.

For each Test \#, the absorption chiller was operated over a duration of time listed in Table 5.1 while data were logged. During the time which data were logged, data were logged every 5 seconds. The experimental duration was selected to allow for approximately 100 instantaneous measurements of data so the average precision error, given by equation 4.29 , would be an order of magnitude lower than the standard deviation. The absorption chiller was also allowed to run and stabilize for a period of 
approximately 30 minutes before the start of experiment to ensure the system was operating at steady state while data were gathered.

The data acquired for Test \#7 are shown in Figures 5.1 and 5.2 as an example of the absorption chiller performance assessment procedure. The data shown in Figure 5.1 are the measurements from thermocouples and thermopiles that were submerged in the generator, condenser/absorber, and evaporator circuits. Thermocouples were located to measure the water temperature at the generator and evaporator outlets. Thermopiles were located to measure the temperature difference between the inlet and outlet of generator and evaporator. In Figure 5.1 the inlet temperatures at the generator and evaporator inlets are found by adding the temperature differences measured by the thermopiles to the outlet temperatures measured by the thermocouples. In the condenser/absorber circuit, there was only a thermocouple to measure the inlet temperature. Also illustrated in Figure 5.1 are error bars which represent the $95 \%$ uncertainty margins of the instantaneous measurements. Equation 4.28, which was discussed in Section 4.3, was used to derive these $95 \%$ uncertainty margins. The error bars are small enough that they are difficult to observe in Figure 5.1.

The temperatures illustrated in Figure 5.1 were averaged for longer than 8 minutes beginning from the start of the experiment. The average temperatures determined were $84.03^{\circ} \mathrm{C}$ and $77.53^{\circ} \mathrm{C}$ at the generator inlet and outlet, $15.27^{\circ} \mathrm{C}$ and $10.07^{\circ} \mathrm{C}$ at the evaporator inlet and outlet and $29.12^{\circ} \mathrm{C}$ at the condenser/absorber inlet. These average values are reported in Appendix G. 


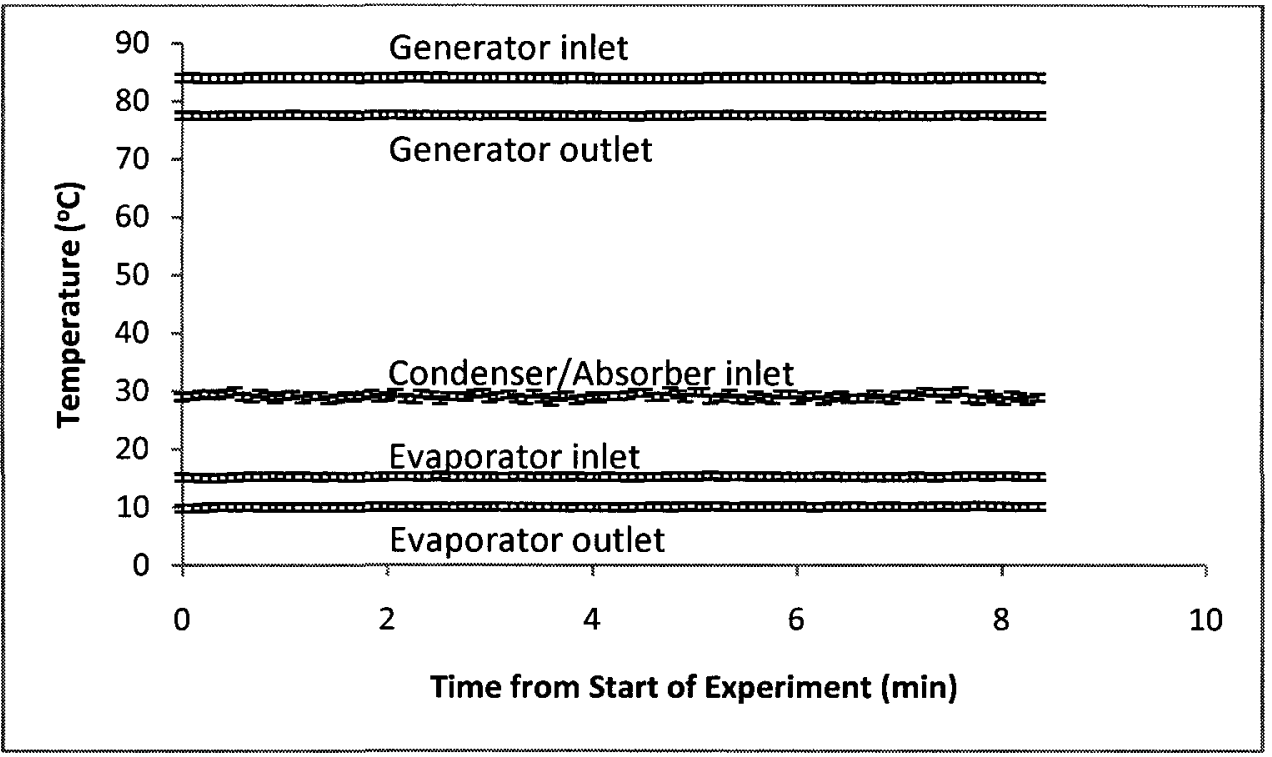

Figure 5.1: Thermal data from absorption chiller performance Test \#7

In addition to thermal boundary conditions, the flow rates within the evaporator and generator were required to calculate the derived quantities which characterize the absorption chiller's performance. Flow rate data from Test \#7 are displayed in Figure 5.2. Also illustrated in Figure 5.2 are error bars which represent the 95\% uncertainty margins of the instantaneous measurements. Equation 4.28, which was discussed in Section 4.3, was used to derive these $95 \%$ uncertainty margins. These error bars are small and difficult to observe. 


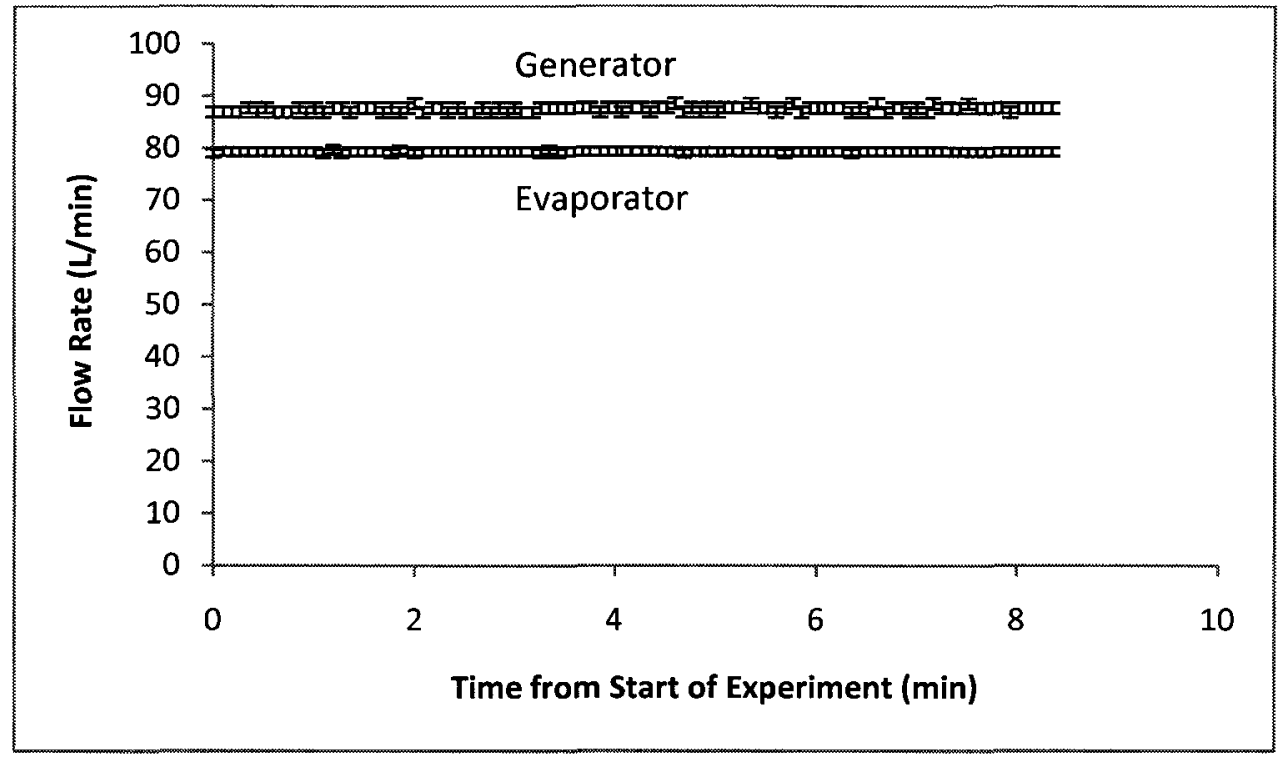

Figure 5.2: Flow rate data from absorption chiller performance Test \#7

The flow rates illustrated in Figure 5.2 were averaged for longer than 8 minutes beginning from the start of the experiment. The average flow rates were $87.49 \mathrm{~L} / \mathrm{min}$ in the generator circuit and $79.29 \mathrm{~L} / \mathrm{min}$ in the evaporator circuit. These average values are reported in Appendix G. The flow rates within the evaporator and generator along with the temperature differences between their inlets and outlets were sufficient to calculate the derived quantities which characterize the absorption chiller's performance.

\subsection{Derived Parameters of an Absorption Chiller Performance Experiment}

The objective of each experiment was to calculate several derived quantities based on the individual measurements of temperature differences and flow rates. The derived quantities were calculated at each instant data were collected. Thermal coefficient 
of performance as well as the heat transferred to the evaporator and generator (COP, $\dot{q}_{E}$ and $\dot{q}_{G}$ ) were the derived quantities of interest given by the following equations.

$$
\begin{gathered}
\dot{q}_{E}=\left(\rho \dot{v} c_{p} \Delta \mathrm{T}\right)_{E} \\
\dot{q}_{G}=\left(\rho \dot{v} c_{p} \Delta \mathrm{T}\right)_{G} \\
C O P=\frac{\left(\rho \dot{v} c_{p} \Delta \mathrm{T}\right)_{E}}{\left(\rho \dot{v} c_{p} \Delta \mathrm{T}\right)_{G}}
\end{gathered}
$$

The term $\Delta \mathrm{T}$ represents the temperature difference of the water between the inlet and outlet of the generator or evaporator in ${ }^{\circ} \mathrm{C}$. The term $\dot{v}$ represents the volumetric flow rate of the water being circulated through the evaporator or generator in $\mathrm{m}^{3} / \mathrm{s}$. The terms $c_{p}$ and $\rho$ represent the physical quantities of specific heat and density in $\mathrm{kJ} / \mathrm{kgK}$ and $\mathrm{kg} / \mathrm{m}^{3}$. Temperature dependent values of the physical quantities of $c_{p}$ and $\rho$ were used in the calculation of the derived quantities. Water was the external working fluid pumped through the evaporator, generator and condenser/absorber. Values of these physical quantities for water were interpolated based on outlet temperature from data tabulated in Mcquiston, Parker and Spitler (2005). The functions used to interpolate values of specific heat and density for water are shown in Table 5.2. The temperatures used in the functions in Table 5.2 are in units of ${ }^{\circ} \mathrm{C}$. The physical quantities of density and specific heat are well known and propagate negligible uncertainty to the derived quantities compared to other sources of error. 


\begin{tabular}{|l|ll|l|}
\hline & $c_{p}(\mathrm{~kJ} / \mathrm{kgK})$ & $\rho\left(\mathrm{kg} / \mathrm{m}^{3}\right)$ \\
\hline Generator & $c_{p}=0.0008 \mathrm{~T}_{\mathrm{GO}}+4.1305$ & $(5.4)$ & $\rho=1020-0.612 \mathrm{~T}_{\mathrm{GO}} \quad(5.5)$ \\
\hline Evaporator & $c_{p}=4.184$ & $(5.6)$ & $\rho=1001.2-0.15 \mathrm{~T}_{\mathrm{EO}}(5.7)$ \\
\hline
\end{tabular}

Table 5.2: Specific heat and density functions for water

The instantaneous derived quantities which were computed for Test $\# 7$ are shown below in Figures 5.3 and 5.4. Also shown in Figures 5.3 and 5.4 are error bars which represent the $95 \%$ uncertainty margins of the instantaneous derived quantities. Equation 4.28, which was discussed in Section 4.3, was used to derive these $95 \%$ uncertainty margins.

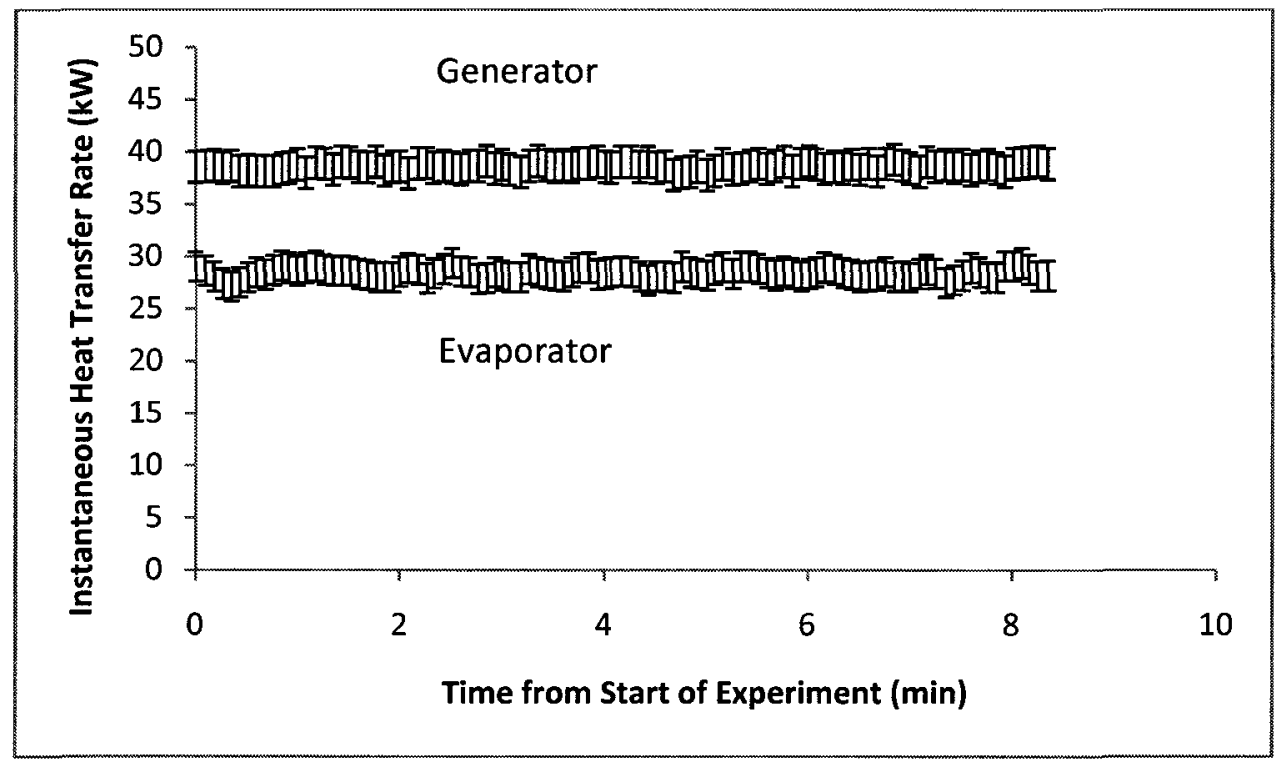

Figure 5.3: Instantaneous heat transfer rates to the evaporator and generator for boundary conditions of Test \#7 


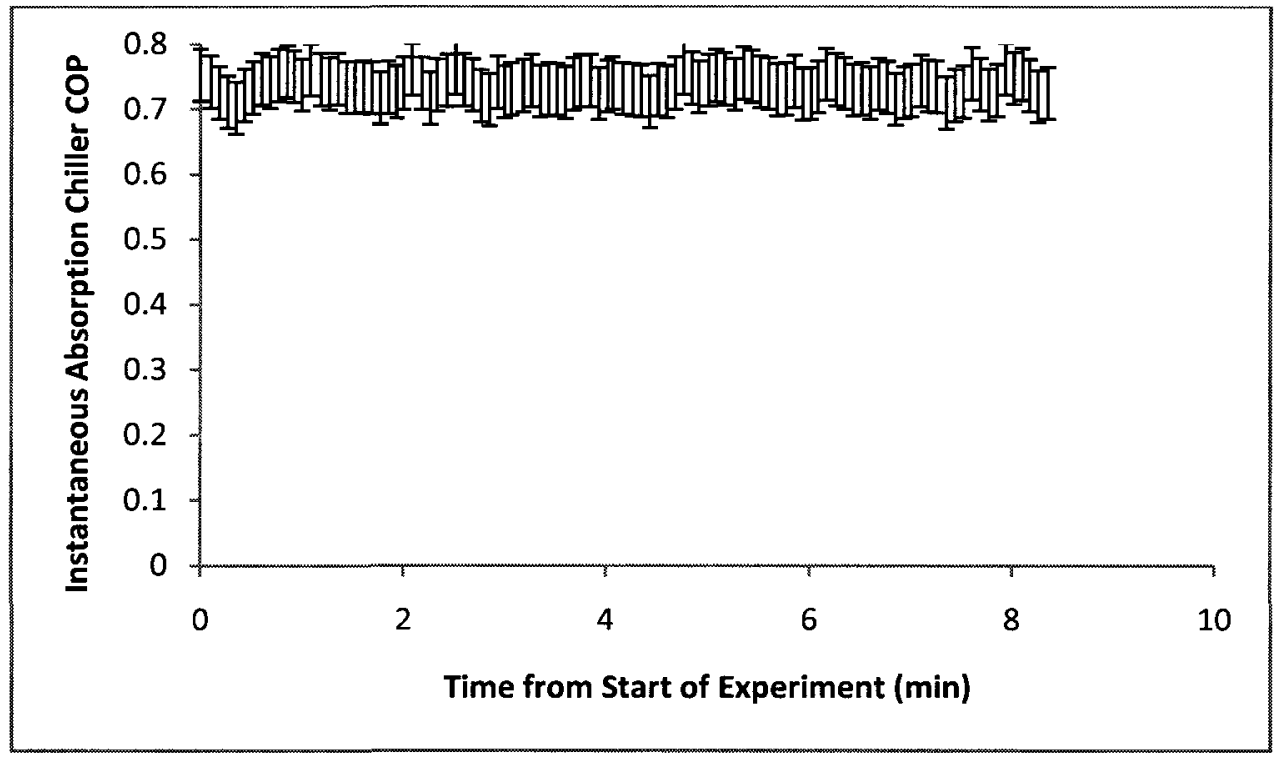

Figure 5.4: Instantaneous absorption chiller COP for boundary conditions of Test \#7

The derived quantities illustrated in Figure 5.3 and 5.4 were averaged longer than 8 minutes beginning from the start of the experiment. The average COP was 0.744 while the average generator and evaporator heat transfer rates were $38.62 \mathrm{~kW}$ and $28.72 \mathrm{~kW}$ respectively. These values are reported in Appendix G.

Figures 5.1 to 5.4 exemplify how the absorption chiller performance was assessed for a given boundary condition combination. The performance assessment procedure that has been described for Test $\# 7$ was repeated for the chiller operating at all the boundary condition combinations listed in Table 5.1. The average absorption chiller performance data along with $95 \%$ uncertainty margins of average quantities for every boundary condition combination of Table 5.1 were reported in Appendix G. Equation 4.30, which was discussed in Section 4.3, was used to derive these $95 \%$ uncertainty margins. 


\subsection{Absorption Chiller Performance Data}

Along with being reported in Appendix G, the gathered absorption chiller performance data are presented in the following graphs. The following graphs in Figures 5.5 to 5.16 illustrate the variation of the absorption chiller derived performance quantities with generator inlet temperature. Each point shown on the graphs in Figures 5.5 to 5.16 corresponded to an experiment identified by a Test \#. For each Test \#, the absorption chiller was operated with boundary conditions whose nominal values appear in Table 5.1. The actual measured averaged data values from absorption chiller performance experiments were reported in Appendix G. The condenser/absorber inlet temperature, evaporator inlet temperature, generator flow rate and evaporator flow rate indicated in Figures 5.5 to 5.16 represent the nominal values listed in Table 5.1. The generator inlet temperature and the derived performance quantities indicated in Figures 5.5 to 5.16 represent the actual measured average values reported in Appendix G. The error bars displayed in Figures 5.5 to 5.16 represent the 95\% uncertainty margins of the averaged data reported in Appendix G. Equation 4.30, which was discussed in Section 4.3, was used to derive these $95 \%$ uncertainty margins.

Some of the data points in the following figures are difficult to distinguish due to similarities in derived performance quantities between different operating conditions. In Figure 5.5 the generator heat transfer rates calculated for evaporator inlet temperatures of $15^{\circ} \mathrm{C}$ and $19^{\circ} \mathrm{C}$ are similar when the generator inlet temperature is approximately $82^{\circ} \mathrm{C}$. Also, in Figure 5.5 the generator heat transfer rates calculated for evaporator inlet temperatures of $15^{\circ} \mathrm{C}$ and $19^{\circ} \mathrm{C}$ are similar when the generator inlet temperature is 
approximately $72^{\circ} \mathrm{C}$. In Figure 5.9 the generator heat transfer rates calculated for evaporator inlet temperatures of $17^{\circ} \mathrm{C}$ and $19^{\circ} \mathrm{C}$ are similar when the generator inlet temperature is approximately $80^{\circ} \mathrm{C}$. 


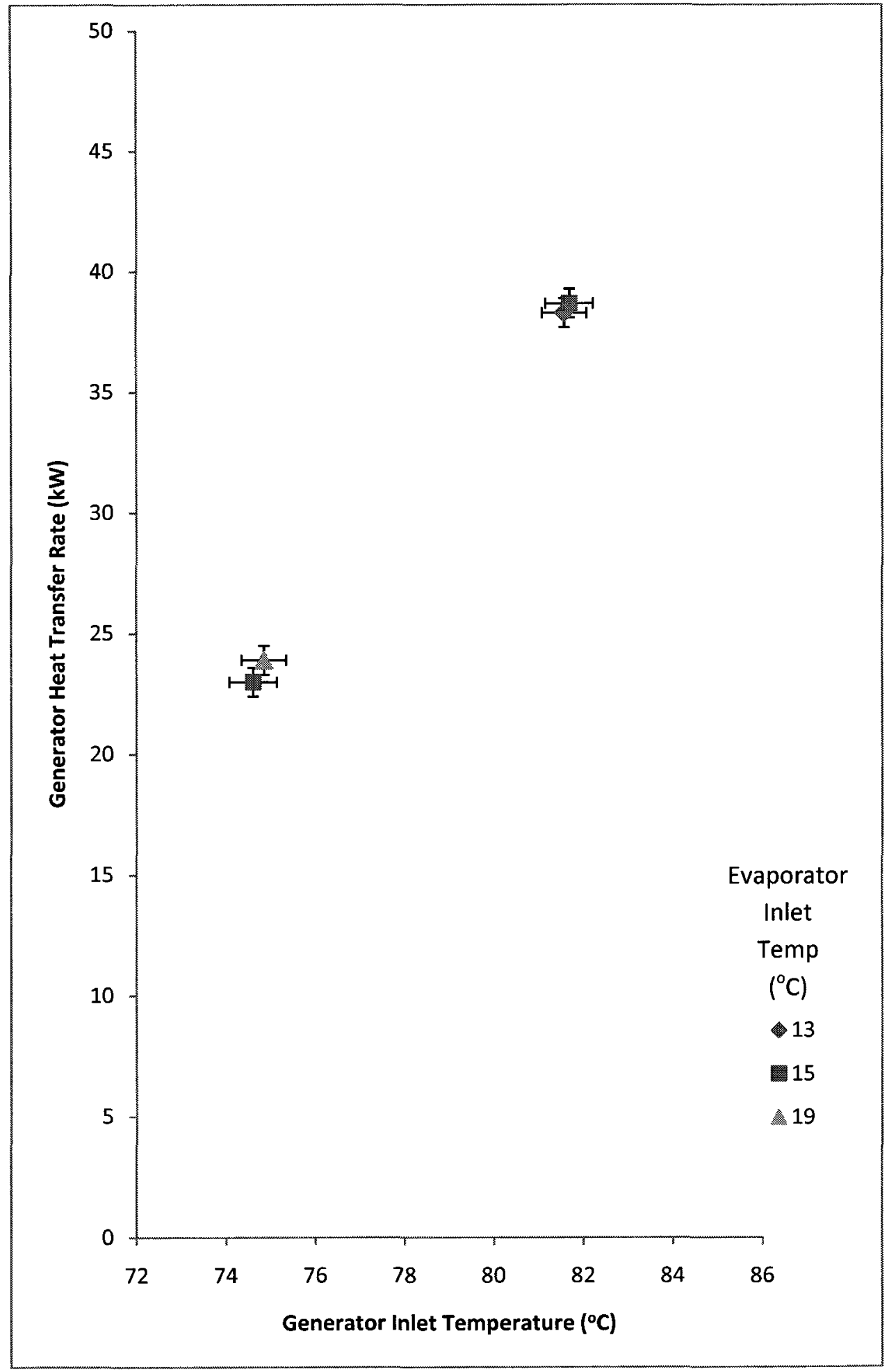

Figure 5.5: Generator heat transfer rates for Test \#1 - 4. Condenser/Absorber inlet temperature: $27^{\circ} \mathrm{C}$. Generator flow: $85 \mathrm{~L} / \mathrm{min}$. Evaporator flow: $82 \mathrm{~L} / \mathrm{min}$ 


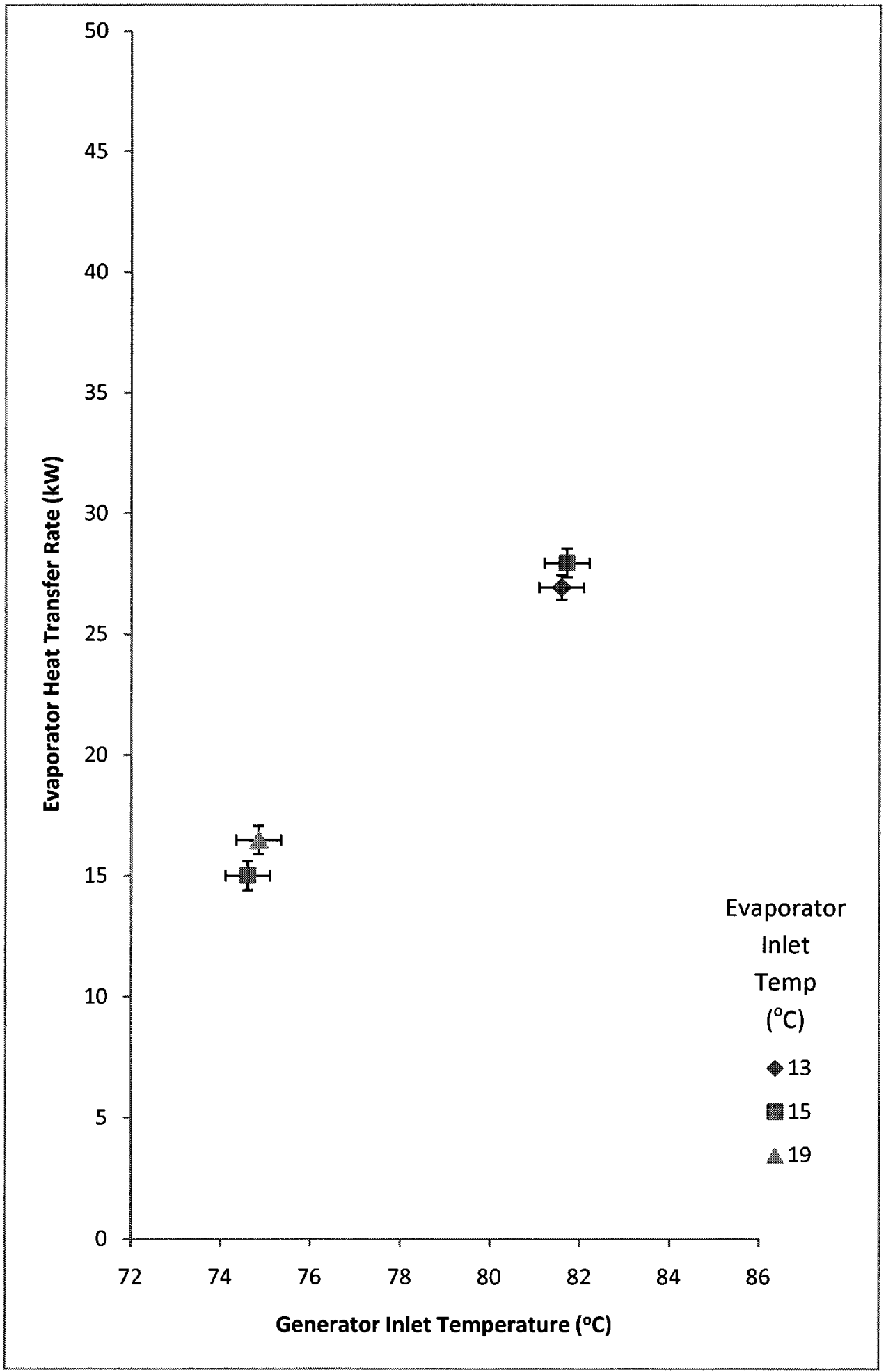

Figure 5.6: Evaporator heat transfer rates for Test $\# 1$ - 4. Condenser/Absorber inlet temperature: $27^{\circ} \mathrm{C}$. Generator flow: $85 \mathrm{~L} / \mathrm{min}$. Evaporator flow: $82 \mathrm{~L} / \mathrm{min}$ 


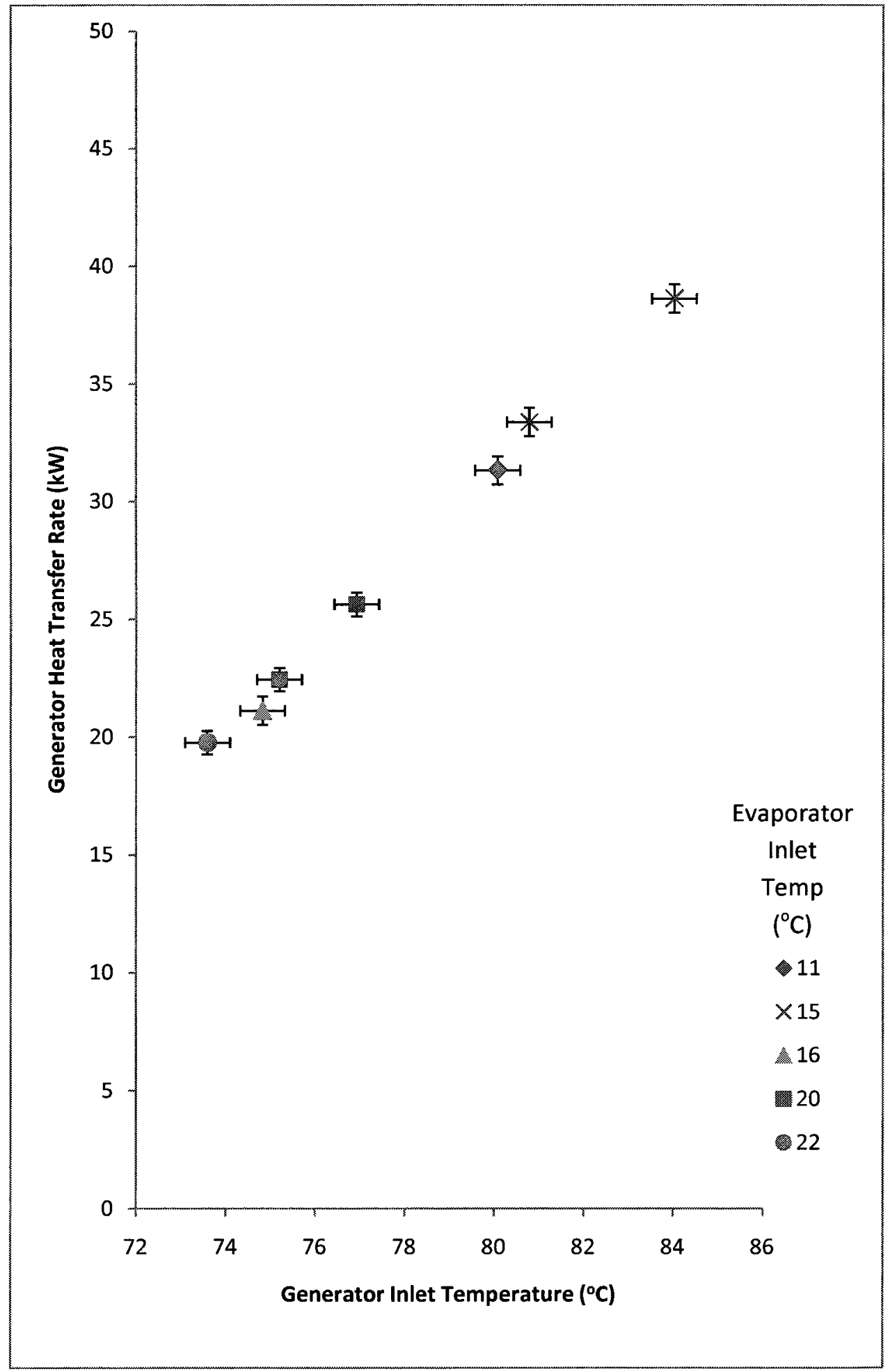

Figure 5.7: Generator heat transfer rates for Test \#5 - 11. Condenser/Absorber inlet temperature: $29^{\circ} \mathrm{C}$. Generator flow: $85 \mathrm{~L} / \mathrm{min}$. Evaporator flow: $82 \mathrm{~L} / \mathrm{min}$ 


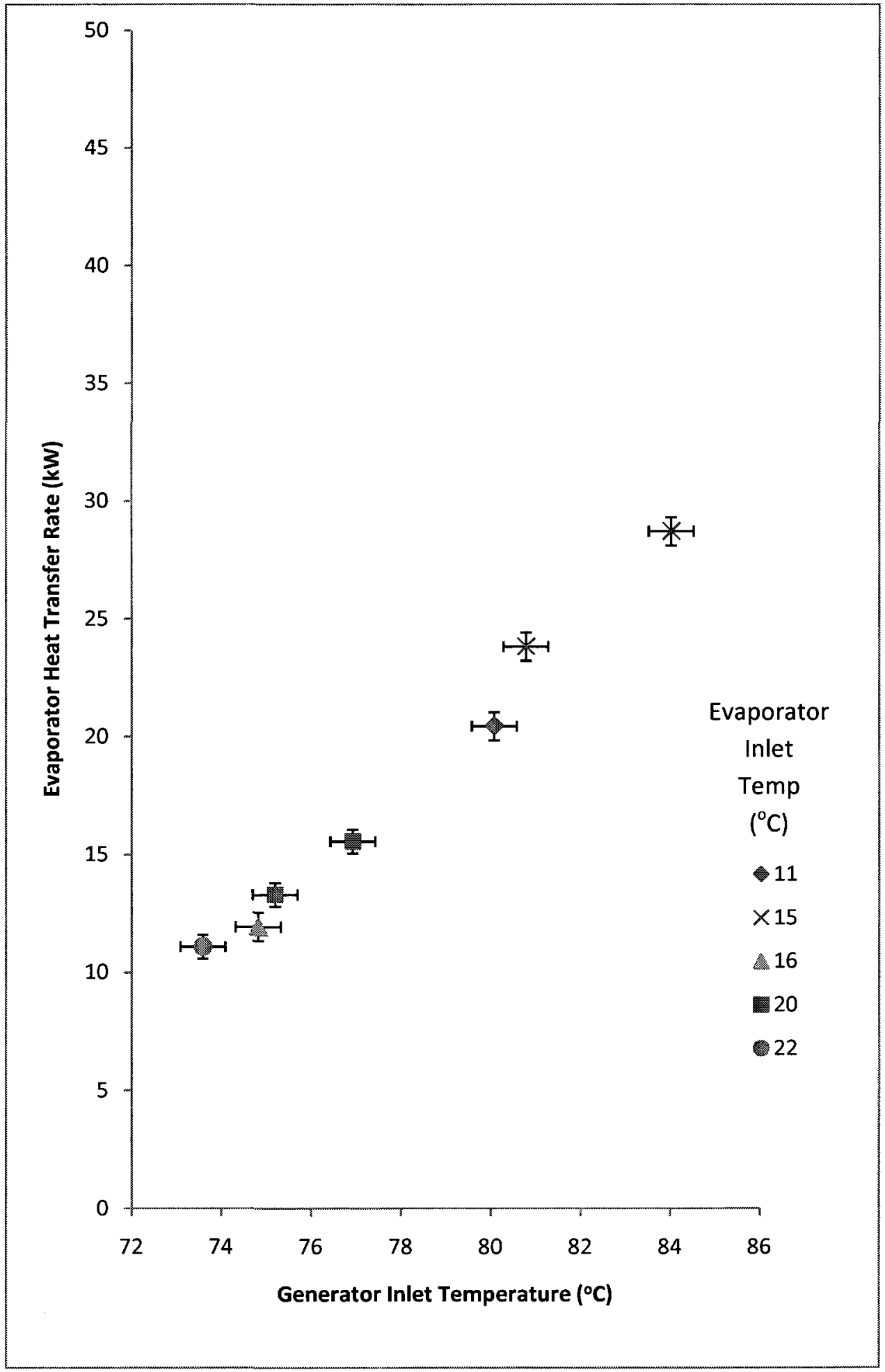

Figure 5.8: Evaporator heat transfer rates for Test \#5 - 11. Condenser/Absorber inlet temperature: $29^{\circ} \mathrm{C}$. Generator flow: $85 \mathrm{~L} / \mathrm{min}$. Evaporator flow: $82 \mathrm{~L} / \mathrm{min}$ 


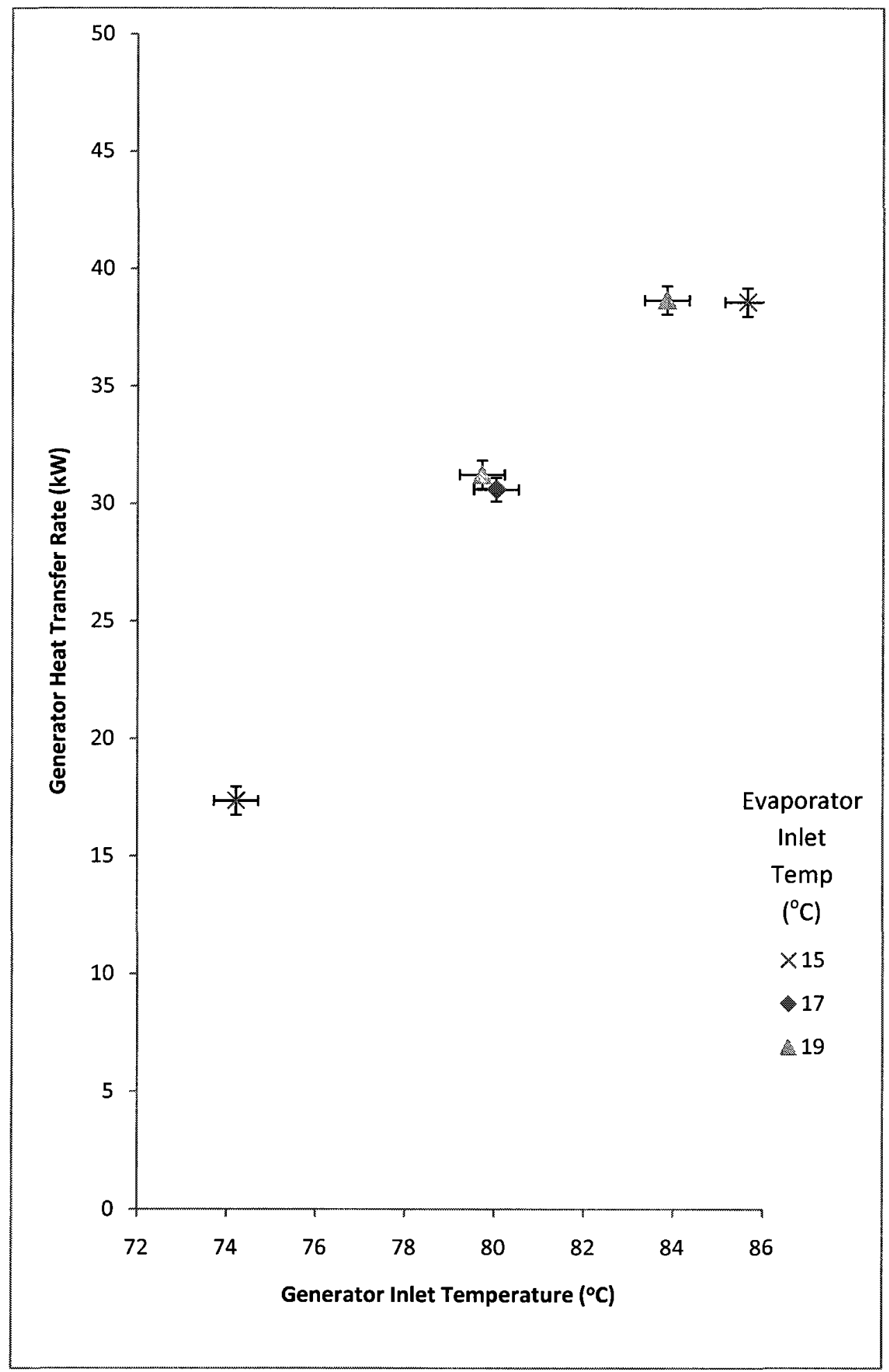

Figure 5.9: Generator heat transfer rates for Test \#12 - 16. Condenser/Absorber inlet temperature: $30^{\circ} \mathrm{C}$ : Generator flow: $85 \mathrm{~L} / \mathrm{min}$. Evaporator flow: $82 \mathrm{~L} / \mathrm{min}$ 


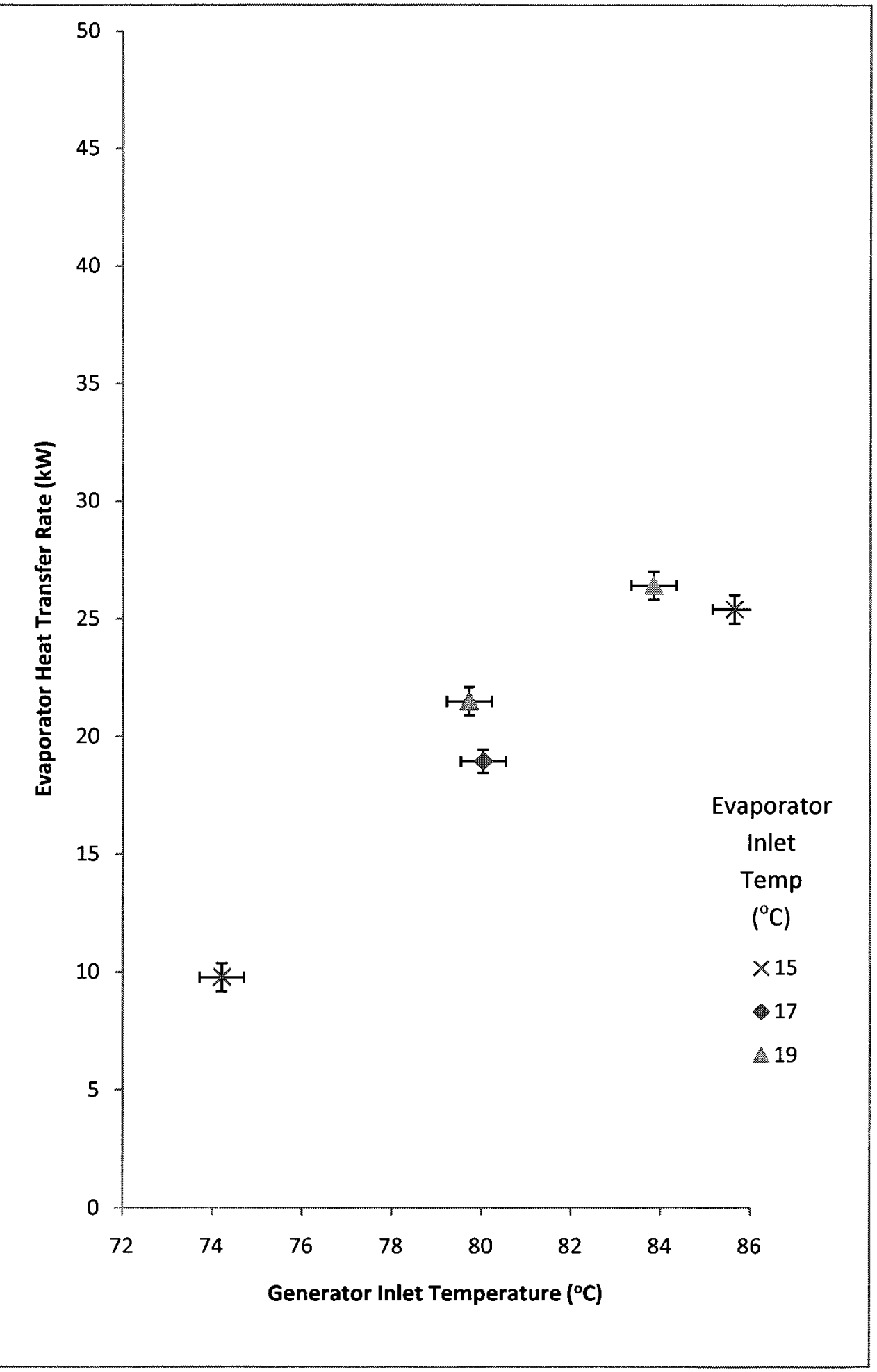

Figure 5.10: Evaporator heat transfer rates for Test \#12 - 16. Condenser/Absorber inlet temperature: $30^{\circ} \mathrm{C}$ : Generator flow: $85 \mathrm{~L} / \mathrm{min}$. Evaporator flow: $82 \mathrm{~L} / \mathrm{min}$ 


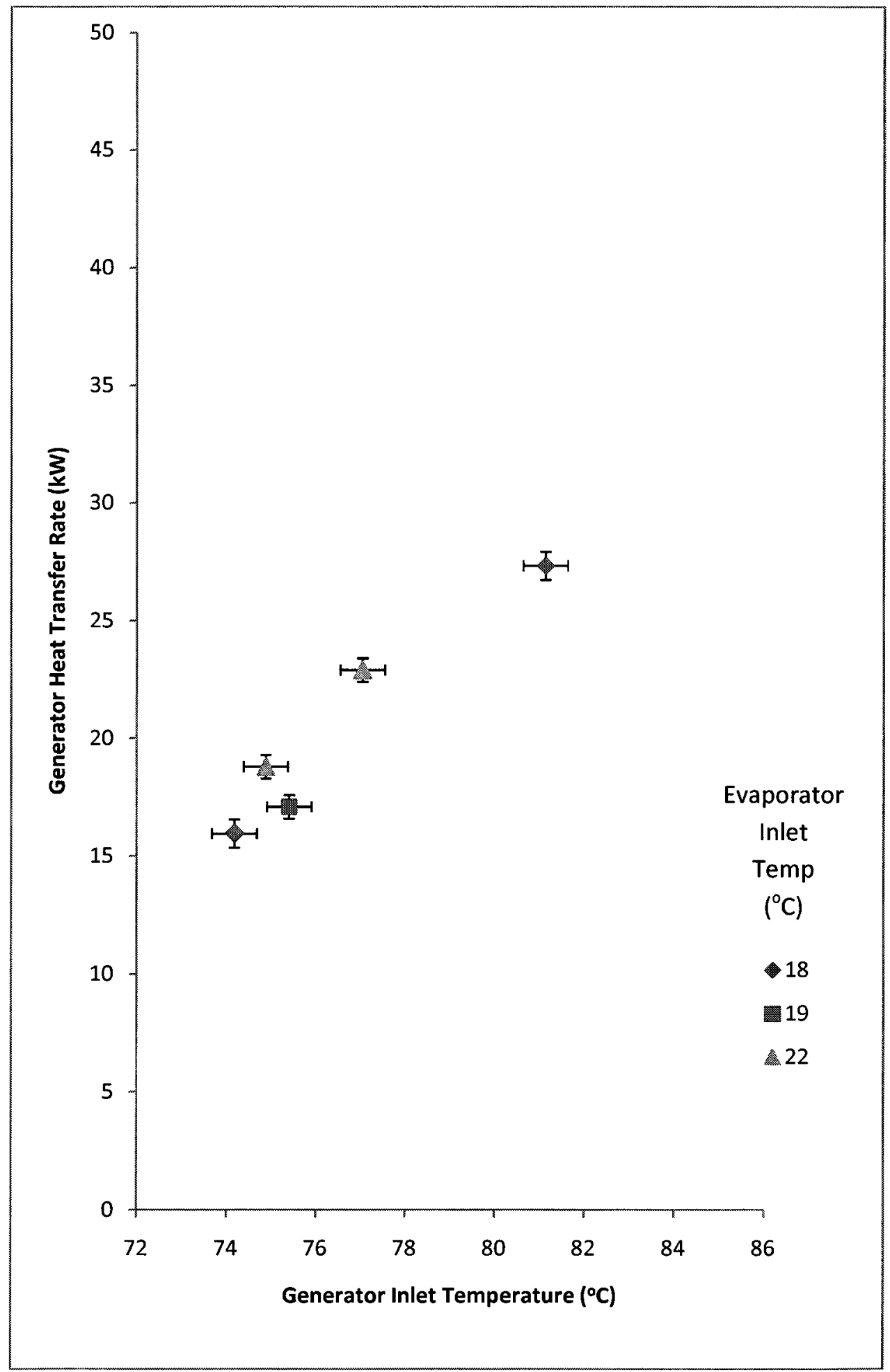

Figure 5.11: Generator heat transfer rates for Test \#17 - 21. Condenser/Absorber inlet temperature: $32^{\circ} \mathrm{C}$ : Generator flow: $85 \mathrm{~L} / \mathrm{min}$. Evaporator flow: $82 \mathrm{~L} / \mathrm{min}$ 


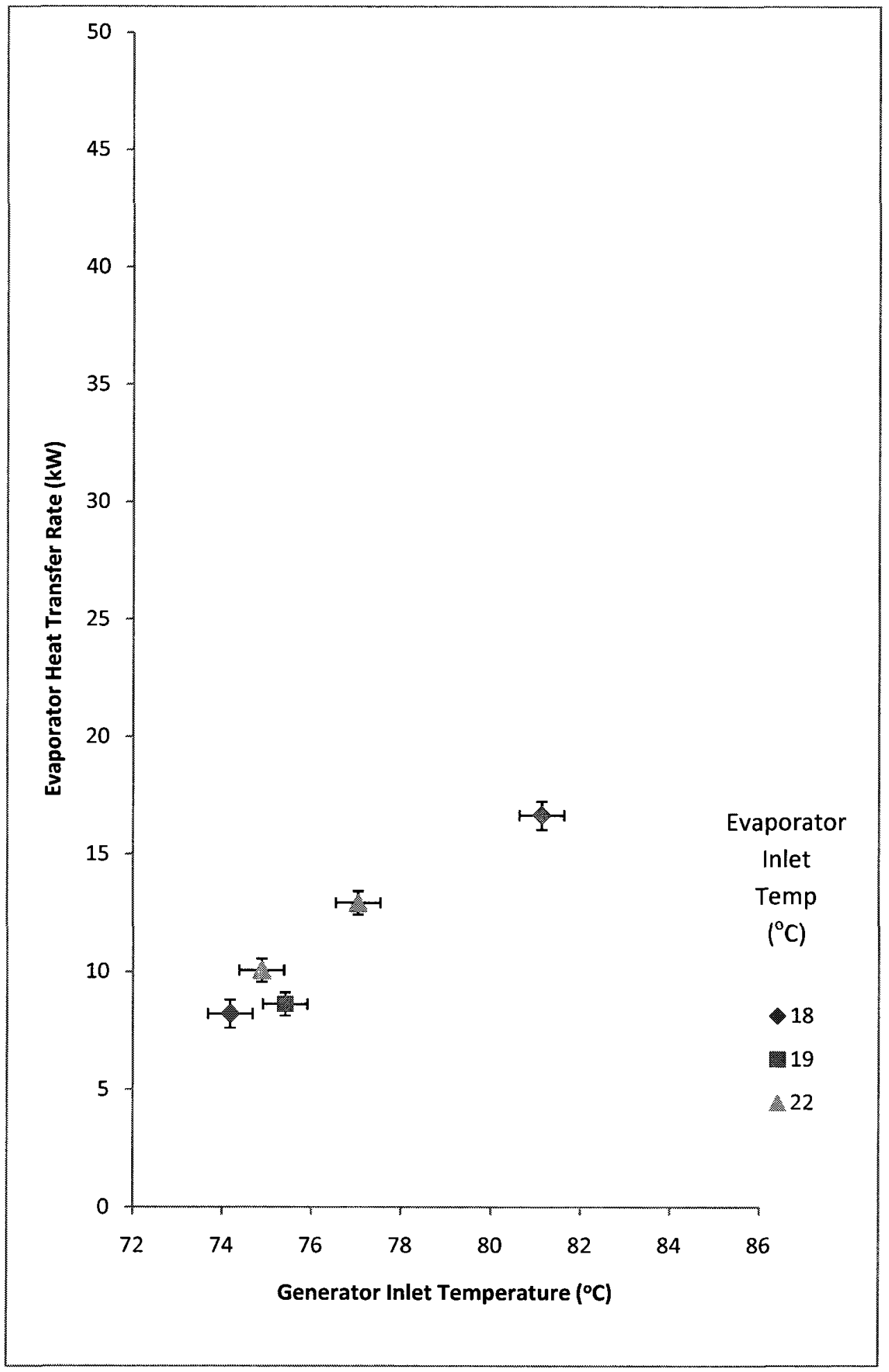

Figure 5.12: Evaporator heat transfer rates for Test \#17 - 21. Condenser/Absorber inlet temperature: $32^{\circ} \mathrm{C}$ : Generator flow: $85 \mathrm{~L} / \mathrm{min}$. Evaporator flow: $82 \mathrm{~L} / \mathrm{min}$ 


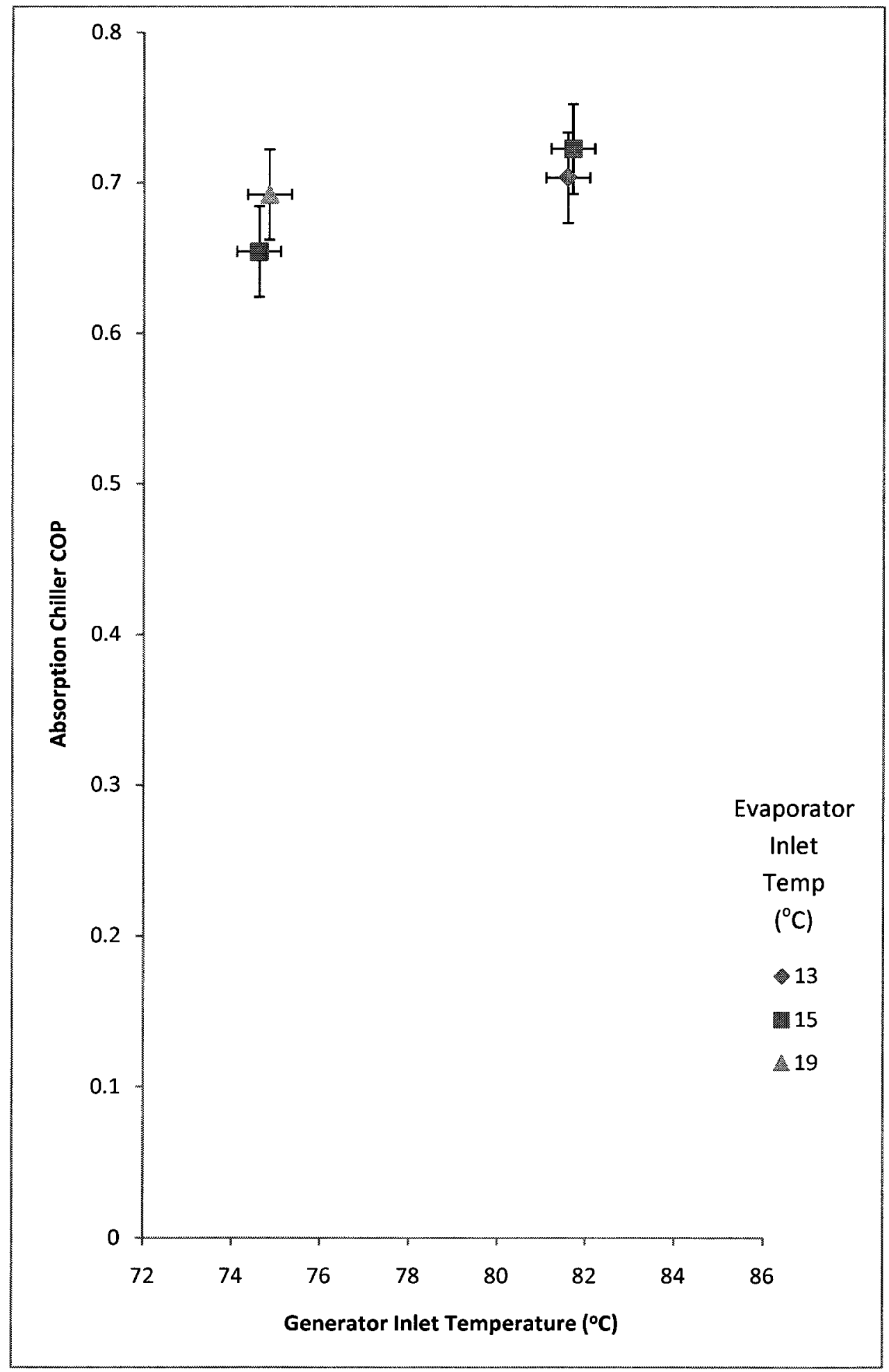

Figure 5.13: COP for Test \#1 - 4. Condenser/Absorber inlet temperature: $27^{\circ} \mathrm{C}$. Generator flow: $85 \mathrm{~L} / \mathrm{min}$. Evaporator flow: $82 \mathrm{~L} / \mathrm{min}$. 


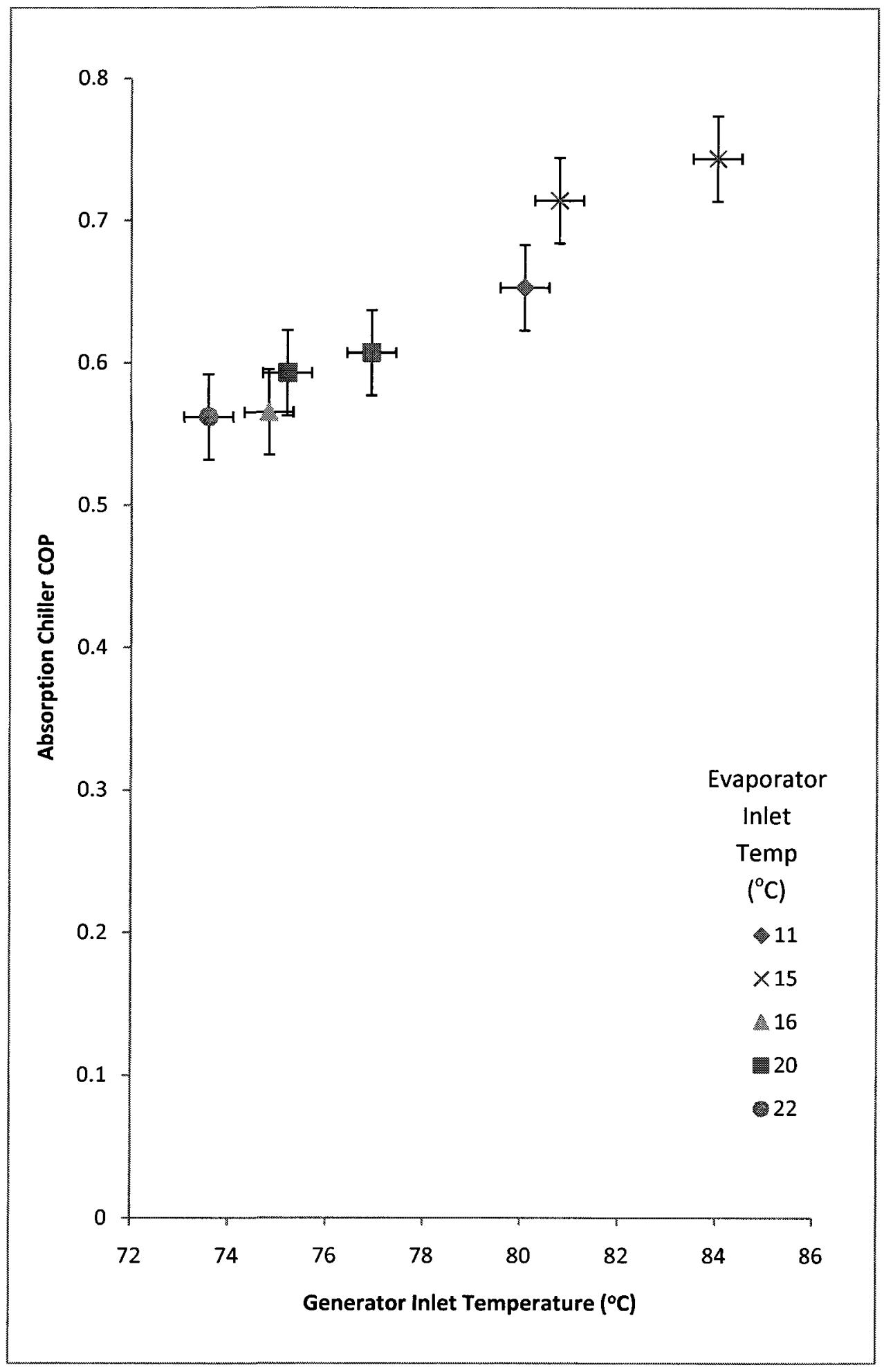

Figure 5.14: COP for Test $\# 5$ - 11. Condenser/Absorber inlet temperature: $29^{\circ} \mathrm{C}$ Generator flow: $85 \mathrm{~L} / \mathrm{min}$. Evaporator flow: $82 \mathrm{~L} / \mathrm{min}$ 


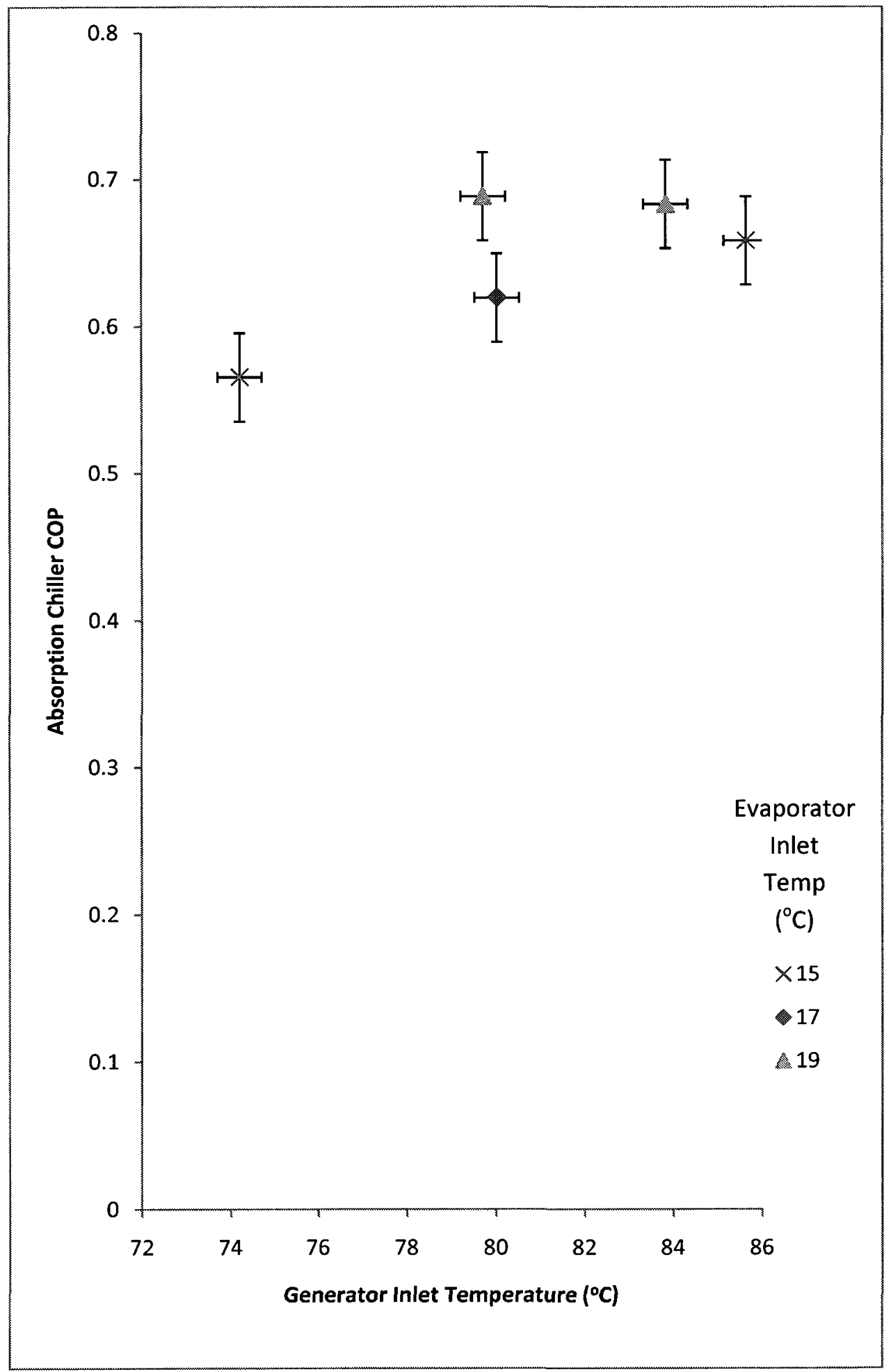

Figure 5.15 COP: for Test $\# 12-16$. Condenser/Absorber inlet temperature: $30^{\circ} \mathrm{C}$ : Generator flow: $85 \mathrm{~L} / \mathrm{min}$. Evaporator flow: $82 \mathrm{~L} / \mathrm{min}$ 


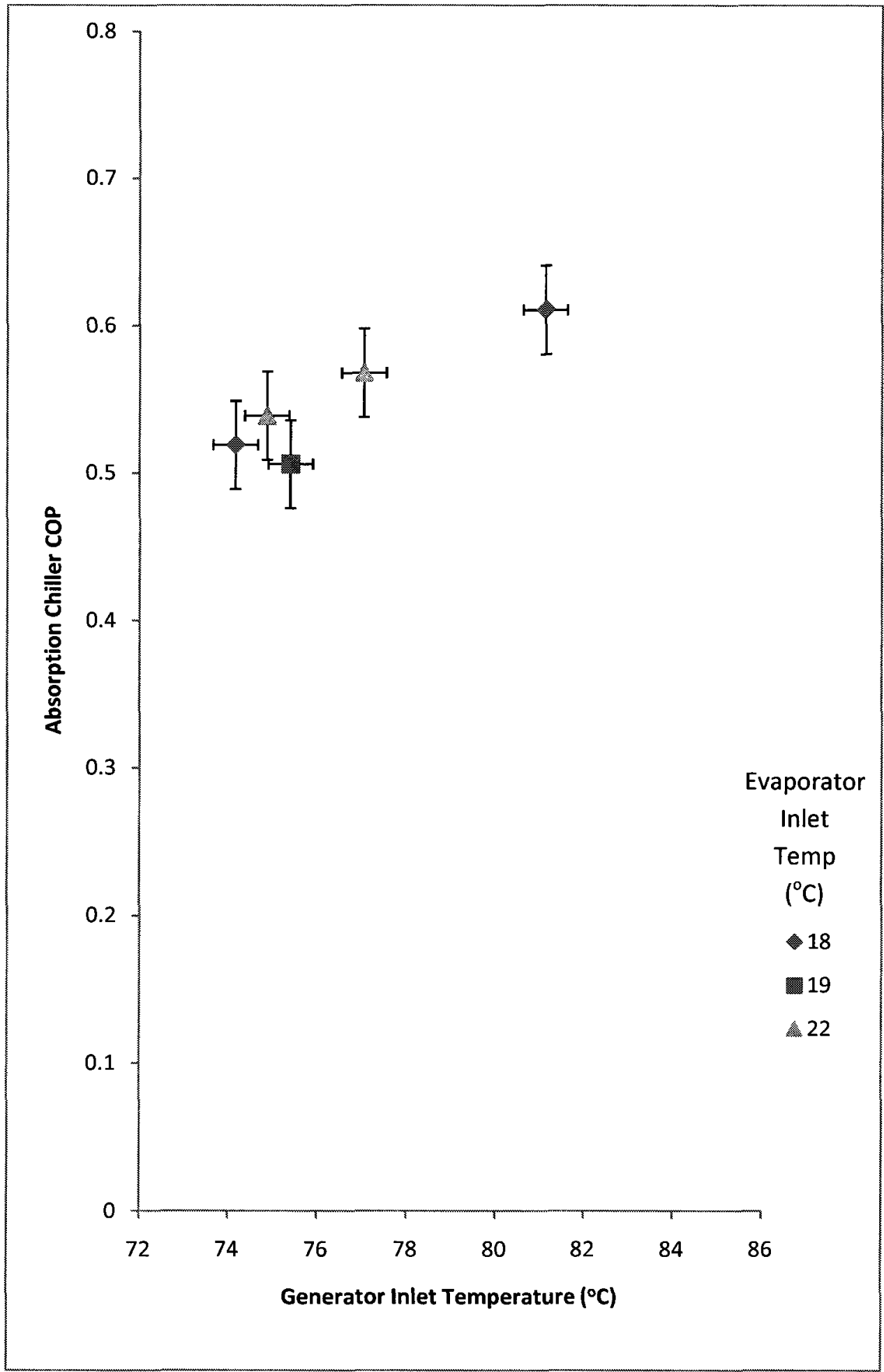

Figure 5.16 COP: for Test $\# 17-21$. Condenser/Absorber inlet temperature: $32^{\circ} \mathrm{C}$ :

Generator flow: $85 \mathrm{~L} / \mathrm{min}$. Evaporator flow: $82 \mathrm{~L} / \mathrm{min}$ 
The graphs in Figures 5.5 to 5.16 illustrate the absorption chiller derived performance quantities' dependence on inlet temperature at the evaporator, generator and condenser/absorber. From these graphs the following trends were observed. The absorption chiller COP increased with generator and evaporator inlet temperature in Figures 5.13 to 5.16. From Figures 5.13 to 5.16 it can also be observed that the absorption chiller COP decreased with increasing condenser/absorber inlet temperature. From Figures 5.5 to 5.12 it can be observed that the evaporator and generator heat transfer rates increased with generator and evaporator inlet temperature. From Figures 5.5 to 5.12 it can also be seen that the evaporator and generator heat transfer rates decreased with increasing condenser/absorber inlet temperature. These trends are characteristic of the absorption chillers studied in the literature reviewed in Section 1.3.

An investigation into the dependence of the absorption chiller derived performance quantities on the generator flow rate was also conducted and is summarized in Table 5.3. Table 5.3 shows average data measured from sensors and the performance quantities derived from them for Test $\# 19$ and $\# 22$. The volumetric flow rates of the generator and evaporator $\left(\dot{v}_{\mathrm{G}}\right.$ and $\left.\dot{v}_{\mathrm{E}}\right)$ in $\mathrm{L} / \mathrm{min}$ are shown. The inlet temperatures of the generator evaporator and condenser/absorber $\left(\mathrm{T}_{\mathrm{GI}}, \mathrm{T}_{\mathrm{EI}}\right.$ and $\left.\mathrm{T}_{\mathrm{CI}}\right)$ in ${ }^{\circ} \mathrm{C}$ are shown. The derived absorption chiller evaporator and generator heat transfer rates $\left(\dot{q}_{\mathrm{G}}\right.$ and $\left.\dot{q}_{\mathrm{E}}\right)$ in $\mathrm{kW}$ along with the COP are shown. Also shown are the average 95\% uncertainty margins $\left(\bar{U}_{95}\right)$ computed from equation 4.30 discussed in Section 4.3. 


\begin{tabular}{|l|r|r|r|r|r|r|r|r|}
\hline & \multicolumn{1}{|c|}{$\begin{array}{c}\dot{v}_{\mathrm{G}} \\
(\mathrm{L} / \mathrm{min})\end{array}$} & \multicolumn{1}{c|}{$\begin{array}{c}\dot{v}_{\mathrm{E}} \\
(\mathrm{L} / \mathrm{min})\end{array}$} & $\begin{array}{c}\mathrm{T}_{\mathrm{GI}} \\
\left({ }^{\circ} \mathrm{C}\right)\end{array}$ & \multicolumn{1}{c|}{$\begin{array}{c}\mathrm{T}_{\mathrm{EI}} \\
\left({ }^{\circ} \mathrm{C}\right)\end{array}$} & $\begin{array}{c}\mathrm{T}_{\mathrm{CI}} \\
\left({ }^{\circ} \mathrm{C}\right)\end{array}$ & $\begin{array}{c}\dot{q}_{\mathrm{G}} \\
(\mathrm{kW})\end{array}$ & $\begin{array}{c}\dot{q}_{\mathrm{E}} \\
(\mathrm{kW})\end{array}$ & \multicolumn{1}{c|}{$\mathrm{COP}$} \\
\hline $\begin{array}{l}\text { Test } \\
\# 19\end{array}$ & 88.29 & 79.86 & 75.41 & 19.17 & 32.72 & 17.09 & 8.63 & 0.506 \\
\hline $\bar{U}_{95}$ & 0.88 & 0.8 & 0.52 & 0.55 & 0.46 & 0.53 & 0.45 & 0.03 \\
\hline $\begin{array}{l}\text { Test } \\
\# 22\end{array}$ & 67.59 & 79.86 & 75.73 & 18.99 & 32.58 & 16.88 & 8.44 & 0.501 \\
\hline $\bar{U}_{95}$ & 0.68 & 0.8 & 0.52 & 0.55 & 0.46 & 0.42 & 0.45 & 0.029 \\
\hline
\end{tabular}

Table 5.3: Absorption chiller performance dependence on generator flow rate

A slight dependence of absorption chiller performance on generator flow rate is observed from the data displayed in Table 5.3. From Test \#19 to \#22 the generator flow rate decreased from $88.29 \mathrm{~L} / \mathrm{min}$ to $67.59 \mathrm{~L} / \mathrm{min}$ while other variables were held approximately constant. From Test $\# 19$ to $\# 22$ the generator and evaporator heat transfer rates along with the COP decreased slightly. It is difficult to tell from Test \#19 and \#22 if there was an actual change in performance or if the apparent performance change is due to the uncertainty with the data.

The flow rates in the evaporator and generator were measured with oval gear flow meters. A flow meter was not used in the condenser/absorber circuit to log data. The condenser/absorber flow rate was within the manufacturer's limits listed in Table 3.3. This was determined with the pressure differential measured across the absorption chiller inlet and outlet in the condenser/absorber circuit with gauges. The pressure differential was estimated with analog gauges to be $70 \mathrm{kPa}$. At this pressure differential the manufacturer of the absorption chiller indicates a flow rate of approximately $306 \mathrm{~L} / \mathrm{min}$. The uncertainty associated with this flow rate is unknown as no data was logged with 
regards to this quantity. It is only known that he condenser/absorber flow rate was the same for every absorption chiller performance experiment summarized in Appendix G.

\subsection{Absorption Chiller Transient Performance During Start-up}

All of the absorption chiller performance data presented in the previous section represented the absorption chiller performance during steady-state operation. During start-up, however, a significant period of time was observed where the absorption chiller performed differently than it would during steady-state operation. Figure 5.17 illustrates the temperature drop across the evaporator during start-up while the inlet temperature to evaporator, generator and condenser/absorber were held approximately constant at $17^{\circ} \mathrm{C}$, $80^{\circ} \mathrm{C}$, and $30^{\circ} \mathrm{C}$. Error bars representing $95 \%$ uncertainty margins are not shown on Figure 5.17 as the temperature difference illustrated is highly transient. It was not possible to obtain steady-state averages of the data shown to estimate the precision error to compute the $95 \%$ uncertainty margins. The data graphed in Figure 5.17 are unsuitable for calibration of the absorption chiller model in ESP-r. The data are shown only to estimate the length of time that the transient start-up performance of the absorption chiller persists. 


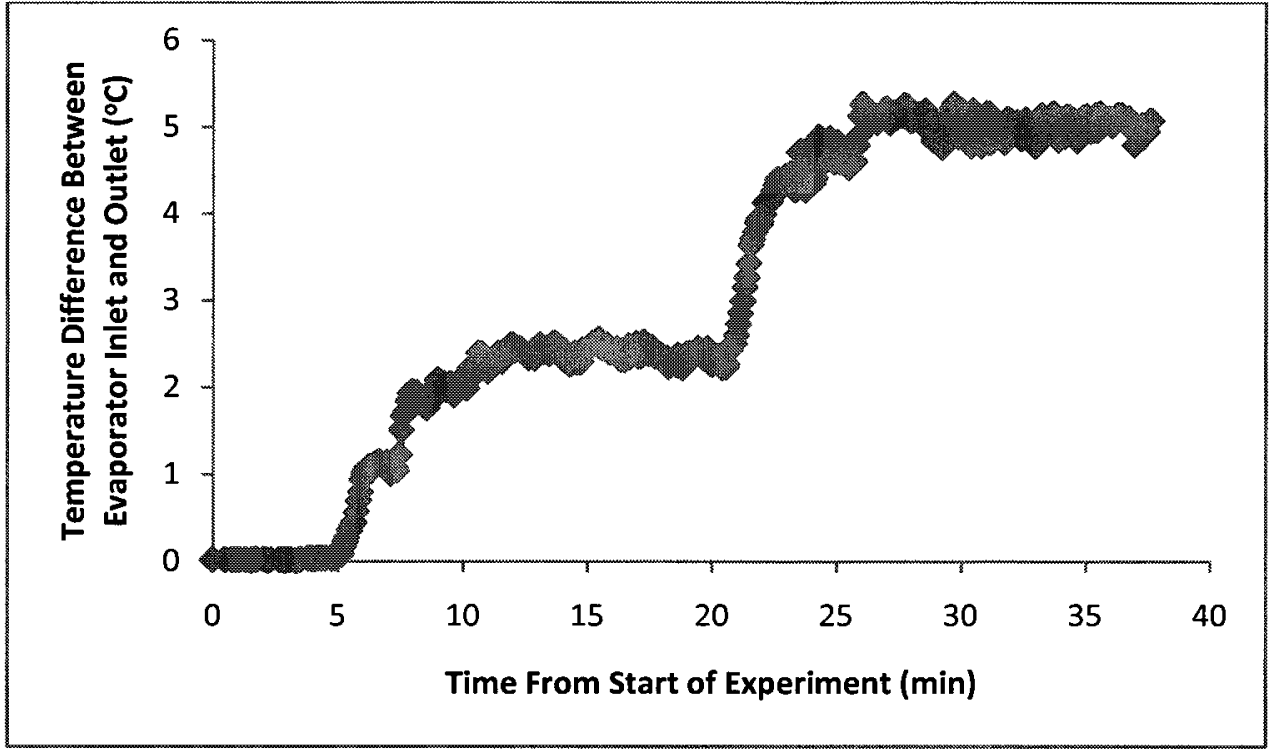

Figure 5.17: Transient absorption chiller performance during start-up

During the experiment illustrated in Figure 5.17, the absorption chiller was switched on near 5 minutes from the start of experiment. It can be seen in the preceding figure that the temperature difference between the evaporator inlet and outlet did not stabilize until after 25 minutes from the start of experiment. It can be concluded that there is a transient start-up period that persists for around 20 minutes. This is relevant to efforts following this research that will focus on modelling the performance of this absorption chiller.

The start-up performance of the Yazaki WFC-SC10 is different than the performance during normal operation because of a safety feature that prevents salt crystallization. The temperatures at different points within the absorption chiller are sensed by a central processing unit. The temperatures are required to exceed a certain 
threshold value otherwise the absorption chiller's expansion valve is commanded to not actuate fully to guard against salt crystallization. The jump in performance seen near 20 minutes from the start of experiment is the point at which the internal temperatures exceed the threshold value and the expansion valve is commanded to fully actuate. This safety feature is usually triggered if the absorption chiller is not active for a period of time and the temperatures internal to the absorption chiller fall below the threshold value prior to operation. This can happen if the chiller is left inactive overnight.

\subsection{Experimental Validation}

In order to validate the data produced by the absorption chiller test facility, the measured performance data from Test $\# 5$ was compared against performance data determined by a graphical method described by Yazaki (2010). The method described by Yazaki (2010) was only valid for evaporator outlet temperatures of $7^{\circ} \mathrm{C}$. It was difficult to produce performance data from the absorption chiller test facility for an evaporator outlet of $7^{\circ} \mathrm{C}$ as only the inlet temperature could be controlled directly. Another source of difficulty to producing performance data for an evaporator outlet of $7^{\circ} \mathrm{C}$ was that the absorption chiller would deactivate if the evaporator temperature was less than $7^{\circ} \mathrm{C} .7^{\circ} \mathrm{C}$ was the factory set point of the absorption chiller.

The method described by Yazaki (2010) suggested the operating conditions at Test \#5 from Appendix G would yield evaporator and generator heat transfer rates of 25 $\mathrm{kW}$ and $38 \mathrm{~kW}$ respectively for the WFC-SC10 absorption chiller. Test \#5 in Appendix G 
was measured performance data from the absorption chiller test facility, indicates an evaporator and generator heat transfer rate of $20 \mathrm{~kW}$ and $31 \mathrm{~kW}$, respectively. The evaporator outlet temperature of Test $\# 5$ was $7.08^{\circ} \mathrm{C}$. There is a discrepancy between the method suggested by Yazaki and the results of the absorption chiller test facility, however, the method suggested by Yazaki relies on absorption chiller performance curves with unreported uncertainty. There is likely significant error associated with the absorption chiller performance predictions of Yazaki's method.

The individual sensors used in the absorption chiller test facility were also validated. In order to have confidence in the signals the individual sensors were outputting there was some redundancy in measurement. The readings from the oval gear flow meters were compared against measurements of pressure differential across the evaporator and generator and agreed well. In order to validate the thermopiles, the output of the heaters in the generator circuit was compared against the maximum heat transferred to the generator as calculated by measurements from the thermopile and the flow meter in the generator circuit. The maximum heat transfer rate to the generator observed in the experiments was $38.69 \mathrm{~kW}$ as observed in Test \#2. The maximum combined output of the heaters based on their rating was $40 \mathrm{~kW}$. The maximum heat transfer rate observed during experiments should be slightly less than the maximum heater output based on their rating. This is true because the heaters also had to supply energy to make up for heat losses to the ambient from the generator circuit. 
A total of three thermopiles were built for these experiments; two to be submerged in the flow for data acquisition and one for calibration purposes which was used to obtain the data in Appendix D. The calibration thermopile and the two thermopiles for data acquisition were all cut from the same strand of thermocouple wire. All three thermopiles were tested at the same temperature and temperature difference and produced identical signals. This reinforced the validity of using the results of the calibration thermopile from Appendix $\mathrm{D}$ to convert the EMF signals of the two submerged thermopiles. A similar procedure was performed for thermocouples.

In this chapter, a subset of the data from absorption chiller performance assessment experiments has been visually presented and validated. Figures 5.5-5.16 depicted the derived absorption chiller performance quantities dependencies on thermal boundary conditions. Also shown in Figures 5.5-5.16 are error bars that represent the 95\% uncertainty margins of the summarized average data in Appendix G. 


\subsection{Conclusions and Future Work}

\subsection{Conclusions}

Solar-absorption A/C systems could possibly help relieve the burden to the central electrical grid caused by current vapour compression air conditioners used in Canadian residential housing. Building performance simulation could be used to assess the potential of solar-absorption $\mathrm{A} / \mathrm{C}$ systems for Canadian residential housing. Building performance simulation models of absorption chillers do exist; however, they require improvements to their calibration to be useful for simulation of solar-absorption $\mathrm{A} / \mathrm{C}$ systems. Current models of absorption chillers are not properly calibrated for solarabsorption $\mathrm{A} / \mathrm{C}$ system applications due to a lack of reliable experimental absorption chiller performance data.

The major goals of this thesis were defined in order to improve current absorption chiller models so they would become more useful in evaluating the potential of solarabsorption $\mathrm{A} / \mathrm{C}$ systems for Canadian residential housing. The first major goal was to acquire an absorption chiller and develop a facility capable of characterizing the absorption chiller's performance over a wide range of operating boundary conditions. The second objective was to gather data from the absorption chiller test facility with low enough uncertainty margins to be suitable for calibration of an absorption chiller model for building performance simulation. 
An absorption chiller was acquired and a facility was constructed capable of operating the absorption chiller over a wide range of boundary conditions. Although data were gathered over a wide range of operating boundary conditions, several technological limitations of the absorption chiller test facility limited the range of boundary conditions that could be explored. The acquired absorption chiller performance data had uncertainty margins that were small enough such that the gathered data are suitable to calibrate an absorption chiller model for building performance simulation. The instrumentation used to acquire the absorption chiller performance data has also been validated.

\subsection{Future Work}

The range of absorption chiller boundary conditions for which performance data were gathered in this thesis could be expanded to cover its entire operational range. The full absorption chiller operational range could not be studied due to several technological limitations of the test facility. The generator flow rate was constrained to a maximum of approximately $85 \mathrm{~L} / \mathrm{min}$ by an undersized pump. The generator inlet temperature was constrained to a maximum of approximately $86^{\circ} \mathrm{C}$ due to undersized heaters. In the generator circuit, the current CR 3-5 pump should be replaced with a larger CR 10-3 pump to expand the flow range. The $30 \mathrm{~kW}$ heater in the evaporator circuit should be switched with the $18 \mathrm{~kW}$ heater in the generator circuit to expand the generator inlet temperature range. 
The research described in this thesis represents only one phase of a much larger research project. The larger goal is to determine the potential of solar-absorption $\mathrm{A} / \mathrm{C}$ systems for Canadian residential housing. Efforts following this research will concentrate on using the performance data gathered from the absorption chiller test facility to calibrate an absorption chiller model for building performance simulation in ESP-r. Once the model has been calibrated, it may be used to more accurately simulate how solarabsorption $\mathrm{A} / \mathrm{C}$ systems perform than previous efforts could.

The calibrated absorption chiller model will not be limited to residential solarabsorption $\mathrm{A} / \mathrm{C}$ system applications alone. The calibrated model of this absorption chiller could be used for building performance simulation of any application where a singleeffect water/lithium-bromide absorption chiller might be used. A single-effect water/lithium-bromide absorption chiller might be used as part of a micro-cogeneration system or for the refrigeration of food.

The possibility also exists to make use of the test facility to gather performance data from absorption chillers other than the Yazaki WFC-SC10. It might be interesting to examine the performance of absorption chillers that use refrigerant/absorbent pairs other than water/lithium-bromide. It might also be interesting to study absorption chillers with different cooling capacities than the Yazaki WFC-SC10. 


\section{References}

Adao P., Pereira M., Costa A. (2008) Pre-commercial development of a cost-effective solar-driven absorption chiller, EUROSUN 2008 Conference Proceedings, Lisbon, Portugal

Agyenim F., Knight I., Rhodes M. (2010) Design and experimental testing of the performance of an outdoor $\mathrm{LiBr} / \mathrm{H} 20$ solar thermal absorption cooling system with a cold store. Solar Energy 84, 735-744

Ali H., Noeres P., Pollerberg C. (2008) Performance assessment of an integrated free cooling and solar powered single-effect lithium bromide-water absorption chiller. Solar Energy 82, 1021-1030

Aphornratana S., Sriveerakul T. (2007) Experimental studies of a single-effect absorption refrigerator using aqueous lithium-bromide: Effect of operating condition to system performance. Experimental Thermal and Fluid Science 32, 658-669

Arnavat M., Villada J., Bruno J., Coronas A. (2010) Analysis and parameter identification for characteristic equations of single and double effect absorption chillers by means of multivariable regression. International Journal of Refrigeration $33,70-78$

Asdrubali F., Baldinelli G., Presciutti A. (2009) An experimental solar cooling system with a small size absorption chiller: design and first measurements. 3rd International Conference Solar Air Conditioning Proceedings, Palermo, Italy 
Asdrubali F., Gignaffini S. (2005) Evaluation of the performances of a $\mathrm{H} 20-\mathrm{LiBr}$ absorption refrigerator under different service conditions. Journal of Refrigeration $28,489-497$

Assilzadeh F., Kalogirou S., Ali Y., Sopian K. (2005) Simulation and optimization of a $\mathrm{LiBr}$ solar-absorption cooling system with evacuated tube collectors. Renewable Energy 30, 1143-1159

Atmaca A., Yigit A. (2003) Simulation of solar-powered absorption cooling system. Renewable Energy 28, 1277-1293

Balghouthi M., Chahbani M., Guizani A. (2005) Solar powered air conditioning as a solution to reduce environmental pollution in Tunisia. Desalination 185, 105-110

Beausoleil-Morrison I. (2009) On predicting the magnitude and temporal variation of cooling loads in detached residential buildings. Building Simulation 2009 Conference Proceedings, Glasgow, Scotland

Beausoleil-Morrison I. (2004) The simulation of a residential space-cooling system powered by the thermal output of a cogeneration device. eSim 2004 Conference Proceedings, Vancouver, Canada

Chua H., Toh H., Ng K. (2002) Thermodynamic modeling of an ammonia-water absorption chiller. International Journal of Refrigeration 25, 896-906

Clarke J. (2001) Energy Simulation in Building Design $2^{\text {nd }}$ edition. ButterworthHeinemann. ISBN 0750650826

Demir H., Mobedi M., Ulku S. (2008) A review on adsorption heat pumps: problems and 
solutions. Renewable and Sustainable Energy Reviews 12, 2381-2403

Fathi R., Guemimi C., Ouaskit S. (2004) An irreversible thermodynamic model for solar absorption refrigerator. Renewable Energy 29, 1349-1365

Figlioa R., Beasley D. (2006) Theory and Design for Mechanical Measurements. Wiley. ISBN 978-0-471-45593-7

Florides G., Kalogirou S., Tassou S., Wroble L. (2003) Design and construction of a LiBr-water absorption machine. Energy Conversion and Management 44, 2483-2508

Florides G., Kalogirou S., Tassou S., Wroble L. (2002) Modelling and simulation of an absorption solar cooling system for Cyprus. Solar Energy 72, 43-51

Helm M., Keil C., Hiebler S., Mehling H., Schwiegler C. (2009) Solar heating and cooling system with absorption chiller and low temperature latent heat storage: Energetic performance and operational experience. International Journal of Refrigeration 32, 596-606

Henning H. (2009) IEA SHC Task 38 - Solar Air Conditioning and Refrigeration $\begin{array}{llll}\text { Industry } & \text { Newsletter } & \text { First } & \text { Edition. }\end{array}$ shc.org/publications/downloads/task38-enewsletter-2009-01.pdf. Accessed Nov. 28, 2010.

Henning H. (2007) Solar Assisted Air-Conditioning in Buildings. Springer Wien. ISBN 978-3-211-73095-9

Herold K., Radermacher R., Klein S. (1996) Absorption Chillers \& Heat Pumps. CRC. ISBN 0-8493-9427-9 
Hidalgo M., Aumente P., Millan M., Neumann A., Mangual R. (2008) Energy and carbon emission savings in Spanish housing air-conditioning using solar driven absorption system. Applied Thermal Engineering 28, 1734-1744

Ileri A. (1995) Yearly simulation of a solar-aided R22-DEGDME absorption heat pump system. Solar Energy 55, 255-265

International Energy Agency (IEA), Solar Heating and Cooling Programme, (2009) Task 38 Solar Air-Conditioning and Refrigeration: List of existing solar heating and cooling installations. Institute for Renewable Energy. http://www.ieashc.org/publications/downloads/task38-Overview.pdf. Accessed Nov. 18, 2010

Independent Electricity Service Operator (IESO) (2009) Hourly Generator Output and Capability Report Aug. 10, 2009. http://www.ieso.ca/imoweb/marketdata/ genEnergy.asp. Accessed Sept. 202009

Izquierdo M., Lizarte R., Marcos J., Gutierrez G. (2005) Air conditioning using an aircooled single effect lithium bromide absorption chiller: Results of a trial conducted in Madrid in August 2005. Applied Thermal Engineering 28, 1074-1081

Jung S., Cagni A. (2009) Solar cooling application in Valle Susa Italy. 3rd International Conference Solar Air Conditioning Proceedings, Palermo, Italy

Kim B., Park J. (2007) Dynamic simulation of a single-effect ammonia-water absorption chiller. International Journal of Refrigeration 30, 535-545

Kim D., Ferreira I. (2008) Analytic modeling of steady state single-effect absorption cycles. International Journal of Refrigeration 31, 1012-1020 
Kohlenbach P. and Ziegler F. (2008a) A dynamic simulation model for transient absorption chiller performance. Part I: The model. International Journal of Refrigeration 31, 217-225

Kohlenbach P. and Ziegler F. (2008b) A dynamic simulation model for transient absorption chiller performance. Part II: Numerical results and experimental verification. International Journal of Refrigeration 31, 226-233

Lecuona A, Ventas R., Venegas M., Zacarı A., Salgado R. (2009) Optimum hot water temperature for absorption solar cooling. Solar Energy 83, 1806-1814

Li Z., Summathy K. (2001) Simulation of a solar absorption air conditioning system. Energy Conversion and Management 42, 313-327

Marc O., Lucas F., Sinama F., Monceyron E. (2010) Experimental investigation of a solar cooling absorption system operating without any backup system under tropical climate. Energy and Buildings 2, 774-782

Marcos J., Izquierdo M., Lizarte R., Palacios E. (2009) Performance optimization of a water-cooled single-effect $\mathrm{LiBr} /$ water low power absorption machine. 3rd International Conference Solar Air conditioning Proceedings, Palermo, Italy

Mateus T., Oliveira A. (2008) Study of solar cooling systems using absorption heat pumps, EUROSUN 2008 Conference Proceedings, Lisbon, Portugal

May S., Sayadi Z., Bellagi A. (2009) Feasibility of air-cooled solar air-conditioning in hot arid climate regions. 3rd International Conference Solar Air Conditioning Proceedings, Palermo, Italy 
Mazloumi M., Naghashzadegan M. Javaherdeh K. (2008) Simulation of solar lithium bromide-water absorption cooling system with parabolic trough collector. Energy Conversion and Management 49, 2820-2832

McQuiston F., Parker J., Spitler J., (2005) Heating, Ventilating and Air Conditioning. Wiley. ISBN 978-0-471-47015-1

Melograno P., Santiago J., Franchini G., Sparber W. (2009) Experimental analysis of a discontinuous sorption chiller operated in steady conditions. 3rd International Conference Solar Air Conditioning Proceedings, Palermo, Italy

Moffat R., (1988) Describing the Uncertainty in Experimental Results. Experimental Thermal and Fluid Science 1, 3-17

Mugnier D. (2006) Thermally driven water chillers: Market status and new developments. IEA Task 38 - Solar air conditioning and refrigeration. http://mora.free.fr/task38/pdf/matin/Mugnier.pdf. Accessed Nov. 28, 2010

National Instruments (2010) Taking Thermocouple Measurements. http://zone.ni.com/devzone/cda/tut/p/id/4237. Accessed Nov. 28, 2010

Natural Resources Canada (NRCan) (2007) Comprehensive Energy Use Database. http://oee.nrcan.gc.ca. Accessed Oct. 2, 2010.

Nunez T., Mittelbach W., Henning H. (2007) Development of an adsorption chiller and heat pump for domestic heating and air conditioning applications. Applied Thermal Engineering 27, 2205-2212

Oliveti G., Arguri N., Bruno R., De Simone M., Vulcano A. (2009) Energy performance 
of a simple effect absorption chiller with cold storage in PCM supplied by solar collectors. 3rd International Conference Solar Air Conditioning Proceedings, Palermo, Italy

Omega (2006) The Temperature Handbook: Canadian Edition Volume 2. Omega Engineering Incorportated.

Pongtornkulpanich A., Thepa S., Amornkitbamrun M., Butcher C. (2008) Experience with fully operational solar-driven 10 -ton $\mathrm{LiBr} / \mathrm{H} 2 \mathrm{O}$ single-effect absorption cooling system in Thailand. Renewable Energy 33, 943-949

Rojas J. (2009a) Flow Meter Report\# 86131-0, Flow Meter: BM10AARP2R1BVAA, Serial Number: C 86131, Brooks

Rojas J. (2009b) Flow Meter Report\# 86132-0, Flow Meter: BM40AARP2R1BVAA, Serial Number: C 86132, Brooks

Safarik M. (2007) Results of monitoring the EAW SE 15 absorption chiller in solar cooling installations. 2nd International Conference Solar Air Conditioning Proceedings, Tarragona, Spain

Vega M., Almendros-Ibanez A., Ruiz G. (2006) Performance of a LiBr-water absorption chiller operating with plate heat exchangers. Energy Conversion and Management $47,3393-3407$

Witte K., Albers J., Krause M., Safarik M., Besana F., Sparber W. Absorption chiller modelling with TRNSYS - requirements and adaptation to the machine EAW Wegracal SE 15. EUROSUN 2008 Conference Proceedings, Lisbon, Portugal 
Yazaki (2010) Water Fired Single Effect Chillers and Chiller Heaters Performance Characteristics. htto://www.yazakienergy.com/waterfiredperformance.htm. Accessed Aug. 2, 2010

Zambrano D., Bordons C., Garcia-Gabin W., Camacho E. (2008) Model development and validation of a solar cooling plant. International Journal of Refrigeration 31, 315327 


\section{Appendix A: Thermocouple Calibration Uncertainty Analysis}

This appendix contains the regression analyses that were performed to derive the relationship between thermocouple signals measured by the data acquisition system in $\mathrm{mV}$ and temperature (measured in $\Omega$ of RTD resistance) from calibration data. Also contained within this appendix is an assessment of various sources of bias that affect the regression equations relevant to thermocouples used in this research. This appendix contains supporting information to the discussion in Section 4.1. The following nomenclature is used throughout this appendix.

$\mathrm{T}_{\text {set: }} \quad$ constant temperature bath set point in ${ }^{\circ} \mathrm{C}$

emf: thermocouple signal measured by data acquisition system in $\mathrm{mV}$

emf: $\quad$ mean thermocouple signal averaged over a 2 minute logging period recorded by the data acquisition system during calibration in $\mathrm{mV}$

S emf: $\quad$ standard deviation of the thermocouple signal over the 2 minute logging period during calibration recorded in $\mathrm{mV}$

R: $\quad$ mean resistance from the platinum RTD averaged over the 2 minute logging period during calibration in $\Omega$

$S$ R: $\quad$ standard deviation of the resistance from the platinum RTD over the 2 minute logging period in $\Omega$

$\hat{\mathrm{R}}$ : $\quad$ predicted RTD resistance by best fit regression equation in $\Omega$

e: $\quad$ absolute value of difference between the platinum RTD resistance and the best fit regression equation prediction in $\Omega$

$\mathrm{T}_{\text {ref }}$ : $\quad$ mean thermocouple cold junction reference temperature measured by a thermistor averaged over the 2 minute logging period during calibration in ${ }^{\circ} \mathrm{C}$

$\mathrm{T}_{\text {ref }}^{\prime}$ : the cold junction reference temperature selected to represent the cold junction temperature of a best fit regression equation in ${ }^{\circ} \mathrm{C}$

$B_{j}: \quad$ a source of bias to the thermocouples in $\pm^{\circ} \mathrm{C}$ 
The following tables contain data that were logged during a thermocouple calibration procedure. For each temperature investigated in the following tables, data were logged every second for approximately 2 minutes. The data from each table were used to perform linear regression analyses to derive equations capable of estimating the temperature (in $\Omega$ of RTD resistance) of the submerged thermocouple junction in the condenser/absorber, evaporator and generator circuits. A separate linear regression equation was derived for each circuit since the temperature range relevant to each circuit (see Table 3.3) varied widely.

\begin{tabular}{|c|c|c|c|c|c|c|c|}
\hline $\begin{array}{l}\mathrm{T}_{\text {set }} \\
\left({ }^{\circ} \mathrm{C}\right)\end{array}$ & $\begin{array}{l}\mathrm{T}_{\mathrm{ref}} \\
\left({ }^{\circ} \mathrm{C}\right)\end{array}$ & $\begin{array}{c}e m f \\
(\mathrm{mV})\end{array}$ & $\begin{array}{l}\text { Semf } \\
(\mathrm{mV})\end{array}$ & $\mathrm{R}(\Omega)$ & $S \mathrm{R}(\Omega)$ & $\hat{\mathrm{R}}(\Omega)$ & e $(\Omega)$ \\
\hline 20 & 21.88 & -0.0717 & 0.0002 & 107.948 & 0.0002 & 107.946 & 0.0016 \\
\hline 25 & 21.88 & 0.1297 & 0.0003 & 109.919 & 0.0025 & 109.895 & 0.0238 \\
\hline 30 & 21.90 & 0.3326 & 0.0000 & 111.884 & 0.0004 & 111.859 & 0.0252 \\
\hline 32.2 & 21.93 & 0.4224 & 0.0006 & 112.747 & 0.0002 & 112.727 & 0.0202 \\
\hline \multirow[t]{2}{*}{35} & 21.91 & 0.5386 & 0.0003 & 113.849 & 0.0004 & 113.852 & 0.0025 \\
\hline & & & & & & $\operatorname{Max} e(\Omega)$ : & 0.0252 \\
\hline
\end{tabular}

Table A.1: Thermocouple calibration data relevant to the temperature range experienced in the condenser/absorber circuit

The regression equation derived from the calibration data relevant to the condenser/absorber circuit temperature range was:

$\mathrm{R} \approx \hat{\mathrm{R}}=9.676 \mathrm{emf}+108.64$

for $\mathrm{T}_{\mathrm{ref}}^{\prime}=21.9^{\circ} \mathrm{C} \pm 0.02{ }^{\circ} \mathrm{C}$ 
$T_{r e f}^{\prime}$ and its bias were selected so all the $T_{\text {ref }}$ data in the Table A.I would be contained within the range specified by $T_{r e f}^{\prime}$ and its bias. This selection of $T_{r e f}^{\prime}$ and its bias captured all $T_{\text {ref }}$ between $21.84^{\circ} \mathrm{C}$ and $22.16^{\circ} \mathrm{C}$.

Sensitivity parameter: $\frac{\partial \mathrm{R}}{\partial \mathrm{emf}} \approx \frac{\partial \hat{\mathrm{R}}}{\partial \mathrm{emf}}=9.676$

$\begin{array}{rlllllll}\begin{array}{r}\mathrm{T}_{\text {set }} \\ \left({ }^{\circ} \mathrm{C}\right)\end{array} & \begin{array}{c}\mathrm{T}_{\text {ref }} \\ \left({ }^{\circ} \mathrm{C}\right)\end{array} & \begin{array}{c}\text { emf } \\ (\mathrm{mV})\end{array} & \begin{array}{l}S \text { emf } \\ (\mathrm{mV})\end{array} & \mathrm{R}(\Omega) & S \mathrm{R}(\Omega) & \hat{\mathrm{R}}(\Omega) & \mathrm{e}(\Omega) \\ 5 & 21.85 & -0.6656 & 0.0006 & 102.012 & 0.0004 & 102.050 & 0.0381 \\ 8 & 21.90 & -0.5508 & 0.0003 & 103.201 & 0.0002 & 103.198 & 0.0033 \\ 11 & 21.93 & -0.4341 & 0.0008 & 104.388 & 0.0003 & 104.363 & 0.0255 \\ 16 & 21.96 & -0.2365 & 0.0003 & 106.370 & 0.0003 & 106.338 & 0.0319 \\ 21 & 21.97 & -0.0362 & 0.0007 & 108.343 & 0.0011 & 108.338 & 0.0049 \\ 25 & 22.01 & 0.1251 & 0.0002 & 109.920 & 0.0006 & 109.950 & 0.0301 \\ & & & & & & \text { Max } \mathrm{e}(\Omega): & 0.0381\end{array}$

Table A.2: Thermocouple calibration data relevant to the temperature range experienced in the evaporator circuit

The regression equation derived from the calibration data relevant to the evaporator circuit temperature range was:

$\mathrm{R} \approx \hat{\mathrm{R}}=9.999 \mathrm{emf}+108.7$

for $\mathrm{T}_{\text {ref }}^{\prime}=22.0^{\circ} \mathrm{C} \pm 0.16^{\circ} \mathrm{C}$

$T_{r e f}^{\prime}$ and its bias were selected so all the $T_{\text {ref }}$ data in Table A.2 would be contained within within the range specified by $T_{r e f}^{\prime}$ and its bias. This selection of $T_{r e f}^{\prime}$ and its bias captured all $T_{\text {ref }}$ between $21.84^{\circ} \mathrm{C}$ and $22.16^{\circ} \mathrm{C}$.

Sensitivity parameter: $\frac{\partial \mathrm{R}}{\partial \mathrm{emf}} \approx \frac{\partial \hat{\mathrm{R}}}{\partial \mathrm{emf}}=9.999$ 


\begin{tabular}{|c|c|c|c|c|c|c|c|}
\hline $\begin{array}{c}\mathrm{T}_{\text {set }} \\
\left({ }^{\circ} \mathrm{C}\right)\end{array}$ & $\begin{array}{l}\mathrm{T}_{\text {ref }} \\
\left({ }^{\circ} \mathrm{C}\right)\end{array}$ & $\begin{array}{c}e m f \\
(\mathrm{mV})\end{array}$ & $\begin{array}{l}\text { S emf } \\
(\mathrm{mV})\end{array}$ & $\mathrm{R}(\Omega)$ & $S \mathrm{R}(\Omega)$ & $\hat{\mathrm{R}}(\Omega)$ & $\mathrm{e}(\Omega)$ \\
\hline 70 & 22.055 & 2.0327 & 0.0005 & 127.494 & 0.0015 & 127.490 & 0.0042 \\
\hline 75 & 22.068 & 2.2538 & 0.0003 & 129.426 & 0.0002 & 129.406 & 0.0196 \\
\hline 80 & 22.083 & 2.4758 & 0.0008 & 131.351 & 0.0017 & 131.331 & 0.0204 \\
\hline \multirow[t]{2}{*}{85} & 22.101 & 2.6992 & 0.0005 & 133.271 & 0.0009 & 133.267 & 0.0044 \\
\hline & & & & & & $\operatorname{Max} e(\Omega)$ : & 0.0204 \\
\hline
\end{tabular}

Table A.3: Thermocouple calibration data relevant to the temperature range experienced in the generator circuit

The regression equation derived from the calibration data relevant to the generator circuit temperature range was:

$\mathrm{R} \approx \hat{\mathrm{R}}=8.668+109.87$

For $\mathrm{T}_{\text {ref }}=22.0^{\circ} \mathrm{C} \pm 0.16^{\circ} \mathrm{C}$

$T_{r e f}^{\prime}$ and its bias were selected so all the $T_{\text {ref }}$ data in Tables A.2 and A.3 would be contained within the range specified by $T_{r e f}^{\prime}$ and its bias. This selection of $T_{r e f}^{\prime}$ and its bias captured all $T_{\text {ref }}$ between $21.84^{\circ} \mathrm{C}$ and $22.16^{\circ} \mathrm{C}$. The data in Table A.2 were needed for cold junction compensation of thermocouples measuring temperature in the generator circuit. Cold junction compensation is discussed in Appendix B. The data in Tables A.2 and A.3 were collected from thermocouples cut from the same strand of wire while the data in Table A.1 was collected from a thermocouple of a different strand of wire.

Sensitivity parameter: $\frac{\partial \mathrm{R}}{\partial \mathrm{emf}} \approx \frac{\partial \hat{\mathrm{R}}}{\partial \mathrm{emf}} \approx 8.668$

The preceding regression analysis from calibration data were affected by four sources of bias. The first source of bias accounted for the fact the regression equations 
did not make perfect predictions. The maximum difference between a predicted result from a regression equation and a known value from calibration was listed at the bottom of the preceding tables. These values needed to be converted from $\Omega$ to ${ }^{\circ} \mathrm{C}$. The conversion was accomplished by multiplying each $\max \mathrm{e}(\Omega)$ listed at the bottom of Tables A.1 to A.3 by 2.55, the sensitivity parameter derived in Appendix C. This source of bias is listed as the regression equation prediction error in Table A.5.

A second source of bias occurred because of the slight variation of $T_{\text {ref }}$ during calibration. This source of bias is listed as the reference junction bias in Table A.5.

A third source of bias occurred because the RTD which measured temperature (in $\Omega$ of RTD resistance) had a bias $\pm 0.02{ }^{\circ} \mathrm{C}$ which was given by the manufacturer. This source of bias is listed as the RTD bias in Table A.5.

A fourth source of bias occurred because the data acquisition system reading had uncertainty. The manufacturer gave this source of bias as $\pm 0.008 \mathrm{mV}$. This bias had to be converted to ${ }^{\circ} \mathrm{C}$ from $\mathrm{mV}$. The unit conversion was accomplished by multiplying the bias in $\mathrm{mV}$ by the sensitivity parameters derived in this appendix and Appendix $\mathrm{C}$. The unit conversion procedure has been summarized in Table 4.5 but is repeated in Table A.4. The bias in ${ }^{\circ} \mathrm{C}$ is displayed in the rightmost column. This bias is what is listed as the data acquisition system read error bias source in Table A.5. 


\begin{tabular}{|l|l|l|l|l|}
\hline $\begin{array}{l}\text { Thermocouple } \\
\text { Location }\end{array}$ & $\begin{array}{c}\frac{\partial \mathrm{R}}{\partial \mathrm{emf}} \\
(\Omega / \mathrm{mV})\end{array}$ & $\begin{array}{c}\frac{\partial \mathrm{T}}{\partial \mathrm{R}} \\
\left({ }^{\circ} \mathrm{C} / \Omega\right)\end{array}$ & $\begin{array}{c}\frac{\partial \mathrm{T}}{\partial \mathrm{emf}} \\
\left({ }^{\circ} \mathrm{C} / \mathrm{mV}\right)\end{array}$ & $\begin{array}{c}B_{J} \\
\left( \pm{ }^{\circ} \mathrm{C}\right)\end{array}$ \\
\hline Generator & 8.668 & 2.55 & 22.10 & 0.18 \\
\hline Condenser/Absorber & 9.676 & 2.55 & 24.67 & 0.20 \\
\hline Evaporator & 9.999 & 2.55 & 25.50 & 0.20 \\
\hline
\end{tabular}

Table A.4: Data acquisition system read error bias unit conversion summary

A summary of the bias sources which affected the regression equations derived in this appendix appears in Table A.5 for the thermocouples used in the various circuits of the absorption chiller test facility. The total listed at the bottom of Table A.5 is the total bias associated with the regression equations derived from calibration. The total listed at the bottom of Table A.5 was assigned as the regression equation bias source in Table 4.6.

\begin{tabular}{|c|c|c|c|}
\hline Bias Source & \multicolumn{3}{|c|}{ Thermocouple Location } \\
\hline & $\begin{array}{c}\text { Condenser/Absorber } \\
\text { Circuit } B_{J}\left( \pm^{\circ} \mathrm{C}\right)\end{array}$ & $\begin{array}{c}\text { Evaporator Circuit } \\
B_{J}\left( \pm^{\circ} \mathrm{C}\right)\end{array}$ & $\begin{array}{c}\text { Generator Circuit } \\
B_{J}\left( \pm^{\circ} \mathrm{C}\right)\end{array}$ \\
\hline $\begin{array}{c}\text { Regression Equation } \\
\text { Prediction Error }\end{array}$ & 0.06 & 0.10 & 0.05 \\
\hline $\begin{array}{c}\text { Reference Junction } \\
\text { Bias }\end{array}$ & 0.02 & 0.16 & 0.16 \\
\hline Read Error & 0.20 & 0.20 & 0.18 \\
\hline RTD Bias & 0.02 & 0.02 & 0.02 \\
\hline Total $=\sqrt{\sum_{J} B_{J}^{2}}$ & 0.21 & 0.28 & 0.25 \\
\hline
\end{tabular}

Table A.5: Regression equation bias source summary 


\section{Appendix B: Thermocouple Cold Junction Compensation Analysis}

In this appendix the method of cold junction compensation used in this research is described. An assessment of the bias sources affecting the thermocouples used in this research due to cold junction compensation is also presented. This appendix contains supporting information to the discussion in Section 4.1. The following nomenclature is used throughout this appendix.

emf: thermocouple signal measured by the data acquisition system in $\mathrm{mV}$

emf $_{\text {meas: }}$ thermocouple signal measured by the data acquisition system during experiments in $\mathrm{mV}$

$\mathrm{T}: \quad$ temperature of the measuring junction of the thermocouple ${ }^{\circ} \mathrm{C}$

$\mathrm{T}_{2}$ : temperature of the cold junction of the thermocouple in ${ }^{\circ} \mathrm{C}$

$\mathrm{T}_{\text {ref }} \quad$ a constant cold junction reference temperature measured during calibration in ${ }^{\circ} \mathrm{C}$

$B_{J} \quad$ elemental bias source of thermocouple

Material A

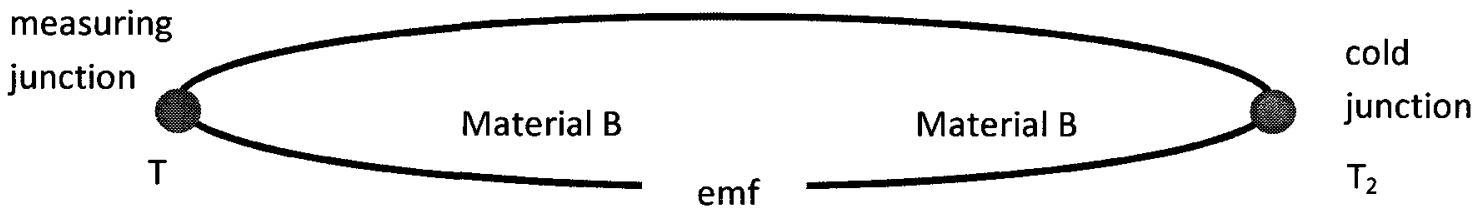

Figure B.1: Thermocouple construction

A thermocouple is a temperature sensor whose construction is illustrated in the preceding figure. The thermocouple is based on thermoelectric phenomena that are caused by junctions between dissimilar metals (material A and B). For the thermocouple illustrated in the preceding diagram, an emf is produced whenever there is a difference in 
temperature between the measuring and cold junctions. The emf is what was logged by the data acquisition system used in this research. The emf, in general, is a function of measuring junction temperature, $T$, only for a constant cold junction temperature $T_{2}=$ $T_{\text {ref. }}$

$$
\text { emf }=f(\mathrm{~T}) \text { for a constant } \mathrm{T}_{2}=\mathrm{T}_{\text {ref }}
$$

Regression equations derived from a calibration procedure were used to approximate the function relating emf to $T$ for an approximately constant $T_{2}=T_{\text {ref }}$ in Appendix A. The cold junction temperatures $T_{2}$ measured during experiments were, in general, different than the constant cold junction temperatures of the calibration procedure $T_{\text {ref. }}$ To account for the fact that $T_{2}$ measured during experiments may have been different than $T_{\text {ref }}$, a technique known as cold junction compensation was employed. National Instruments (2010) gave the following formula for cold junction compensation:

$$
\operatorname{emf}(\mathrm{T})=\mathrm{emf}_{\text {meas }}+\operatorname{emf}\left(\mathrm{T}_{2}\right)
$$

In the preceding formula $\mathrm{emf}_{\text {meas }}$ is what was logged by the data acquisition system during experiments. The term $\operatorname{emf}\left(\mathrm{T}_{2}\right)$ is the emf that would be generated by a thermocouple with measuring junction temperature equal to $T_{2}$ and cold junction temperature equal to $T_{\text {ref. }}$ The value of $\operatorname{emf}\left(T_{2}\right)$ was estimated by measuring $T_{2}$ with a thermistor and then calculating $\operatorname{emf}\left(\mathrm{T}_{2}\right)$ by using the regression equations derived in Appendices $\mathrm{A}$ and $\mathrm{C}$. The values for $\operatorname{emf}\left(\mathrm{T}_{2}\right)$ and $\mathrm{emf}_{\text {meas }}$ were added together to calculate $\operatorname{emf}(\mathrm{T})$. The value for $\operatorname{emf}(\mathrm{T})$ could then be used to calculate $\mathrm{T}$ with the regression equations derived in Appendices A and C. 
This method of cold junction compensation introduced bias to the thermocouples. The thermistor used to measure cold junction temperature had a measurement bias of $\pm 0.25{ }^{\circ} \mathrm{C}$. This is listed as the thermistor bias source in Table B.1. The thermistor also was not located directly on the cold junctions. A bias of $\pm 0.20^{\circ} \mathrm{C}$ accounted for the fact the thermistor was not located directly on the cold junction in the data acquisition system. This is termed the thermistor location bias source and is listed in Table B.1. These sources of bias were given by the manufacturer of the data acquisition system, National Instruments.

The regression equations derived in Appendix A used to calculate emf $\left(T_{2}\right)$ also introduced bias to the cold junction compensation method. Bias associated with the use of regression equations for the thermocouples used in the evaporator, generator and condenser/absorber circuits was assessed in Appendix A. This is listed as the regression equation source of bias in Table B.1. A summary of the various bias sources affecting the cold junction compensation method used in this research is contained in the following table. The various sources of bias are combined into a total cold junction compensation method bias. The total listed at the bottom of the following table was assigned as the cold junction bias source in Table 4.6.

\begin{tabular}{|c|c|c|c|}
\hline Bias Source & \multicolumn{3}{|c|}{ Thermocouple Location } \\
\hline & $\begin{array}{c}\text { Condenser/Absorber } \\
\text { Circuit } B_{J}\left( \pm^{\circ} \mathrm{C}\right)\end{array}$ & $\begin{array}{c}\text { Evaporator Circuit } \\
B_{J}\left( \pm^{\circ} \mathrm{C}\right)\end{array}$ & $\begin{array}{c}\text { Generator Circuit } \\
B_{l}\left( \pm^{\circ} \mathrm{C}\right)\end{array}$ \\
\hline Regression Equation & 0.21 & 0.28 & 0.25 \\
\hline Thermistor & 0.25 & 0.25 & 0.25 \\
\hline Thermistor Location & 0.20 & 0.20 & 0.20 \\
\hline Total $=\sqrt{\sum_{J} B_{J}^{2}}$ & 0.38 & 0.42 & 0.41 \\
\hline
\end{tabular}

Table B.1: Thermocouple cold junction bias source summary 


\section{Appendix C: Platinum RTD Uncertainty Analysis}

This appendix contains calibration data and a regression analysis for both RTDs used in this research. The calibration data for both RTDs were given by the manufacturer. The data given in this appendix complements the discussions in Sections 4.1 and 4.2. The following nomenclature is used throughout this appendix.

R: $\quad$ RTD resistance given by manufacturer's calibration data in $\Omega$

T: $\quad$ temperature which corresponds to a resistance given by the RTD manufacturer's calibration data in ${ }^{\circ} \mathrm{C}$

$\hat{\mathrm{T}}: \quad$ temperature predicted by interpolating curve of best fit in ${ }^{\circ} \mathrm{C}$

e: $\quad$ absolute value of difference between known temperature from manufacturer's calibration data and curve of best fit prediction in ${ }^{\circ} \mathrm{C}$

The following table is applicable to the RTD which was used to measure the thermopile cold junction temperature during thermopile calibration discussed in Section 4.2 and Appendix D. This RTD was used during thermocouple calibration discussed in Section 4.1 and in Appendix A. The table contains the calibration data given by the RTD manufacturer in the first two columns. The prediction of the interpolating curve of best fit is tabulated in the third column. The predicted value and known value from calibration are compared in the final column. 


$\begin{array}{rrrr}\mathrm{R}(\Omega) & \mathrm{T}\left({ }^{\circ} \mathrm{C}\right) & \hat{\mathrm{T}}\left({ }^{\circ} \mathrm{C}\right) & \mathrm{e}\left({ }^{\circ} \mathrm{C}\right) \\ 102.3674 & 6 & 6.0024 & 0.00241 \\ 103.9574 & 10 & 10.0017 & 0.00177 \\ 107.9238 & 20 & 20.0006 & 0.00060 \\ 111.878 & 30 & 29.9999 & 0.00001 \\ 115.8202 & 40 & 40.0001 & 0.00016 \\ 119.7503 & 50 & 50.0005 & 0.00057 \\ 123.6683 & 60 & 60.0009 & 0.00095 \\ 127.5743 & 70 & 70.0012 & 0.00126 \\ 131.4684 & 80 & 80.0014 & 0.00147 \\ 135.3504 & 90 & 90.0008 & 0.00080 \\ & & \mathrm{Max}\left({ }^{\circ} \mathrm{C}\right) & 0.00241\end{array}$

Regression equation: $\mathrm{T} \approx \hat{\mathrm{T}}=0.001 \mathrm{R}^{2}+2.309 \mathrm{R}-240.843$

Sensitivity parameter: $\frac{\partial \mathrm{T}}{\partial \mathrm{R}} \approx \frac{\partial \hat{\mathrm{T}}}{\partial \mathrm{R}} \approx 2.55$

** the regression equation was highly linear in the region of interest

The maximum error caused by the preceding regression equation was small compared to other bias sources to temperature sensors in this research. Consequently, this error was neglected as a source of bias to temperature sensors used in this research.

The following table is applicable to the RTD which was used to measure the thermopile warm junction temperature during thermopile calibration discussed in Section 4.2 and Appendix D. The table contains the calibration data given by the RTD manufacturer in the first two columns. The prediction of the interpolating curve of best fit is tabulated in the third column. The predicted value and known value from calibration are compared in the final column. 


$\begin{array}{rrrr}\mathrm{R}(\Omega) & \mathrm{T}\left({ }^{\circ} \mathrm{C}\right) & \hat{\mathrm{T}}\left({ }^{\circ} \mathrm{C}\right) & \mathrm{e}\left({ }^{\circ} \mathrm{C}\right) \\ 102.3737 & 6 & 5.9983 & 0.00175 \\ 103.9638 & 10 & 9.9978 & 0.00211 \\ 107.9307 & 20 & 19.9980 & 0.00198 \\ 111.8854 & 30 & 29.9987 & 0.00127 \\ 115.8281 & 40 & 40.0002 & 0.00023 \\ 119.7587 & 50 & 50.0019 & 0.00198 \\ 123.6773 & 60 & 60.0039 & 0.00396 \\ 127.5838 & 70 & 70.0056 & 0.00562 \\ 131.4784 & 80 & 80.0072 & 0.00719 \\ 135.3611 & 90 & 90.0084 & 0.00840 \\ & & \mathrm{Max}\left({ }^{\circ} \mathrm{C}\right) & 0.00840\end{array}$

Interpolating curve of best fit: $\mathrm{T} \approx \hat{\mathrm{T}}=0.001 \mathrm{R}^{2}+2.309 \mathrm{R}-240.863$

Sensitivity parameter: $\frac{\partial \mathrm{T}}{\partial \mathrm{R}} \approx \frac{\partial \hat{\mathrm{T}}}{\partial \mathrm{R}} \approx 2.55$

** the interpolating curve was highly linear in the region of interest.

The maximum error caused by the preceding regression equation was small compared to other bias sources to temperature sensors in this research. Consequently, this error is neglected as a source of bias to temperature sensors used in this research. 


\section{Appendix D: Thermopile Calibration}

This appendix contains all of the data gathered during thermopile calibration summarized in a table. The data contained in this appendix is relevant to the discussion in Section 4.2. The following nomenclature is used throughout this appendix.

T: $\quad$ constant temperature bath set point in ${ }^{\circ} \mathrm{C}$

EMF : mean signal from thermocouple over the 5 minute logging period in $\mathrm{mV}$

$S$ EMF : $\quad$ standard deviation of the signal from thermocouple over the 5 minute logging period in $\mathrm{mV}$

R: $\quad$ mean resistance from the platinum RTD over the 5 minute logging period in $\Omega$

S R: $\quad$ standard deviation of the resistance from the platinum RTD over the 5 minute logging period in $\Omega$

Subscripts

1: warm constant temperature bath

2: $\quad$ cold constant temperature bath

$\begin{array}{llllllll}\mathrm{T}_{2}\left({ }^{\circ} \mathrm{C}\right) & \mathrm{T}_{1}\left({ }^{\circ} \mathrm{C}\right) & \begin{array}{l}\mathrm{EMF} \\ (\mathrm{mV})\end{array} & \begin{array}{l}S \mathrm{EMF} \\ (\mathrm{mV})\end{array} & \begin{array}{l}\mathrm{R}_{2} \\ (\Omega)\end{array} & \begin{array}{l}S \mathrm{R}_{2} \\ (\Omega)\end{array} & \begin{array}{l}\mathrm{R}_{1} \\ (\Omega)\end{array} & \begin{array}{l}S \mathrm{R}_{1} \\ (\Omega)\end{array} \\ 3 & 3 & 0.0099 & 0.0012 & 101.221 & 0.0002 & 101.216 & 0.0002 \\ 3 & 5 & 0.3976 & 0.0011 & 101.221 & 0.0006 & 102.009 & 0.0010 \\ 3 & 7 & 0.7864 & 0.0011 & 101.224 & 0.0003 & 102.804 & 0.0030 \\ 7 & 10 & 1.3739 & 0.0023 & 101.223 & 0.0003 & 103.992 & 0.0064 \\ 7 & 7 & 0.0068 & 0.0013 & 102.812 & 0.0003 & 102.817 & 0.0005 \\ 7 & 8 & 0.2013 & 0.0012 & 102.812 & 0.0004 & 103.212 & 0.0002 \\ 7 & 9 & 0.3972 & 0.0013 & 102.812 & 0.0002 & 103.608 & 0.0003 \\ 7 & 10 & 0.5936 & 0.0013 & 102.812 & 0.0002 & 104.003 & 0.0003 \\ 7 & 11 & 0.7912 & 0.0013 & 102.812 & 0.0005 & 104.402 & 0.0005 \\ 8 & 13 & 1.1871 & 0.0013 & 102.812 & 0.0003 & 105.194 & 0.0005 \\ 8 & 8 & 0.0008 & 0.0025 & 103.208 & 0.0002 & 103.213 & 0.0004 \\ 8 & 10 & 0.3897 & 0.0021 & 103.208 & 0.0002 & 104.005 & 0.0007 \\ & 12 & 0.7753 & 0.0021 & 103.209 & 0.0005 & 104.794 & 0.0005\end{array}$




\begin{tabular}{|c|c|c|c|c|c|c|c|}
\hline $\mathrm{T}_{2}\left({ }^{\circ} \mathrm{C}\right)$ & $\mathrm{T}_{1}\left({ }^{\circ} \mathrm{C}\right)$ & $\begin{array}{l}\text { EMF } \\
(\mathrm{mV})\end{array}$ & $\begin{array}{l}S \text { EMF } \\
(\mathrm{mV})\end{array}$ & $\begin{array}{l}\mathrm{R}_{2} \\
(\Omega)\end{array}$ & $\begin{array}{l}S \mathrm{R}_{2} \\
(\Omega)\end{array}$ & $\begin{array}{l}\mathrm{R}_{1} \\
(\Omega)\end{array}$ & $\begin{array}{l}S \mathrm{R}_{1} \\
(\Omega)\end{array}$ \\
\hline 8 & 14 & 1.1881 & 0.0014 & 103.207 & 0.0003 & 105.586 & 0.0011 \\
\hline 8 & 16 & 1.5865 & 0.0014 & 103.208 & 0.0002 & 106.378 & 0.0004 \\
\hline 9 & 9 & 0.0007 & 0.0027 & 103.604 & 0.0006 & 103.610 & 0.0004 \\
\hline 9 & 11 & 0.3929 & 0.0021 & 103.604 & 0.0005 & 104.400 & 0.0006 \\
\hline 9 & 13 & 0.7885 & 0.0022 & 103.603 & 0.0002 & 105.194 & 0.0004 \\
\hline 9 & 15 & 1.1710 & 0.0021 & 103.602 & 0.0011 & 105.984 & 0.0002 \\
\hline 10 & 10 & 0.0020 & 0.0013 & 103.998 & 0.0007 & 104.002 & 0.0017 \\
\hline 10 & 12 & 0.3930 & 0.0011 & 103.998 & 0.0002 & 104.793 & 0.0004 \\
\hline 10 & 14 & 0.7888 & 0.0011 & 103.998 & 0.0004 & 105.587 & 0.0004 \\
\hline 10 & 16 & 1.1838 & 0.0012 & 103.998 & 0.0004 & 106.378 & 0.0002 \\
\hline 11 & 11 & 0.0004 & 0.0013 & 104.395 & 0.0019 & 104.399 & 0.0014 \\
\hline 11 & 15 & 0.7754 & 0.0024 & 104.394 & 0.0005 & 105.981 & 0.0007 \\
\hline 11 & 18 & 1.3805 & 0.0017 & 104.394 & 0.0002 & 107.167 & 0.0003 \\
\hline 12 & 12 & 0.0076 & 0.0012 & 104.787 & 0.0002 & 104.801 & 0.0003 \\
\hline 13 & 13 & 0.0021 & 0.0010 & 105.184 & 0.0002 & 105.193 & 0.0003 \\
\hline 13 & 17 & 0.7955 & 0.0012 & 105.185 & 0.0002 & 106.774 & 0.0002 \\
\hline 13 & 20 & 1.3951 & 0.0009 & 105.185 & 0.0004 & 107.958 & 0.0002 \\
\hline 15 & 15 & 0.0014 & 0.0017 & 105.976 & 0.0004 & 105.978 & 0.0030 \\
\hline 15 & 18 & 0.6022 & 0.0011 & 105.974 & 0.0003 & 107.167 & 0.0007 \\
\hline 15 & 21 & 1.2046 & 0.0008 & 105.974 & 0.0002 & 108.351 & 0.0003 \\
\hline 17 & 17 & 0.0019 & 0.0016 & 106.763 & 0.0006 & 106.772 & 0.0002 \\
\hline 17 & 21 & 0.8018 & 0.0013 & 106.763 & 0.0001 & 108.351 & 0.0002 \\
\hline 17 & 24 & 1.4053 & 0.0011 & 106.763 & 0.0007 & 109.533 & 0.0014 \\
\hline 18 & 19 & 0.2073 & 0.0009 & 107.144 & 0.0004 & 107.535 & 0.0009 \\
\hline 18 & 20 & 0.4080 & 0.0010 & 107.141 & 0.0004 & 107.928 & 0.0005 \\
\hline 18 & 21 & 0.6074 & 0.0007 & 107.135 & 0.0004 & 108.314 & 0.0005 \\
\hline 20 & 20 & 0.0025 & 0.0010 & 107.947 & 0.0004 & 107.951 & 0.0018 \\
\hline 20 & 24 & 0.8110 & 0.0017 & 107.948 & 0.0019 & 109.534 & 0.0003 \\
\hline 20 & 27 & 1.4113 & 0.0012 & 107.948 & 0.0004 & 110.710 & 0.0003 \\
\hline 69 & 69 & 0.0162 & 0.0027 & 127.088 & 0.0011 & 127.127 & 0.0013 \\
\hline 69 & 72 & 0.678 & 0.0036 & 127.081 & 0.003 & 128.288 & 0.0008 \\
\hline 69 & 75 & 1.3227 & 0.0054 & 127.085 & 0.0019 & 129.445 & 0.0007 \\
\hline 69 & 79 & 2.221 & 0.004 & 127.079 & 0.0019 & 130.987 & 0.0006 \\
\hline 71 & 74 & 0.6803 & 0.0037 & 127.840 & 0.0016 & 129.002 & 0.0011 \\
\hline 71 & 77 & 1.3384 & 0.0035 & 127.836 & 0.0042 & 130.164 & 0.0007 \\
\hline 71 & 81 & 2.2148 & 0.0052 & 127.834 & 0.0014 & 131.702 & 0.0021 \\
\hline 73 & 73 & 0.0212 & 0.0031 & 128.64 & 0.0053 & 128.663 & 0.0001 \\
\hline 73 & 76 & 0.6703 & 0.0034 & 128.647 & 0.0037 & 129.82 & 0.0009 \\
\hline 73 & 79 & 1.332 & 0.0026 & 128.634 & 0.0026 & 130.976 & 0.0009 \\
\hline 73 & 83 & 2.2032 & 0.0058 & 128.629 & 0.0018 & 132.51 & 0.0014 \\
\hline
\end{tabular}




$\begin{array}{llllllll}\mathrm{T}_{2}\left({ }^{\circ} \mathrm{C}\right) & \mathrm{T}_{1}\left({ }^{\circ} \mathrm{C}\right) & \begin{array}{l}\mathrm{EMF} \\ (\mathrm{mV})\end{array} & \begin{array}{l}S \mathrm{EMF} \\ (\mathrm{mV})\end{array} & \begin{array}{l}\mathrm{R}_{2} \\ (\Omega)\end{array} & \begin{array}{l}S \mathrm{R}_{2} \\ (\Omega)\end{array} & \begin{array}{l}\mathrm{R}_{1} \\ (\Omega)\end{array} & \begin{array}{l}S \mathrm{R}_{1} \\ (\Omega)\end{array} \\ 75 & 75 & 0.0409 & 0.0026 & 129.407 & 0.0048 & 129.438 & 0.0005 \\ 75 & 78 & 0.6764 & 0.0026 & 129.417 & 0.0009 & 130.591 & 0.0009 \\ 77 & 81 & 1.3419 & 0.0024 & 129.417 & 0.0019 & 131.74 & 0.0014 \\ 77 & 80 & 0.0189 & 0.0029 & 130.158 & 0.0025 & 130.197 & 0.0012 \\ 77 & 83 & 1.3544 & 0.0029 & 130.159 & 0.0018 & 131.355 & 0.0013 \\ 77 & 87 & 2.2531 & 0.0043 & 130.156 & 0.0019 & 132.5 & 0.0012 \\ 79 & 79 & 0.0089 & 0.003 & 130.16 & 0.0033 & 134.045 & 0.0015 \\ 79 & 82 & 0.6896 & 0.0032 & 130.978 & 0.0022 & 132.176 & 0.0024 \\ 79 & 85 & 1.354 & 0.0042 & 130.975 & 0.0033 & 133.308 & 0.0024 \\ 79 & 89 & 2.2479 & 0.005 & 130.979 & 0.0042 & 134.843 & 0.0043 \\ 81 & 81 & 0.0147 & 0.0041 & 131.745 & 0.0039 & 131.776 & 0.0026 \\ 81 & 84 & 0.6899 & 0.0058 & 131.744 & 0.0032 & 132.93 & 0.0058 \\ 81 & 87 & 1.3557 & 0.0058 & 131.744 & 1.7156 & 134.081 & 0.0018 \\ 81 & 91 & 2.2589 & 0.0053 & 131.74 & 0.0017 & 135.6 & 0.0025 \\ 83 & 83 & 0.0208 & 0.0046 & 132.505 & 0.0005 & 132.542 & 0.0028 \\ 83 & 86 & 0.6889 & 0.0047 & 132.509 & 0.002 & 133.695 & 0.0038 \\ 83 & 89 & 1.3636 & 0.0034 & 132.51 & 0.0047 & 134.833 & 0.0022 \\ 83 & 93 & 2.2814 & 0.0031 & 132.493 & 0.004 & 136.364 & 0.0021 \\ 85 & 85 & 0.0064 & 0.0042 & 133.261 & 0.0037 & 133.272 & 0.001 \\ 85 & 88 & 0.6775 & 0.0038 & 133.273 & 0.0031 & 134.42 & 0.0005 \\ 85 & 91 & 1.3672 & 0.0043 & 133.245 & 0.0047 & 135.563 & 0.0018 \\ 85 & 95 & 2.2809 & 0.0049 & 133.25 & 0.004 & 137.102 & 0.0028 \\ 87 & 87 & 0.0049 & 0.0041 & 134.037 & 0.0038 & 134.038 & 0.0022 \\ 87 & 90 & 0.6765 & 0.005 & 134.146 & 0.0048 & 135.185 & 0.0008 \\ 87 & 93 & 1.3593 & 0.0039 & 134.04 & 0.0051 & 136.332 & 0.002 \\ 87 & 97 & 2.2743 & 0.0052 & 134.032 & 0.0031 & 137.863 & 0.0025\end{array}$




\section{Appendix E: Thermopile Conversion from $\mathrm{mV}$ to ${ }^{\circ} \mathrm{C}$ Matlab Syntax}

This appendix contains Matlab syntax for a function which was used to interpolate between regression equations derived from thermopile calibration. The function syntax below is relevant to the discussion in Section 4.2.

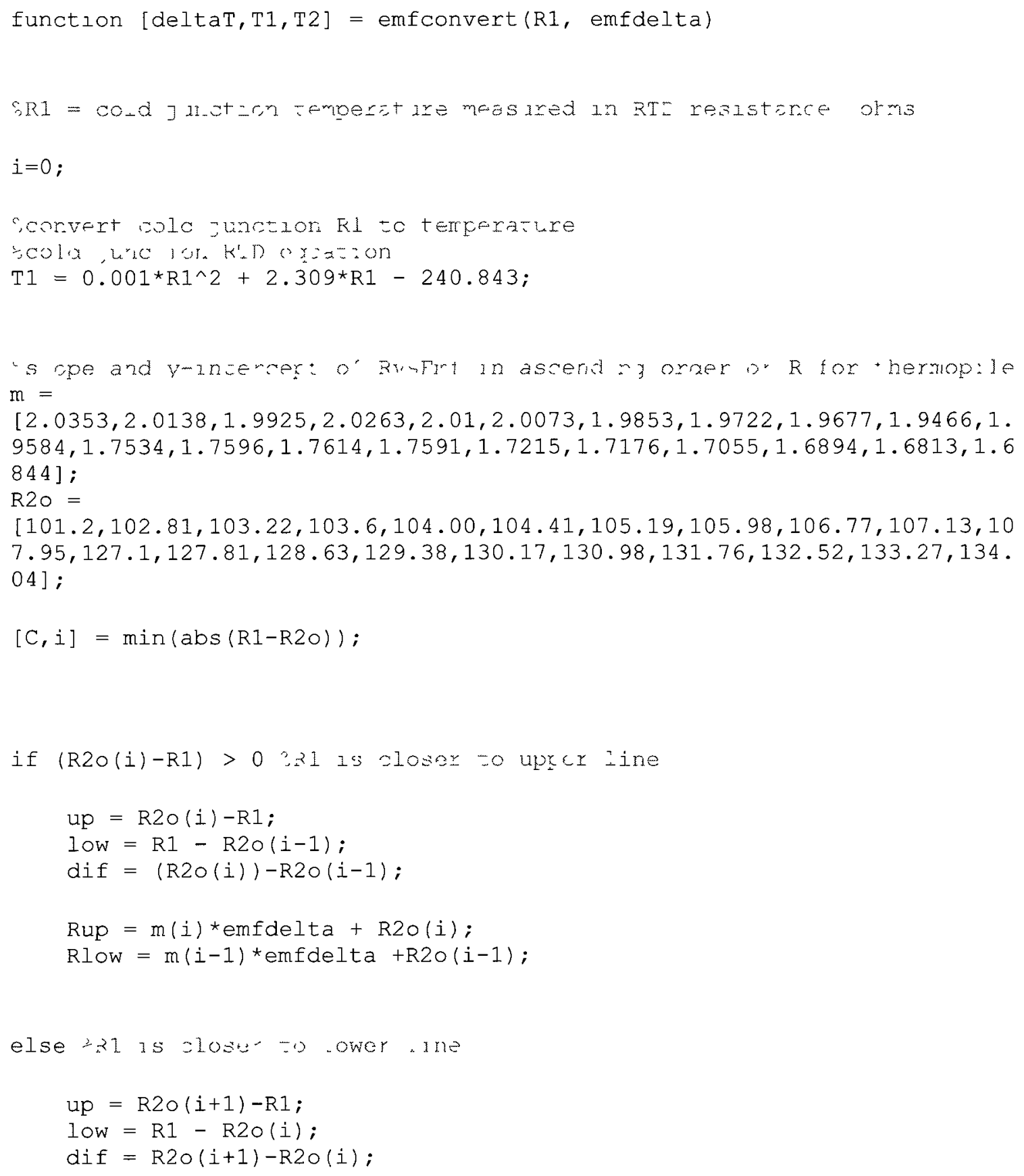


Rup $=m(i+1) *$ emfdelta $+R 20(i+1)$;

Rlow $=m(i) *$ emfdelta + R2o(i);

end

R2 $=\left(\right.$ Rup $^{\star}$ low/dif + Rlow $^{\star} u p /$ dif $) ;$

Swam ذlinction Rir cyudzon

$\mathrm{T} 2=0.001 * \mathrm{R} 2 \wedge 2+2.309 * \mathrm{R} 2-240.863$;

deltaT $=\mathrm{T} 2-\mathrm{T} 1$;

end 


\section{Appendix F: Uncertainty Margin Calculation Matlab Syntax}

This appendix contains Matlab syntax for a function which was used to calculate 95\% uncertainty margins on all average measured values during absorption chiller performance experiments and the quantities derived from them. This function reads average experimental measurements and precision errors and calculates the overall $95 \%$ uncertainty margins average quantities. The function syntax below is relevant to the discussion in Section 4.3.

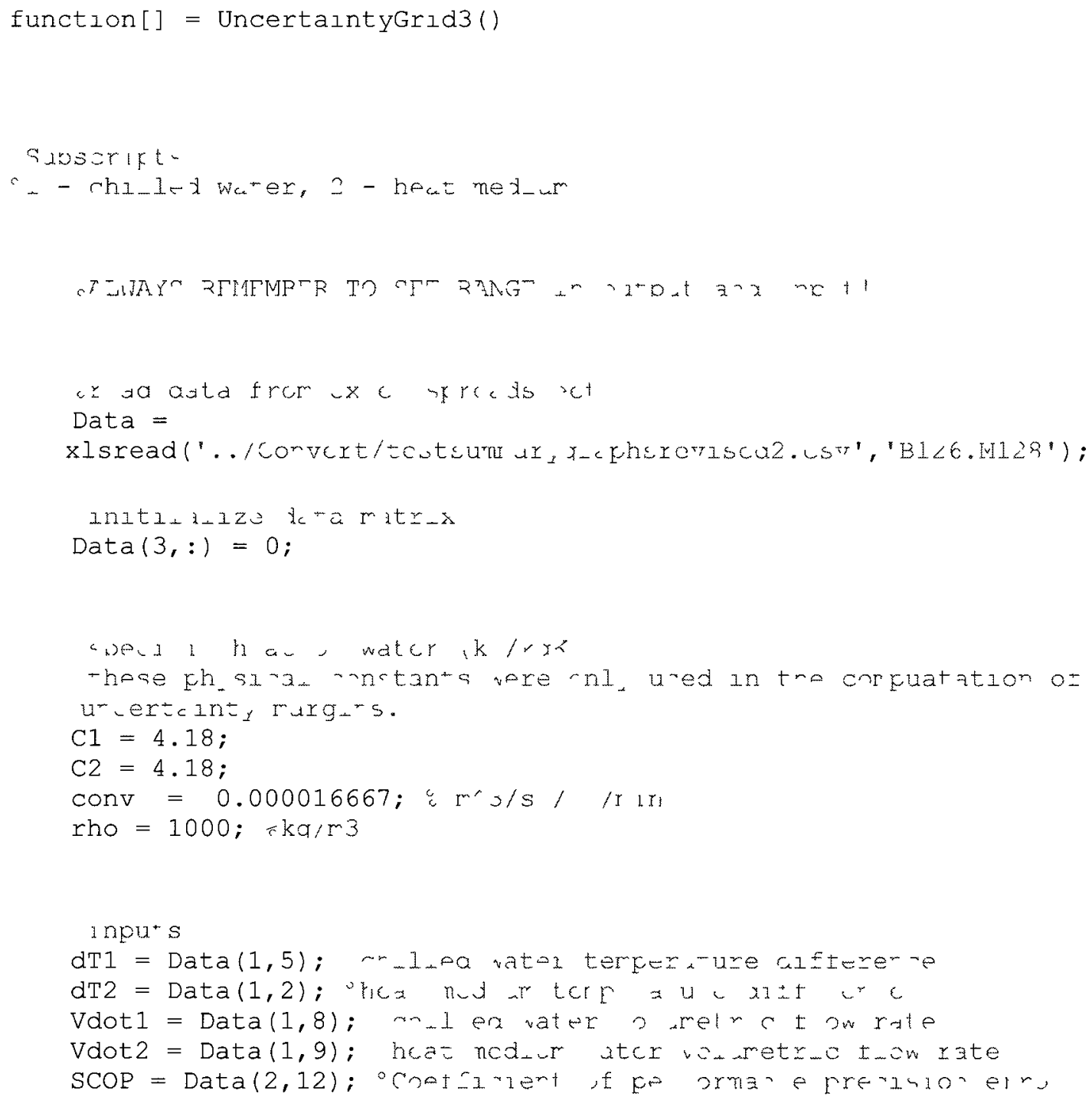




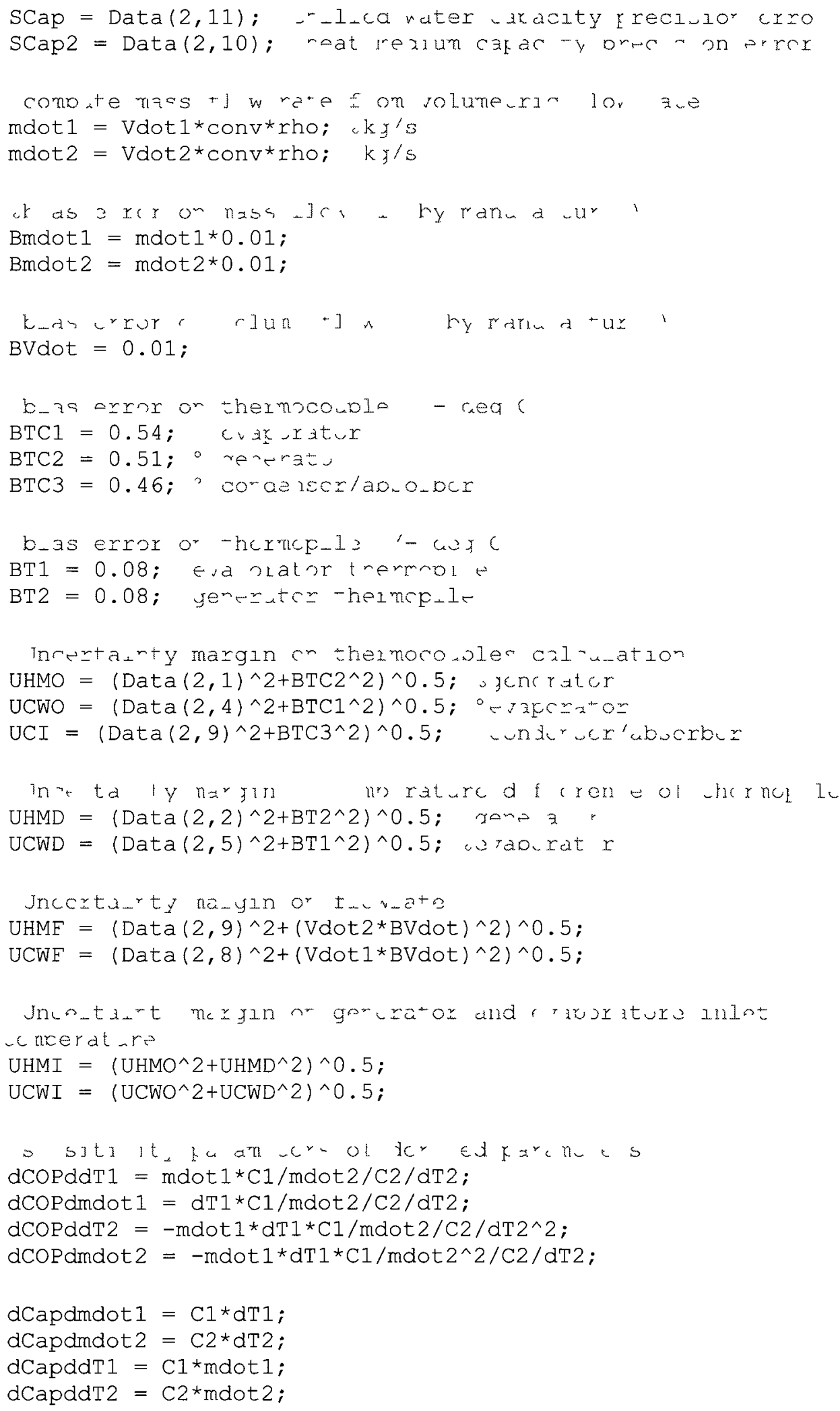




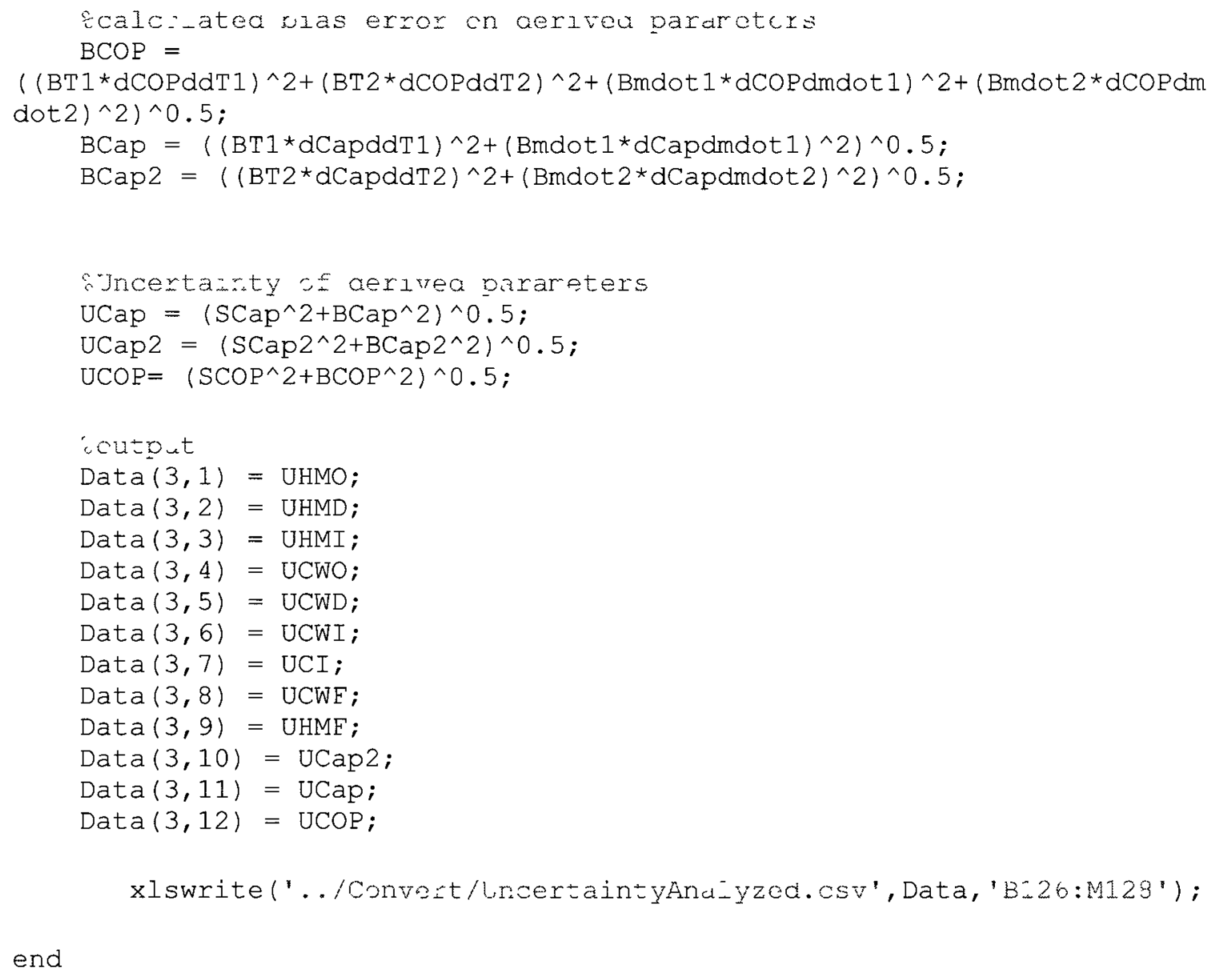




\section{Appendix G: Absorption Chiller Performance Data}

The data in the following table is a summary of the data gathered from the experiments of the absorption chiller test facility. The data is presented along with the uncertainty margins. The abbreviations used in the following table are:

$\bar{x}$ : average value

$\bar{U}_{95}: 95 \%$ uncertainty margin

$\bar{S}$ : precision error of average value

E: evaporator

C: condenser/absorber

G: generator

$B$ : bias error

$\dot{q}:$ heat transfer rate in $\mathrm{kW}$

COP: coefficient of performance

Test \#: experiment number

$\Delta$ : temperature difference in ${ }^{\circ} \mathrm{C}$

Temp: temperature in ${ }^{\circ} \mathrm{C}$ 


\begin{tabular}{|c|c|c|c|c|c|c|c|c|c|c|c|c|}
\hline о̊̀) & & $\mid \begin{array}{l}0 \\
0 \\
0\end{array}$ & ڤ్ & $\mid \begin{array}{l}\infty \\
0 \\
0 \\
0 \\
0\end{array}$ & & 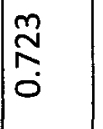 & $\mid \begin{array}{l}\infty \\
0 \\
0 \\
0 \\
0\end{array}$ & 文 & & $\begin{array}{l}\text { 苔 } \\
\text { o. }\end{array}$ & 㝵 & 晜 \\
\hline 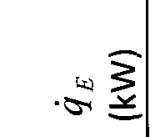 & & 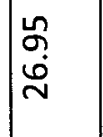 & 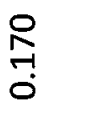 & 苞 & & \begin{tabular}{l}
$\stackrel{8}{9}$ \\
\multirow{2}{*}{}
\end{tabular} & 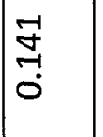 & 雚 & & 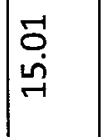 & Z̃ & 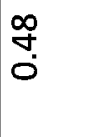 \\
\hline .0 & & 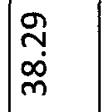 & $\begin{array}{l}\text { Z̃ } \\
0\end{array}$ & ़ְ & & $\begin{array}{l}0 \\
0 \\
\infty \\
\infty \\
m\end{array}$ & 焉 & : & & $\begin{array}{l}\mathscr{g} \\
\text { ลे }\end{array}$ & 齐 & กุ \\
\hline 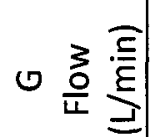 & & 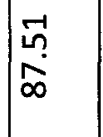 & 룽. & $\mid \begin{array}{c}\infty \\
\infty \\
0 \\
0\end{array}$ & & 垈 & gi & 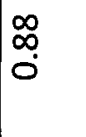 & & 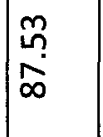 & $\begin{array}{l}\hat{\theta} \\
0 \\
0\end{array}$ & 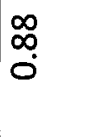 \\
\hline w $\frac{z}{\frac{z}{4}} \frac{\overline{\underline{\varepsilon}}}{\underline{\underline{\xi}}}$ & & $\mid \begin{array}{l}2 \\
\infty \\
\infty \\
0\end{array}$ & 号 & 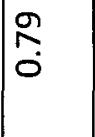 & & $\begin{array}{l}8 \\
\substack{8 \\
\infty}\end{array}$ & 吕 & î & & 亗 & 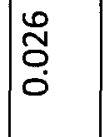 & 每 \\
\hline 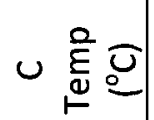 & & 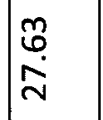 & $\begin{array}{l}\infty \\
\\
0\end{array}$ & I̊ & & 总 & 号 & \&̊. & & $\underset{\substack{n \\
N}}{\stackrel{n}{n}}$ & 旡 & \&̊ \\
\hline \multirow{3}{*}{ 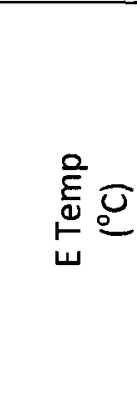 } & $\subseteq$ & 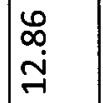 & & $\begin{array}{l}\text { 㖞 } \\
\text { on }\end{array}$ & & 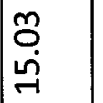 & & 萼 & & 竎 & & 䓍 \\
\hline & $\triangleleft$ & 哥 & 范 & \%ั. & & $\mid \begin{array}{l}\infty \\
0 \\
\dot{i n}\end{array}$ & 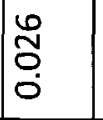 & 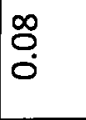 & & ¿্రి & 兽 & 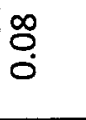 \\
\hline & 亏े & 告 & 㒸 & 菅 & & ڤ̆ & 盀 & 雚 & & $\underset{\stackrel{ }{ }}{\stackrel{ }{7}}$ & 瓷 & 苞 \\
\hline \multirow{4}{*}{ 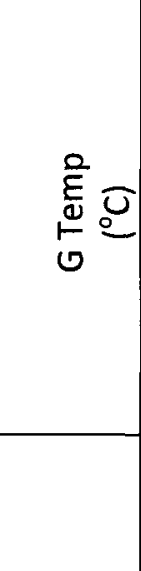 } & $\subseteq$ & 占 & & น้̂ & & $\mid \begin{array}{l}R \\
\dot{\infty} \\
\infty\end{array}$ & & นุ้ & & $\begin{array}{l}\stackrel{8}{0} \\
\stackrel{+}{\pi}\end{array}$ & & గ̂̃ \\
\hline & $\triangleleft$ & 疍 & ஜ̊ & $\stackrel{\infty}{0}$ & & ఫ़ & Oे & $\stackrel{\infty}{0}$ & & $\mid \begin{array}{l}\infty \\
\infty \\
m\end{array}$ & $\mid \begin{array}{l}\infty \\
0 \\
0 \\
0\end{array}$ & $\begin{array}{l}\infty \\
0 \\
0\end{array}$ \\
\hline & $\bar{z}$ & $\begin{array}{l}\text { 年 } \\
\text { in } \\
\end{array}$ & 今̈ & in & & $\begin{array}{l}\text { Iñ } \\
\text { ñ }\end{array}$ & 吕 & ñ. & & $\mid \begin{array}{l}1 \\
0 \\
0 \\
0\end{array}$ & $\stackrel{n}{2}$ & تี่ \\
\hline & 蘂 & 18 & in & $15^{2}$ & 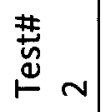 & $\mid x$ & $|n|$ & $15^{\circ}$ & 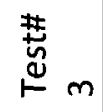 & $1 x$ & in & $10^{n}$ \\
\hline
\end{tabular}




\begin{tabular}{|c|c|c|c|c|c|c|c|c|c|c|c|c|}
\hline 亏ั) & & 跑 & 莣 & $\begin{array}{l}\mathscr{0} \\
\stackrel{0}{0} \\
0\end{array}$ & & 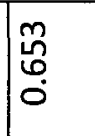 & $\mid \begin{array}{l}0 \\
-1 \\
8 \\
0 \\
0\end{array}$ & 咅 & & 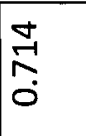 & $\tilde{m}$ & Oे \\
\hline. & & $\begin{array}{l}\infty \\
0 \\
\text { d. } \\
-1\end{array}$ & $\mid \begin{array}{l}\hat{a} \\
0 \\
0\end{array}$ & g̊? & & 莳 & $\mid \begin{array}{l}n \\
\tilde{y} \\
0 \\
0\end{array}$ & g̊ & & $\begin{array}{l}\tilde{D} \\
\tilde{n} \\
\tilde{n}\end{array}$ & 兽 & 苟 \\
\hline . & & $\begin{array}{l}8 \\
\stackrel{\infty}{\sim} \\
\sim\end{array}$ & $\underset{\mathrm{f}}{\stackrel{f}{\sigma}}$ & n̊. & & $\begin{array}{l}\tilde{m} \\
\dot{m} \\
\dot{m}\end{array}$ & $\begin{array}{l}\text { I } \\
\text { Oे } \\
0\end{array}$ & 总 & & 雍 & 岇 & : \\
\hline ৩ & & 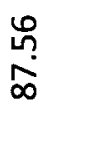 & 号 & $\begin{array}{l}\infty \\
\infty \\
\infty \\
0\end{array}$ & & 虫 & 竎 & $\mid \begin{array}{c}\infty \\
\infty \\
\infty \\
0\end{array}$ & & 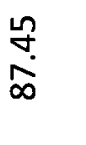 & 年 & $\mid \begin{array}{l}\infty \\
\infty \\
\infty \\
0\end{array}$ \\
\hline w 은 & & $\frac{\pi}{\stackrel{i}{\infty}}$ & $\mid \begin{array}{l}0 \\
0 \\
0 \\
0\end{array}$ & 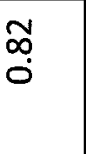 & & $\begin{array}{l} \\
0 \\
0 \\
\end{array}$ & $\begin{array}{l}0 \\
0 \\
0 \\
0\end{array}$ & $\begin{array}{l}9 \\
\hat{0} \\
0\end{array}$ & & $\begin{array}{l}\text { กิ } \\
\text { กิ }\end{array}$ & 管 & $\begin{array}{l}9 \\
\hat{0} \\
0\end{array}$ \\
\hline 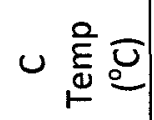 & $\underline{\subseteq}$ & $\begin{array}{l}\infty \\
\stackrel{\infty}{N} \\
\stackrel{\sim}{N}\end{array}$ & 恋 & $\begin{array}{l}0 \\
\vdots \\
0\end{array}$ & & 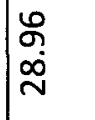 & $\mid \begin{array}{l}0 \\
0 \\
0 \\
0\end{array}$ & $\mid$\begin{tabular}{l}
0 \\
\multirow{2}{*}{} \\
0
\end{tabular} & & नิ & 早 & 总 \\
\hline \multirow{3}{*}{ 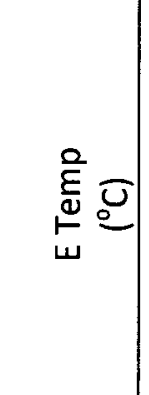 } & $\leq$ & $\begin{array}{l}\stackrel{n}{n} \\
\infty \\
\rightarrow \\
-1\end{array}$ & & 亗 & & $\begin{array}{l}2 \\
\hat{0} \\
0 \\
\pi\end{array}$ & & 绝 & & 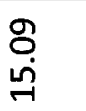 & & 绐 \\
\hline & $\triangleleft$ & \& & $\mid \begin{array}{l}n \\
0 \\
0 \\
0\end{array}$ & $\begin{array}{l}\infty \\
0 \\
0 \\
0\end{array}$ & & $\stackrel{\vec{r}}{\dot{m}}$ & $\mid \begin{array}{l}0 \\
0 \\
0\end{array}$ & 每 & & $\vec{m}$ & $\ddot{0}$ & 足 \\
\hline & క & 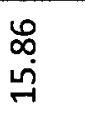 & $\overrightarrow{\tilde{n}}$ & 萼 & & $\underset{\substack{\infty\\
}}{ }$ & 梂 & 苞 & & 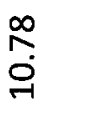 & $\underset{\Xi}{\tilde{O}}$ & 苟 \\
\hline \multirow{4}{*}{ 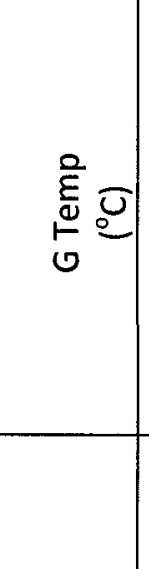 } & $\subseteq$ & 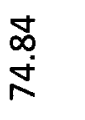 & & กี้ & & 文 & & గñ & & $\begin{array}{l}\infty \\
\stackrel{\infty}{\infty}\end{array}$ & & గึ్ \\
\hline & $\triangleleft$ & $\underset{+}{\stackrel{8}{+}}$ & $\begin{array}{l}\stackrel{2}{0} \\
0 \\
0 \\
0\end{array}$ & $\begin{array}{l}\infty \\
0 \\
0\end{array}$ & & 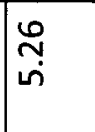 & ஜֶ & 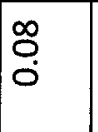 & & $\begin{array}{l}\overrightarrow{0} \\
\text { in }\end{array}$ & 足 & 文 \\
\hline & 范 & 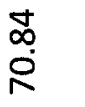 & $\underset{0}{\tilde{O}}$ & กี่ & & 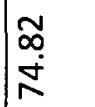 & 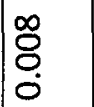 & 苞 & & 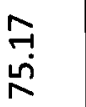 & 品 & ज़̃ \\
\hline & 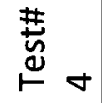 & 18 & ins & $15^{n}$ & 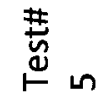 & Is & in & $15^{2}$ & $\begin{array}{l}\text { 䓵 } \\
\stackrel{5}{\circ}\end{array}$ & $1 \%$ & Is & $1 D^{2}$ \\
\hline
\end{tabular}




\begin{tabular}{|c|c|c|c|c|c|c|c|c|c|c|c|c|}
\hline 잉 & & $\frac{⿱}{2}$ & m & 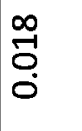 & & 吕 & $\stackrel{n}{2}$ & 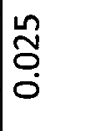 & & חึ & 免 & $\underset{d}{\mathbb{Z}}$ \\
\hline$\cdot \sqrt{5}$ & & $\underset{N}{N}$ & 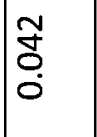 & חึ? & & 总 & $\underset{\dddot{\infty}}{\infty}$ & $\stackrel{9}{q}$ & & pr & 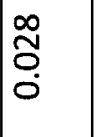 & $\stackrel{\substack{f \\
0}}{0}$ \\
\hline$\cdot 0 \underline{\underline{z}}$ & & $\mid \begin{array}{l}\sigma \\
\infty \\
\infty \\
m\end{array}$ & $\stackrel{m}{\mathscr{O}}$ & $\begin{array}{l}n \\
0 \\
0\end{array}$ & & 華 & 离 & 譁 & & $\begin{array}{l}J \\
\stackrel{N}{N}\end{array}$ & 㒸 & 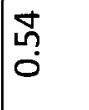 \\
\hline 0 은 $\frac{\text { 를 }}{\Xi}$ & & 守 & \begin{tabular}{l}
$\infty$ \\
\multirow{0}{0}{} \\
0
\end{tabular} & $\begin{array}{l}\infty \\
\infty \\
0 \\
0\end{array}$ & & $\begin{array}{l}\tilde{m} \\
\infty \\
\infty\end{array}$ & $\begin{array}{l}\infty \\
\mathscr{n} \\
0 \\
0\end{array}$ & $\begin{array}{l}\infty \\
\infty \\
0 \\
0\end{array}$ & & $\begin{array}{l}\stackrel{\infty}{m} \\
\stackrel{\infty}{\infty}\end{array}$ & $\begin{array}{l}\tilde{J} \\
\text { Z } \\
0\end{array}$ & $\begin{array}{l}\infty \\
\infty \\
0\end{array}$ \\
\hline 山 은 & & 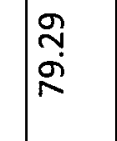 & \begin{tabular}{l}
\multirow{1}{7}{} \\
0 \\
0 \\
0
\end{tabular} & $\frac{9}{0}$ & & 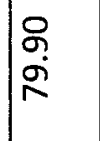 & $\begin{array}{l}0 \\
\mathscr{1} \\
0 \\
0\end{array}$ & $\stackrel{0}{\infty}$ & & 禺 & 朵 & $\stackrel{\infty}{\stackrel{\infty}{0}}$ \\
\hline 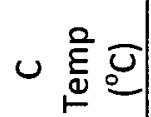 & $\subseteq$ & $\begin{array}{l}\dddot{r} \\
\stackrel{\sim}{g}\end{array}$ & ֻั & & & 它 & $\underset{\mathscr{O}}{\mathscr{m}}$ & $\stackrel{0}{\mathscr{0}}$ & & $\stackrel{\infty}{\sim}$ & O̊ & 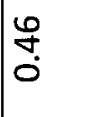 \\
\hline \multirow{3}{*}{ 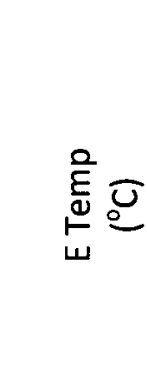 } & $\leqq$ & ڤุ & & นุก & & $\underset{\sim}{\tilde{\omega}}$ & F্요 & ஸึ̊ & & 嗒 & & นึ่ \\
\hline & $\triangleleft$ & $\begin{array}{l}\text { O } \\
\text { ni }\end{array}$ & O̊ & o & & $\stackrel{n}{\sim}$ & 농 & $\stackrel{\infty}{0}$ & & $\underset{⿱}{n}$ & $\stackrel{n}{8}$ & 足 \\
\hline & $\stackrel{5}{3}$ & 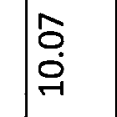 & ஜ̊ & 密 & & $\underset{O}{S}$ & \begin{tabular}{l}
-1 \\
\hdashline \\
0 \\
0
\end{tabular} & 菅 & & 吕 & $\stackrel{n}{n}$ & 敬 \\
\hline \multirow{4}{*}{ 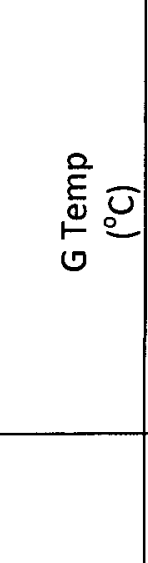 } & $\subseteq$ & $\begin{array}{l}m \\
0 \\
\dot{0} \\
\infty\end{array}$ & & กุ้ & & $\begin{array}{l}\infty \\
\infty \\
\mathbb{N}\end{array}$ & 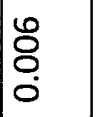 & กั่ & & 衤 & & กั่ \\
\hline & $\triangleleft$ & 유 & Ln & $\stackrel{\infty}{\infty}$ & & in & 눙 & 文 & & $\stackrel{N}{n}$ & ஜ & 足 \\
\hline & 苛 & นึ? & 电 & 룽 & & 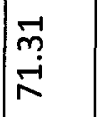 & o & 敬 & & $\frac{m}{i}$ & $\begin{array}{l}8 \\
8 \\
0 \\
0\end{array}$ & 萄 \\
\hline & 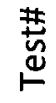 & $1 x$ & $\ln$ & $15^{2}$ & $\stackrel{\stackrel{\#}{\mathscr{y}}}{\models} \infty$ & $|\varkappa|$ & $1 \sigma_{2}$ & $15^{2}$ & $\stackrel{\stackrel{H}{\mathscr{E}}}{=} \sigma$ & $\mid H$ & $\ln$ & $10^{n}$ \\
\hline
\end{tabular}




\begin{tabular}{|c|c|c|c|c|c|c|c|c|c|c|c|c|}
\hline 엄 & & 周 & $\begin{array}{l}0 \\
0 \\
8 \\
0 \\
0\end{array}$ & $\underset{\Xi}{\tilde{O}}$ & & 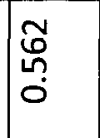 & $\begin{array}{l}m \\
\mathscr{n} \\
0 \\
0\end{array}$ & â & & $\mid \begin{array}{l}0 \\
0 \\
\\
0 \\
0\end{array}$ & 章 & ֶ̃ \\
\hline$\cdot \sigma \underline{\underline{z}}$ & & 占 & $\tilde{O}$ & $\stackrel{\mathscr{L}}{\stackrel{\leftrightarrow}{\circ}}$ & & $\stackrel{g}{\circ}$ & $\mid \begin{array}{l}0 \\
\\
0 \\
0\end{array}$ & ֻ & & $\frac{\infty}{\stackrel{\infty}{\sigma}}$ & 号 & f̊ \\
\hline . & & 芯 & $\begin{array}{l}\hat{m} \\
0 \\
0\end{array}$ & 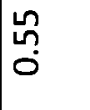 & & Na & $\mid \begin{array}{l}9 \\
0 \\
0 \\
0\end{array}$ & 苫 & & 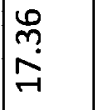 & $\underset{⿱ ㇒}{\stackrel{m}{r}}$ & 敬 \\
\hline 0 은 $\frac{3}{E}$ & & $\underset{\infty}{\dot{J}}$ & ñ & $\begin{array}{l}\infty \\
\infty \\
0 \\
0\end{array}$ & & 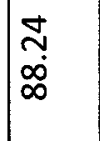 & 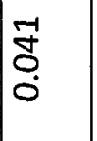 & $\begin{array}{l}\infty \\
\infty \\
0 \\
0\end{array}$ & & $\frac{P}{i}$ & $\begin{array}{l}\infty \\
0 \\
0 \\
0 \\
0\end{array}$ & $\begin{array}{l}\infty \\
\infty \\
0 \\
0\end{array}$ \\
\hline 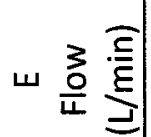 & & 象 & \begin{tabular}{l}
\multirow{Z}{7}{} \\
- \\
0 \\
0
\end{tabular} & $\stackrel{\infty}{\stackrel{\infty}{0}}$ & & הi & 咅 & $\begin{array}{l}\infty \\
\infty \\
0\end{array}$ & & 守 & ָ̃ & 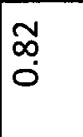 \\
\hline 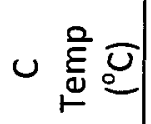 & $\leqq$ & 文 & 帒 & 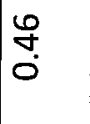 & & f & $\begin{array}{l}0 \\
0 \\
0 \\
0\end{array}$ & 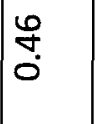 & & 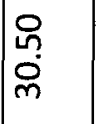 & 공 & 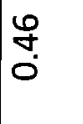 \\
\hline \multirow{3}{*}{ 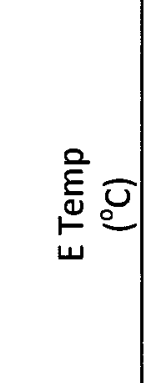 } & ㄷ & iี & & ஸึ? & & $\begin{array}{l}\omega \\
\stackrel{\sim}{N} \\
\sim\end{array}$ & & นึ & & 迎 & & 望 \\
\hline & $\Delta$ & $\stackrel{\infty}{\sim}$ & $\begin{array}{l}8 \\
0 \\
0\end{array}$ & 舟 & & 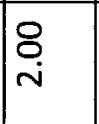 & O̊ & 舫 & & $\underset{-1}{\mathbb{N}}$ & 章 & 悉 \\
\hline & 亏3 & 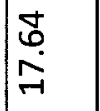 & 呑 & 菅 & & 占 & O̊ & 冢 & & 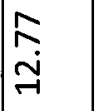 & $\stackrel{m}{\mathscr{Z}}$ & 蒈 \\
\hline \multirow{4}{*}{ 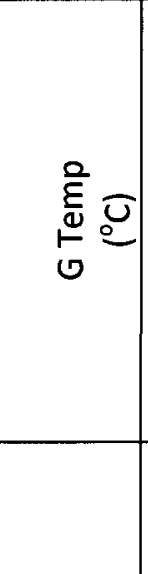 } & $\underline{E}$ & $\begin{array}{l}n \\
\sigma \\
\grave{n}\end{array}$ & & กู่ & & 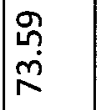 & & กิ & & 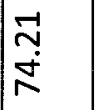 & & กู \\
\hline & $\triangleleft$ & $\underset{m}{\stackrel{p}{\sigma}}$ & ஜே & $\stackrel{\infty}{0}$ & & $\underset{m}{\stackrel{g}{m}}$ & 帒 & ơ & & 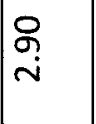 & $\underset{d}{d}$ & 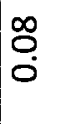 \\
\hline & $\overrightarrow{0}$ & $\begin{array}{l}\tilde{W} \\
\text { N }\end{array}$ & i̊ & กั่ & & ro & $\begin{array}{l}ન \\
\\
0 \\
0\end{array}$ & 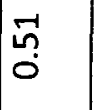 & & $\vec{m}$ & $\underset{0}{-1}$ & กั \\
\hline & $\stackrel{\text { 菍 }}{ }$ & $\mid x$ & ins & $12^{a}$ & 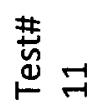 & 18 & $\mid \omega s$ & $12^{2}$ & 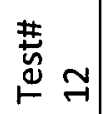 & $|x|$ & 12 & $10^{2}$ \\
\hline
\end{tabular}




\begin{tabular}{|c|c|c|c|c|c|c|c|c|c|c|c|c|}
\hline s) & & $\mid \begin{array}{l}\infty \\
0 \\
0 \\
0 \\
0\end{array}$ & $\begin{array}{l}0 \\
0 \\
0 \\
0 \\
0\end{array}$ & $\hat{a}$ & & 造 & 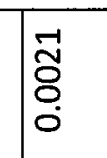 & Oें & & 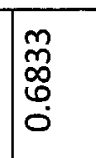 & $\begin{array}{l}\tilde{0} \\
\tilde{O} \\
0 \\
0 \\
0\end{array}$ & $\hat{0}$ \\
\hline.$\infty \bar{s}$ & & 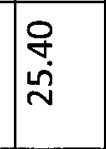 & 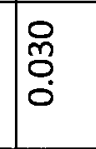 & 艿 & & \begin{tabular}{|l|}
$\begin{array}{l}n \\
0 \\
0 \\
\end{array}$ \\
\end{tabular} & $\mid \begin{array}{l}0 \\
0 \\
0 \\
0 \\
0\end{array}$ & gृ & & 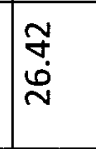 & 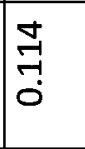 & ñ \\
\hline$\therefore \bar{s}$ & & $\mid \begin{array}{l}\infty \\
0 \\
\infty \\
\infty \\
m\end{array}$ & 思 & 它 & & $\begin{array}{l}\stackrel{0}{0} \\
\dot{m} \\
0\end{array}$ & $\begin{array}{l}0 \\
0 \\
0 \\
0 \\
0\end{array}$ & भु & & $\begin{array}{l}0 \\
\infty \\
\infty \\
m \\
m\end{array}$ & $\begin{array}{l}0 \\
\text { OO } \\
0 \\
0\end{array}$ & 菖 \\
\hline 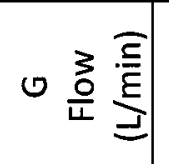 & & $\mid$ & 厷 & $\tilde{\infty}_{\infty}^{\infty}$ & & $\begin{array}{l}\text { శి } \\
\infty \\
\infty \\
\infty\end{array}$ & 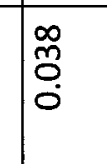 & $\begin{array}{c}\infty \\
\infty \\
\infty \\
0\end{array}$ & & 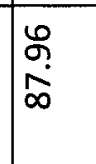 & 童 & $\begin{array}{l}\infty \\
\infty \\
\infty \\
0\end{array}$ \\
\hline ए $\frac{3}{4} \frac{\bar{a}}{\underline{\xi}}$ & & $\mid$\begin{tabular}{|c|} 
\\
$\tilde{D}$ \\
$\tilde{D}$ \\
$\infty$
\end{tabular} & F & $\underset{\infty}{\infty}$ & & 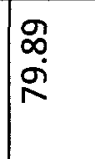 & 总 & $\infty_{0}$ & & $\begin{array}{l}\frac{1}{2} \\
8 \\
\end{array}$ & 合 & 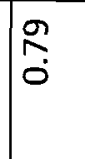 \\
\hline 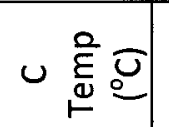 & $\subseteq$ & 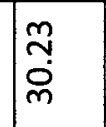 & 管 & 过 & & 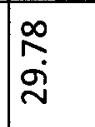 & 告 & 量 & & $\begin{array}{l}\infty \\
\infty \\
\text { i }\end{array}$ & 㝵 & 过 \\
\hline \multirow{3}{*}{ 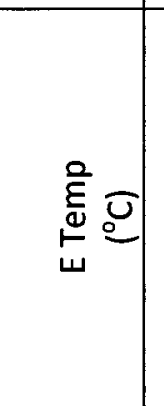 } & $\subseteq$ & $\overrightarrow{7}$ & & 峘 & & 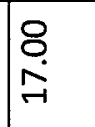 & & 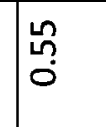 & & \begin{tabular}{l}
$\infty$ \\
\hdashline \\
9 \\
9
\end{tabular} & & 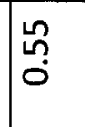 \\
\hline & $\triangleleft$ & $\underset{f}{q}$ & 尊 & $\overbrace{0}^{\infty}$ & & $\begin{array}{l}g \\
\dot{q} \\
m\end{array}$ & $\begin{array}{l}0 \\
0 \\
0 \\
0\end{array}$ & 冓 & & $\stackrel{\infty}{\sigma}$ & 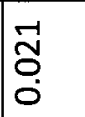 & 恶 \\
\hline & ثे & 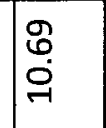 & $\begin{array}{l}\overrightarrow{1} \\
0 \\
0\end{array}$ & 苟 & & 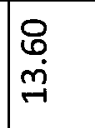 & $\mid \begin{array}{l}\infty \\
0 \\
0 \\
0 \\
0\end{array}$ & 苟 & & $\begin{array}{l}\vec{F} \\
\dot{A}\end{array}$ & 总 & 若 \\
\hline \multirow{4}{*}{ 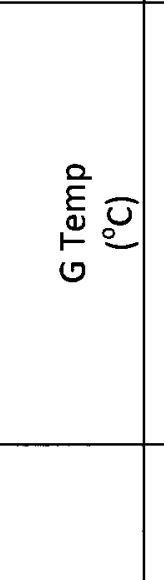 } & $\subseteq$ & 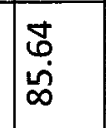 & & స్. & & 总 & & స్م & & 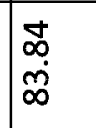 & & 繁 \\
\hline & $\Delta$ & $\begin{array}{l}\overrightarrow{0} \\
0 \\
0\end{array}$ & $\begin{array}{l}\text { no } \\
0 \\
0 \\
0\end{array}$ & $\dddot{\infty}_{0}^{\infty}$ & & ig & 吕 & 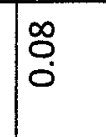 & & f & \begin{tabular}{l}
$\infty$ \\
\hdashline \\
0 \\
0
\end{tabular} & 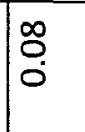 \\
\hline & పे & $\mid \begin{array}{l}\infty \\
\substack{\infty \\
\infty}\end{array}$ & : & 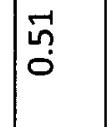 & & 艿 & : & 䓟 & & 鲁 & סृ & 䓟 \\
\hline & 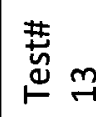 & $1 x$ & in & $12^{5}$ & 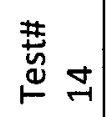 & 1x & ins & $15^{\infty}$ & 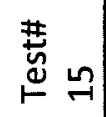 & 1x & in & $15^{\circ}$ \\
\hline
\end{tabular}




\begin{tabular}{|c|c|c|c|c|c|c|c|c|c|c|c|c|}
\hline ఫัن & & $\mid \begin{array}{l}\mathscr{0} \\
0 \\
0 \\
0 \\
0\end{array}$ & బิ & O̊̊. & & $\underset{G}{-1}$ & ஜூ & 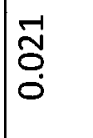 & & 角 & 造 & ஜ̃ \\
\hline$\cdot 0$ 章 & & 요 & 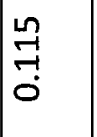 & ڤึ & & $\mid \begin{array}{l}\mathscr{0} \\
\stackrel{0}{0}\end{array}$ & 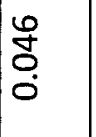 & f̊ & & $\underset{\infty}{\infty}$ & 尚 & I্ \\
\hline . & & 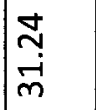 & $\mid \begin{array}{l}0 \\
0 \\
0 \\
0\end{array}$ & 命 & & $\stackrel{m}{m}$ & $\begin{array}{l}\stackrel{9}{m} \\
\stackrel{7}{0}\end{array}$ & $\stackrel{\infty}{0}$ & & 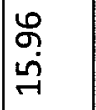 & 品 & חִn \\
\hline 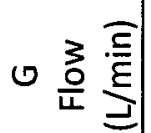 & & $\underset{N}{N}$ & ¿-1 & $\begin{array}{l}\infty \\
\infty \\
0 \\
0\end{array}$ & & 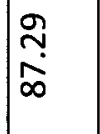 & $\begin{array}{l}-1 \\
\\
0\end{array}$ & $\begin{array}{c}\infty \\
0 \\
0\end{array}$ & & f & 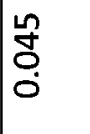 & $\mid \begin{array}{l}\infty \\
\infty \\
0 \\
0\end{array}$ \\
\hline w & & $\begin{array}{l}\infty \\
m \\
\\
\end{array}$ & $\frac{n}{0}$ & $\frac{9}{2}$ & & 离 & 공 & $\frac{\infty}{i}$ & & م̊ & 辇 & $\stackrel{\infty}{\stackrel{\infty}{0}}$ \\
\hline 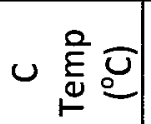 & $\subseteq$ & $\begin{array}{l}\text { ㅇ } \\
\text { शิ }\end{array}$ & Ỹ & 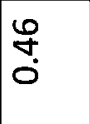 & & $\begin{array}{l}\mathscr{o} \\
\underset{N}{n} \\
m\end{array}$ & ஸ̂ & 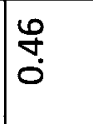 & & कृ & 吕 & O্ \\
\hline \multirow{3}{*}{ 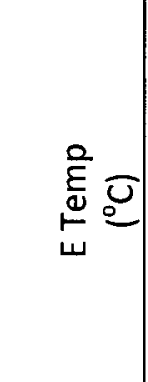 } & $\subseteq$ & $\begin{array}{l}\text { ने } \\
\text { नें }\end{array}$ & & 占 & & 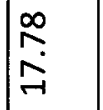 & & นึ้ & & 文 & & นึ \\
\hline & $\triangleleft$ & $\begin{array}{l}\infty \\
\infty \\
\dot{m}\end{array}$ & İ & : & & Oे & $\begin{array}{l}\infty \\
8 \\
0 \\
0\end{array}$ & 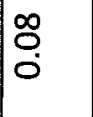 & & तn & $\begin{array}{l}0 \\
8 \\
0 \\
0\end{array}$ & 足 \\
\hline & $\stackrel{5}{3}$ & m.- & $\stackrel{n}{\mathscr{O}}$ & फ़ं & & $\begin{array}{l}r \\
\dot{H} \\
\dot{H}\end{array}$ & $\begin{array}{l}\infty \\
8 \\
0 \\
0\end{array}$ & 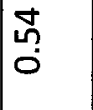 & & $\begin{array}{l}0 \\
q \\
\dot{\sigma}\end{array}$ & 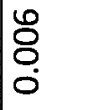 & Lั? \\
\hline \multirow{4}{*}{ 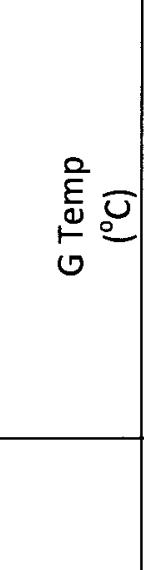 } & $\subseteq$ & T̃ & & กิ? & & $\begin{array}{c}m \\
\stackrel{\sim}{-1} \\
\infty\end{array}$ & & กุ? & & नि & & กิ่ \\
\hline & $\triangleleft$ & $\underset{N}{N}$ & \begin{tabular}{c}
$m$ \\
\hdashline \\
0 \\
0
\end{tabular} & $\begin{array}{l}\infty \\
0 \\
0\end{array}$ & & $\underset{\sigma}{\stackrel{0}{\sigma}}$ & 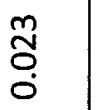 & 足 & & $\begin{array}{l}\infty \\
\ddot{i} \\
i\end{array}$ & 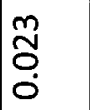 & $\underset{\infty}{\infty}$ \\
\hline & $\stackrel{5}{5}$ & $\begin{array}{l}\stackrel{g}{+} \\
\dot{N}\end{array}$ & مُ & in & & 蓻 & $\begin{array}{l}-1 \\
\stackrel{1}{\circ} \\
0 \\
0\end{array}$ & 萄 & & $\begin{array}{l}\text { 年 } \\
\text { ri }\end{array}$ & 8 & กี่ \\
\hline & 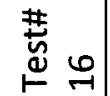 & $|\psi|$ & $1 \sigma_{2}$ & $10^{n}$ & 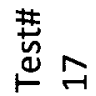 & $\mid \neq 1$ & 10 & $15^{2}$ & 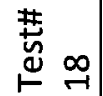 & $|x|$ & 10 & $1 \omega^{2}$ \\
\hline
\end{tabular}




\begin{tabular}{|c|c|c|c|c|c|c|c|c|c|c|c|c|}
\hline ర్రి & & $\mid \begin{array}{l}0 \\
0 \\
0 \\
0 \\
0\end{array}$ & ס্ஜি & O্ & & $\mid \begin{array}{l}\infty \\
0 \\
\\
0 \\
0\end{array}$ & $\begin{array}{l}\infty \\
\stackrel{\infty}{8} \\
0 \\
0\end{array}$ & 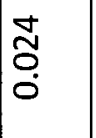 & & 命 & Oे & $\underset{\mathscr{o}}{0}$ \\
\hline . & & $\begin{array}{l}n \\
0 \\
\infty \\
\infty\end{array}$ & 芦 & 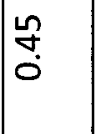 & & ホั & 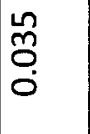 & 是 & & 今̊ & 囟 & 昌 \\
\hline.$\stackrel{\text { O }}{3}$ & & $\begin{array}{l}\text { g. } \\
\stackrel{-}{-1}\end{array}$ & 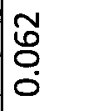 & 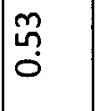 & & స̇ & 文 & 每 & & $\begin{array}{l}\infty \\
\infty \\
\infty \\
-1\end{array}$ & 鬲 & นึم \\
\hline 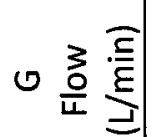 & & $\begin{array}{l}\text { Dิ } \\
\infty \\
\infty \\
\infty\end{array}$ & ஜ̂̀ & 免 & & $\begin{array}{l}\mathbb{N} \\
\infty \\
\infty\end{array}$ & סे & $\mid \begin{array}{l}\infty \\
\infty \\
0 \\
0\end{array}$ & & $\begin{array}{l}\underset{1}{N} \\
\infty \\
\infty\end{array}$ & $\underset{\mathcal{Z}}{\tilde{O}}$ & $\begin{array}{l}\infty \\
\infty \\
0 \\
0\end{array}$ \\
\hline 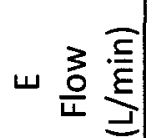 & & $\begin{array}{l}\infty \\
\infty \\
\end{array}$ & 合 & 足 & & $\begin{array}{l}\hat{\sigma} \\
\text { g̊ }\end{array}$ & नि' & $\begin{array}{l}0 \\
\infty \\
0\end{array}$ & & 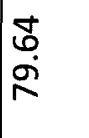 & $\mid \begin{array}{l}0 \\
\dddot{1} \\
0 \\
0\end{array}$ & $\begin{array}{l}\circ \\
\infty \\
0\end{array}$ \\
\hline 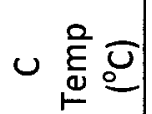 & $\subseteq$ & $\begin{array}{l}N \\
\tilde{n}\end{array}$ & $\begin{array}{l}9 \\
0 \\
0 \\
0\end{array}$ & 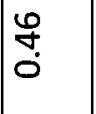 & & $\begin{array}{l}\tilde{N} \\
\vec{m} \\
m\end{array}$ & $\begin{array}{l}\mathscr{0} \\
\stackrel{0}{0}\end{array}$ & 是 & & $\stackrel{\substack{n\\
}}{m}$ & 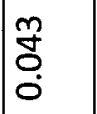 & 电 \\
\hline \multirow{3}{*}{$\underset{w}{\stackrel{ }{\varepsilon}} \stackrel{-}{\varrho}$} & $\subseteq$ & निं & & 㖞 & & $\underset{\sim}{\sim}$ & & 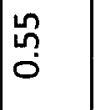 & & 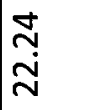 & & 䓍 \\
\hline & $\triangleleft$ & 帒 & ஜ & o & & $\stackrel{m}{m}$ & 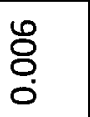 & 足 & & م & ஜ & $\begin{array}{l}\infty \\
\stackrel{0}{0} \\
0\end{array}$ \\
\hline & 亏ै & 范 & 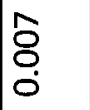 & นึ? & & 笠 & $\begin{array}{l}\hat{8} \\
\text { ¿ }\end{array}$ & 苞 & & İ & $\begin{array}{l}\infty \\
0 \\
0 \\
0\end{array}$ & 䔉 \\
\hline \multirow{4}{*}{$\underset{\sigma}{\stackrel{0}{E}} \stackrel{0}{\sigma}$} & $\subseteq$ & $\begin{array}{l}\vec{y} \\
\stackrel{+}{i} \\
i\end{array}$ & & กึ้ & & \begin{tabular}{l}
$\stackrel{2}{\circ}$ \\
\multirow{1}{N}{}
\end{tabular} & & กึ? & & $\begin{array}{l}\infty \\
\infty \\
\stackrel{\mathbb{N}}{N}\end{array}$ & & กึ์ \\
\hline & $\triangleleft$ & $\begin{array}{l}\dot{W} \\
\infty \\
i\end{array}$ & O & O̊ & & $\begin{array}{l}\overrightarrow{1} \\
\infty \\
\dot{m}\end{array}$ & $\begin{array}{l}\stackrel{乛}{0} \\
0 \\
0\end{array}$ & O্ & & $\stackrel{m}{\sim}$ & $\begin{array}{l}\mathscr{Z} \\
0 \\
0\end{array}$ & $\begin{array}{l}\infty \\
\stackrel{\circ}{0}\end{array}$ \\
\hline & $\stackrel{ \pm}{亏}$ & חָ & \begin{tabular}{l}
\multirow{1}{7}{} \\
0 \\
0 \\
0
\end{tabular} & กี่ & & $\underset{\sim}{m}$ & $\stackrel{n}{0}$ & تี่ & & $\frac{n}{r}$ & $\begin{array}{l}0 \\
\stackrel{1}{0} \\
0 \\
0\end{array}$ & 룽 \\
\hline & 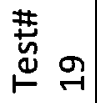 & 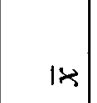 & 102 & $15^{2}$ & $\stackrel{\text { 䓌 }}{\stackrel{N}{上}}$ & $1 *$ & $1 \backsim$ & $15^{n}$ & 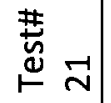 & $1 x$ & $10 s$ & $15^{n}$ \\
\hline
\end{tabular}




\begin{tabular}{|c|c|c|c|c|c|c|c|c|c|}
\hline 엉 & & 年 & 足 & ஜृ & & 总 & 号 & $\stackrel{\Perp}{\overparen{O}}$ & \\
\hline$\cdot 0$ & & $\underset{\infty}{\mathscr{D}}$ & 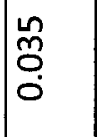 & 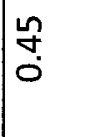 & & $\frac{n}{\stackrel{n}{7}}$ & 离 & 웅 & \\
\hline . O & & $\begin{array}{l}\infty \\
\infty \\
0 \\
\ddots \\
-1\end{array}$ & 잉 & ֻั & & ס & 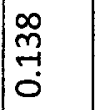 & ஸ̊ & \\
\hline ৩ & & 欮 & 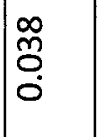 & $\begin{array}{l}0 \\
0 \\
0 \\
0\end{array}$ & & 帒 & 蒿 & $\begin{array}{l}\infty \\
\infty \\
0 \\
0\end{array}$ & \\
\hline w & & $\begin{array}{l}\mathscr{\infty} \\
\infty \\
\end{array}$ & नि & 足 & & 䓟 & O্ণ & م & \\
\hline$\cup \stackrel{\varrho}{\frac{\varrho}{\alpha}} \circlearrowleft$ & $\subseteq$ & חָׁ & $\begin{array}{l}\text { f } \\
0 \\
0\end{array}$ & & & 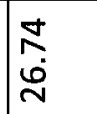 & 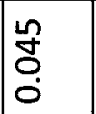 & 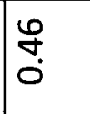 & \\
\hline \multirow{3}{*}{$\underset{w}{\stackrel{ }{E}} \stackrel{ }{\varrho}$} & $\subseteq$ & $\begin{array}{l}\text { बे } \\
\text { क } \\
\text { - }\end{array}$ & & นึ้ & & $\frac{⿱}{N}$ & & นึ้ & \\
\hline & $\triangleleft$ & กั & 号 & 舟 & & $\stackrel{\sim}{\sim}$ & $\stackrel{n}{2}$ & $\stackrel{\infty}{\infty}$ & \\
\hline & $\overrightarrow{3}$ & ने & ஜ & นึ? & & $\underset{\sigma}{\tilde{-}}$ & $\stackrel{m}{\mathscr{m}}$ & 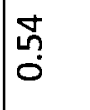 & \\
\hline \multirow{4}{*}{$\underset{0}{\stackrel{ }{E}} \stackrel{0}{\varrho}$} & $\subseteq$ & $\stackrel{m}{n}$ & & กั่ & & $\begin{array}{l}m \\
0 \\
\text { ñ }\end{array}$ & & กู่ & \\
\hline & $\triangleleft$ & $\begin{array}{l}\hat{b} \\
\dot{m}\end{array}$ & $\stackrel{m}{\stackrel{m}{0}}$ & 足 & & 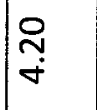 & $\underset{m}{\tilde{O}}$ & 足 & \\
\hline & $\vec{\partial}$ & $\begin{array}{l}\mathscr{O} \\
\stackrel{N}{N}\end{array}$ & 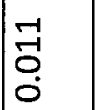 & 동 & & $\begin{array}{l}\infty \\
\infty \\
\infty\end{array}$ & $\begin{array}{l}\infty \\
0 \\
\\
0 \\
0\end{array}$ & ำ & \\
\hline & 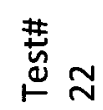 & 18 & 10 & $10^{2}$ & $\stackrel{\#}{\stackrel{H}{\leftrightarrows}}$ & $1 x$ & $\ln 2$ & $10^{n}$ & \\
\hline
\end{tabular}

